\title{
Etienne Biasotto
}

\section{Metodologia para o desenvolvimento de um novo padrão estrutural e elétrico de cruzeta para redes de $15 \mathbf{k V}^{1}$}

Tese apresentada à Escola de Engenharia de São Carlos da Universidade de São Paulo, como parte dos requisitos para obtenção do título de Doutor em Ciências pelo Programa de Engenharia Elétrica.

Área de Concentração: Sistemas Elétricos de Potência Orientador: Prof. Dr. Mário Oleskovicz 
AUTORIZO A REPRODUÇÃO E DIVULGAÇÃO TOTAL OU PARCIAL DESTE TRABALHO, POR QUALQUER MEIO CONVENCIONAL OU ELETRÔNICO, PARA FINS DE ESTUDO E PESQUISA, DESDE QUE CITADA A FONTE.

Ficha catalográfica preparada pela Seção de Atendimento ao Usuário do Serviço de Biblioteca - EESC/USP

Biasotto, Etienne
Metodologia para o desenvolvimento de um novo padrão estrutural e elétrico de cruzeta para redes de $15 \mathrm{kV}$. / Etienne Biasotto; orientador Mário Oleskovicz. São Carlos, 2012 .

Tese (Doutorado) - Programa de Pós-Graduação em Engenharia Elétrica e Área de Concentração em Sistemas Elétricos de Potência -- Escola de Engenharia de São Carlos da Universidade de São Paulo, 2012.

1. Distribuição de energia elétrica. 2. Transitórios eletromagnéticos. 3. Classe de $15 \mathrm{kV}$. 4. Isolador tipo pino. 5. Cruzeta de madeira. 6. Elementos finitos. I. Título. 


\section{FOLHA DE JULGAMENTO}

Candidato: Engenheiro ETIENNE BIASOTTO.

Título da tese: "Metodologia para o desenvolvimento de um novo padrão estrutural e elétrico de cruzeta para redes de $15 \mathrm{kV}$ ".

Data da defesa: 28/06/2012

\section{Comissão Julgadora:}

Prof. Dr. Mário Oleskovicz (Orientador)

(Escola de Engenharia de São Carlos/EESC)

Prof. Titular Denis Vinicius Coury

(Escola de Engenharia de São Carlos/EESC)

Prof. Dr. Antonio Alves Dias

(Escola de Engenharia de São Carlos/EESC)

Prof ${ }^{a}$. Dr ${ }^{a}$. Ahda Pionkoski Grilo Pavani

(Universidade Federal do ABC/UFABC)

Prof. Dr. Madson Cortes de Almeida

(Universidade Estadual de Campinas/UNICAMP)
Resultado:

APROVADO

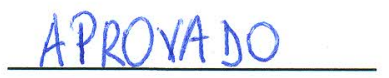

APRLVADO

APROVADO

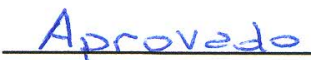

Coordenador do Programa de Pós-Graduação em Engenharia Elétrica e Presidente da Comissão de Pós-Graduação:

Prof. Titular Denis Vinicius Coury 


\section{Dedicatória}

Aos meus pais, Wilson e Helena, às minhas irmãs Mirella e Milenne, à minha noiva Camila e a todos os que acreditaram na realização desse trabalho. 


\section{Agradecimentos}

À Deus, primeiramente, por minha existência e por iluminar meus passos.

Ao Prof. Dr Mário Oleskovicz, pela orientação, confiança e paciência com que me atendeu ao longo dessa caminhada.

Aos professores Denis Vinicius Coury e José Carlos de Melo Vieira Júnior, pelos conselhos e pela agradável companhia, e aos demais professores do Programa que acrescentaram tanto à minha formação.

Aos amigos que tive a felicidade de encontrar no decorrer dessa trajetória, em especial: Aldir, Amilcar, Alexandre, Eduardo, Gerson, Gustavo, Elvio, Helson, Hermes, Lucas, Marcelo, Monaro, Patrick, Ricardo, Ulisses e Venicio. Enfim, a todos com quem pude desfrutar tão valiosos momentos.

À Camila, companheira de todos os momentos, pela atenção, carinho, paciência e amor.

Ao meu pai, Wilson, e à minha irmã, Milenne, pelas correções e disponibilidade em ler meu trabalho.

À minha mãe, Helena, e à minha irmã Mirella, pelo apoio e incentivo em todos os momentos.

A todos os funcionários da Escola de Engenharia de São Carlos - USP, pela atenção e cordialidade. 
"Matar o sonho é matarmo-nos. É mutilar a nossa alma. O sonho é o que temos de realmente nosso, de impenetravelmente e inexpugnavelmente nosso." Fernando Pessoa 


\section{Sumário}

$\begin{array}{ll}\text { Lista de Siglas } & \text { ix }\end{array}$

Lista de Tabelas $\quad$ xi

Lista de Figuras $\quad$ xiii

Resumo xvii

Abstract $\quad$ xix

1 Introdução 1

1.1 Objetivos e Metas . . . . . . . . . . . . . . . . 4

1.2 Aspectos Inovadores $\ldots \ldots \ldots \ldots \ldots \ldots$

1.3 Metodologia aplicada . . . . . . . . . . . . . . . . . 5

Simulações de transitórios eletromagnéticos . . . . . . . . . . . 6

Simulações de campos elétricos e linhas equipotenciais . . . . . . . . . . . 7

Análise de desempenho da linha em estudo . . . . . . . . . . . . . . . . . 7

Ensaios elétricos e mecânicos . . . . . . . . . . . . . . . . . . . . 7

1.4 Estrutura do Documento . . . . . . . . . . . . . . . . . 7

2 Pesquisas e Assuntos Correlacionados 9

3 Modelagem do Sistema de Distribuição Teste através do software ATP 17

3.1 A Modelagem do Sistema Elétrico . . . . . . . . . . . . . . . . 18

3.1 .1 Subestação . . . . . . . . . . . . . . . . . . . . . . 18

3.1 .2 Linha de Distribuição . . . . . . . . . . . . . . . . . . . . . 19

$3.1 .3 \quad$ Carga . . . . . . . . . . . . . . . . . . . . 19

3.2 Simulação dos Transitórios: Curtos-Circuitos . . . . . . . . . . . . . . . . 21

3.2.1 Diferença de potencial entre as fases A e B . . . . . . . . . . . . 22

3.2.2 Diferença de potencial entre as fases A e C . . . . . . . . . . . . . 23 
3.2.3 Diferença de potencial entre as fases B e C . . . . . . . . . . . . 23

4 Modelagem da Cruzeta e demais Componentes pelo Método de Elementos Finitos

4.1 Simulações no Programa FLUX 3D: Modelo atual da Cruzeta . . . . . . . . . . . 28

4.1.1 Campo elétrico e linhas equipotenciais devido ao distúrbio que apresentou a máxima DDP entre as fases A e B . . . . . . . . . . . . 35

4.1.2 Campo elétrico e linhas equipotenciais devido ao distúrbio que apresentou a máxima DDP entre as fases A e C . . . . . . . . . . . . 36

4.1.3 Campo elétrico e linhas equipotenciais devido ao distúrbio que apresentou a máxima DDP entre as fases B e C . . . . . . . . . . . . . 38

4.2 Simulações no Programa FLUX 3D: Modelo Novo da Cruzeta . . . . . . . . . . . 40

4.2.1 Campo elétrico e linhas equipotenciais devido ao distúrbio que apresentou a máxima DDP entre as fases A e B . . . . . . . . . . . . . . . 47

4.2.2 Campo elétrico e linhas equipotenciais devido ao distúrbio que apresentou a máxima DDP entre as fases A e C . . . . . . . . . . . . . . 49

4.2.3 Campo elétrico e linhas equipotenciais devido ao distúrbio que apresentou a máxima DDP entre as fases B e C . . . . . . . . . . . . . . . 51

4.2.4 Análise simplificada da nova estrutura em postes de madeira, concreto e de ferro . . . . . . . . . . . . . . . . . . . . . 5 53

4.3 Análise Direta da Atual e da Nova Estrutura em Poste de Madeira . . . . . . . . 56

5 Análise de Desempenho da Linha de Distribuição 59

5.1 Modelagem da Linha de Distribuição no programa DIgSILENT PowerFactory . . 59

5.2 Estudo de Fluxo de Potência . . . . . . . . . . . . . . . . . . . . . . 61

5.3 Estudo de Máximo Carregamento . . . . . . . . . . . . . . . . . . . 65

6 Ensaios Elétricos e Mecânicos para a Nova Estrutura $\quad 69$

6.1 Ensaios Elétricos da Nova Estrutura . . . . . . . . . . . . . . . . . . . . . 69

6.1 .1 Tensão de impulso atmosférico . . . . . . . . . . . . . . . . . 69

6.1.2 Ensaios elétricos sob frequência industrial . . . . . . . . . . . . . 71

6.2 Ensaio Mecânico da Nova Estrutura . . . . . . . . . . . . . . . . . . . . . . . 72

$\begin{array}{lll}7 & \text { Comentários Finais } & 73\end{array}$

$\begin{array}{ll}\text { Referências Bibliográficas } & 82\end{array}$ 


\section{Lista de Siglas}

AIEE American Institute of Electrical Engineers

ANEEL Agência Nacional de Energia Elétrica

ANSI American National Standards Institute

ATP Alternative Transients Program

BPA Boneville Power Administration

BEM Boundary Element Method

CCA Chromated Copper Arsenate

CFO Critical Flashover Voltage

CPFL Companhia Paulista de Força e Luz

DCG Development Coordination Group

DPL DIgSILENT Programming Language

EMTP ElectroMagnetic Transients Program

EMT ElectroMagnetic Transients

EPRI Electric Power Research Institute

LaMEM Laboratório de Madeiras e de Estruturas de Madeira

LCC Line Cable Constants

LEC Leuven EMTP Center-Leuven-Bélgica 
LSEE Laboratório de Sistemas de Energia Elétrica

MEF Método dos Elementos Finitos

MLC Madeira Laminada Colada

NBI Nível Básico de Isolamento

SE Subestação de Energia

SEP Sistema Elétrico de Potência

SFSD Steep Front Short Duration

UBC Universidade de Britsh Columbia 


\section{Lista de Tabelas}

3.1 Valores das impedâncias de sequência zero e positiva do sistema, representadas

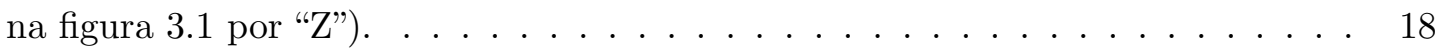

3.2 Resistência e indutância da carga calculados a partir das potências ativa e reativa. 20

3.3 Valores de tensão real e simulados na saída da subestação e na entrada da cidade. 21

4.1 Permissividade relativa dos materiais utilizados. . . . . . . . . . . . . . . . . 30

4.2 Evolução na qualidade da malha de elementos finitos para a estrutura atual da cruzeta (valores em porcentagem). . . . . . . . . . . . . . . . . . . 31

4.3 Evolução na qualidade da malha de elementos finitos para a estrutura proposta(valores em porcentagem $) \ldots \ldots \ldots \ldots \ldots \ldots \ldots$. . . . . . . . . . . . . 45

4.4 Condutividade elétrica dos materiais utilizados. . . . . . . . . . . . . . . . . 54

4.5 Diferenças de potencial entre as linhas equipotenciais próximas ao isolador da fase C e o ponto de conexão da mão francesa com o poste. . . . . . . . . . . . . . . 57

5.1 Tensões nas três fases para a linha com a estrutura atual e a nova estrutura. . . . 63

5.2 Comparação entre as perdas ativa e reativa para a linha de distribuição em análise. 65

6.1 Condição de precipitação padrão. Fonte: (IEEE-Std-4 (1995)) . . . . . . . . . . 72

6.2 Resistência à flexão. (Fonte: ABNT (1984)) . . . . . . . . . . . . . . . . . . . 72 


\section{Lista de Figuras}

3.1 Diagrama representando o sistema elétrico simulado. . . . . . . . . . . . . . . . 18

3.2 Modelo de uma estrutura de cruzeta (N1), contendo alguns dos componentes comumente agregados. (Fonte:CPFL (2009)) . . . . . . . . . . . . . . . 19

3.3 Curva de carga típica no período de 17 à 27 de fevereiro de 2011 (Fonte: Santos

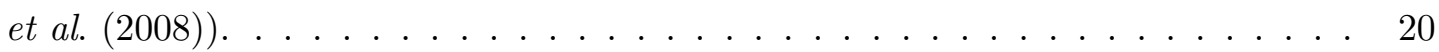

3.4 Tensão nas três fases do sistema na saída da Subestação de Energia (SE). . . . . 21

3.5 Regime permanente - método para o registro dos valores de tensão nas três fases

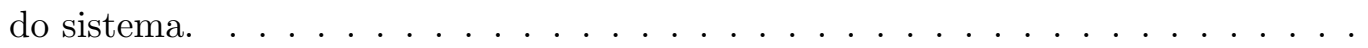

3.6 Transitório eletromagnético devido a um curto-circuito monofásico, envolvendo a fase A e o terra, localizado a 10,95 km da SE, com um tempo de inserção da falta

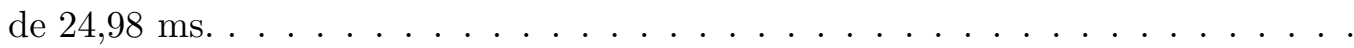

3.7 Transitório eletromagnético devido a um curto-circuito monofásico, envolvendo a fase A e o terra, localizado a 10,95 km da SE, com um tempo de inserção da falta de 16,66 ms. . . . . . . . . . . . . . . . . . . .

3.8 Transitório eletromagnético devido a um curto-circuito bifásico, envolvendo as fases B e C, localizado a $7,3 \mathrm{~km}$ da SE. . . . . . . . . . . . . . . 25

4.1 Estrutura N1 modelada no software FLUX 3D. . . . . . . . . . . . . . . . 29

4.2 Malha de elementos finitos criada para ilustrar os elementos de baixa qualidade. 31

4.3 Malha de elementos finitos criada para a simulação dos campos elétricos e linhas

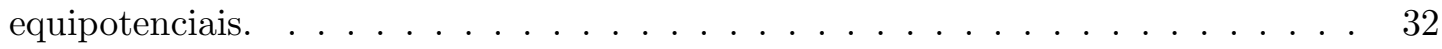

4.4 Detalhe das Fases A, B e C. . . . . . . . . . . . . . . . 33 
4.5 Campo elétrico devido à operação nominal do sistema apresentado na figura 3.4 (vista posterior) . . . . . . . . . . . . . . . . . . . 33

4.6 Campo elétrico devido à máxima diferença de potencial encontrada no transitório apresentado na figura 3.4 (vista frontal) . . . . . . . . . . . . . . . . . . 34

4.7 Linhas equipotenciais devido à máxima diferença de potencial encontrada no transitório apresentado na figura 3.4 (vista frontal) . . . . . . . . . . . . . . . . 34

4.8 Campo elétrico devido à máxima diferença de potencial encontrada no transitório apresentado na figura 3.6 (vista frontal) . . . . . . . . . . . . . 35

4.9 Campo elétrico devido à máxima diferença de potencial encontrada no transitório apresentado na figura 3.6 (vista posterior) . . . . . . . . . . . 36

4.10 Linhas equipotenciais devido à máxima diferença de potencial encontrada no transitório apresentado na figura 3.6 (vista posterior) . . . . . . . . . . . . . . . 36

4.11 Campo elétrico devido à máxima diferença de potencial encontrada no transitório apresentado na figura 3.7 (vista frontal) . . . . . . . . . . . . . . . . 37

4.12 Campo elétrico devido à máxima diferença de potencial encontrada no transitório apresentado na figura 3.7 (vista posterior) . . . . . . . . . . . . . . 37

4.13 Campo elétrico devido à máxima diferença de potencial encontrada no transitório apresentado na figura 3.7 (vista posterior) . . . . . . . . . . . . . 38

4.14 Campo elétrico devido à máxima diferença de potencial encontrada no transitório apresentado na figura 3.8 (vista frontal $) \ldots \ldots \ldots$. . . . . . . . . . . . 39

4.15 Campo elétrico devido à máxima diferença de potencial encontrada no transitório apresentado na figura 3.8 (vista posterior) . . . . . . . . . . . . . . . . 39

4.16 Campo elétrico devido à máxima diferença de potencial encontrada no transitório apresentado na figura 3.8 (vista posterior) . . . . . . . . . . . . . . . . . 40

4.17 Modelo de cruzeta baseado na estrutura N1. . . . . . . . . . . . . . . . . . 41

4.18 Modelo de cruzeta baseado na estrutura M1. . . . . . . . . . . . . . . . . . . 42

4.19 Modelo proposto final baseado na estrutura N1 . . . . . . . . . . . . . . . 42

4.20 Vista frontal da nova composição. . . . . . . . . . . . . . . . . . . . . . 43

4.21 Vista lateral da nova composição. . . . . . . . . . . . . . . . . . . . . . . 43 
4.22 Vista frontal da nova composição modelada no FLUX 3D. . . . . . . . . . . . . . 44

4.23 Campo elétrico devido à operação nominal do sistema, apresentado na figura 3.4, para a nova estrutura proposta (vista posterior). . . . . . . . . . . . .

4.24 Campo elétrico devido à operação nominal do sistema, apresentado na figura 3.4, para a nova estrutura (vista frontal). . . . . . . . . . . . . . . . . . 46

4.25 Linhas equipotenciais devido à operação nominal do sistema, apresentado na figura 3.4, para a nova estrutura proposta (vista posterior). . . . . . . . . . . .

4.26 Campo elétrico devido à máxima diferença de potencial encontrada no transitório apresentado na figura 3.6, para a nova estrutura (vista frontal). . . . . . . . . .

4.27 Campo elétrico devido à máxima diferença de potencial encontrada no transitório apresentado na figura 3.6, para a nova estrutura (vista posterior). . . . . . . . .

4.28 Linhas equipotenciais devido à máxima diferença de potencial encontrada no transitório apresentado na figura 3.6, para a nova estrutura proposta (vista posterior). 49

4.29 Campo elétrico devido à máxima diferença de potencial encontrada no transitório apresentado na figura 3.7, para a nova estrutura proposta (vista frontal). . . . .

4.30 Campo elétrico devido à máxima diferença de potencial encontrada no transitório apresentado na figura 3.7, para a nova estrutura (vista posterior). . . . . . . . .

4.31 Linhas equipotenciais devido à máxima diferença de potencial encontrada no transitório apresentado na figura 3.7, para a nova estrutura proposta (vista posterior). 51

4.32 Campo elétrico devido à máxima diferença de potencial encontrada no transitório apresentado na figura 3.8, para a nova estrutura proposta (vista frontal). . . . . . 52

4.33 Campo elétrico devido à máxima diferença de potencial encontrada no transitório apresentado na figura 3.8, para a nova estrutura proposta (vista posterior). . . . 52

4.34 Linhas equipotenciais devido à máxima diferença de potencial encontrada no transitório apresentado na figura 3.8, para a nova estrutura proposta (vista posterior). 53

4.35 Campo elétrico na estrutura - poste de madeira. . . . . . . . . . . . . . . 54

4.36 Campo elétrico na estrutura - poste de concreto. . . . . . . . . . . . . 55

4.37 Campo elétrico na base do poste de concreto com um vergalhão. . . . . . . . 56

4.38 Campo elétrico na estrutura - poste de ferro. . . . . . . . . . . . . . . 56 
5.1 Sistema modelado no programa DIgSILENT PowerFactory. . . . . . . . . . . . 61

5.2 Resultado do fluxo de potência para o sistema com a estrutura atualmente utilizada. 62

5.3 Resultado do fluxo de potência para o sistema com a estrutura proposta. . . . . . 62

5.4 Curva PV para um sistema de transmissão genérico. (Fonte:Kundur et al. (1994)) 66

5.5 Curva PV para a linha que utiliza a estrutura atual e a nova cruzeta. . . . . . . 67

6.1 Impulso atmosférico pleno. Fonte: (IEEE-Std-4, 1995) . . . . . . . . . . . . 70

6.2 Ensaio de flexão. . . . . . . . . . . . . . . . . . . . . . . . . . . 72 


\title{
Resumo
}

\author{
Biasotto, E. Metodologia para o desenvolvimento de um novo padrão estrutural e \\ elétrico de cruzeta para redes de $\mathbf{1 5}$ kV. 2012. 82 f. Tese (Doutorado) - Escola de
} Engenharia de São Carlos, Universidade de São Paulo, São Carlos, 2012.

O conceito de preservação ambiental dos dias atuais não permite que haja exageros na utilização dos bens naturais, fazendo com que as pessoas se adaptem e reduzam a utilização, ou promovam a reciclagem de materiais. Nessa conjuntura, esse trabalho de doutorado versa sobre a especificação e a necessidade de se obter novos padrões estruturais e elétricos de cruzetas a serem utilizados nas redes de distribuição de $15 \mathrm{kV}$ e procurará desenvolver opções compatíveis com a preservação do meio ambiente. Neste sentido, o principal foco está direcionado à definição de novas geometrias para as cruzetas de madeira, induzindo a uma redução direta na utilização das madeiras retiradas de florestas tropicais. Cabe colocar que quando da proposição de uma nova geometria, todos os aspectos elétricos e mecânicos relacionados à definição deste novo padrão devem ser descritos e comprovados em termos da viabilidade prática e técnica de aplicação, dispondo-se de várias análises e procedimentos de testes que o garantam frente às possíveis operações que o sistema elétrico, na classe de tensão de $15 \mathrm{kV}$, venha a enfrentar. Na realização do trabalho, utilizou-se três softwares, o Alternative Transients Program (ATP), o FLUX 3D e o DIgSILENT PowerFactory, para as simulações dos transitórios eletromagnéticos, simulações de campos elétricos e análises de desempenho das linhas, respectivamente. Pela metodologia aplicada, os resultados observados ressaltam uma considerável margem de segurança no comprimento da estrutura da cruzeta atualmente empregada em campo, permitindo a diminuição desejada e confiável para um modelo alternativo.

Palavras-chave: Linhas de Distribuição, Transitórios Eletromagnéticos, Classe de 15 kV, Isolador tipo Pino, Cruzeta de Madeira, Elementos Finitos. 


\section{Abstract}

Biasotto, E. Method for the development of a new pattern of structural and electrical crossarm to $15 \mathrm{kV}$ networks. 2012. 82 f. Tese (Doutorado) - Escola de Engenharia de São Carlos, Universidade de São Paulo, São Carlos, 2012.

The current concept of environmental preservation does not allow any exaggeration in the use of natural resources, leading people to adapt themselves and reduce the use, or promote the recycling of materials. At this juncture, this doctoral work focuses on the specification and the need to obtain new structural and electrical patterns for crossarms to be used in $15 \mathrm{kV}$ distribution networks and seek to develop compatible options with the preservation of the environment. In this sense, the main focus is directed toward the definition of new geometries for wood crossarms, inducing an evident reduction in the use of wood taken from tropical forests. It is important to place that when a new geometry is proposed, all electrical and mechanical aspects related to the definition of this new pattern should be described and demonstrated in terms of practicability and technic of application, arranging various analyzes and testing procedures that guarantee it against the possible operations that the electrical system with voltage rating of $15 \mathrm{kV}$ can be face. In carrying out the work, three softwares (ATP, FLUX 3D e DIgSILENT) were used for the simulation of electromagnetic transients, the simulation of electric fields and analysis of performance of the lines, respectively. For the methodology applied, the observed results highlight a significant safety margin in the length of the crossarm structure currently employed in the field, allowing the desired and reliable reduction for an alternative model.

Keywords: Distribution Lines, Electromagnetic Transients, $15 \mathrm{kV}$ Class, Pin-type insulators, Wooden Crossarm, Finite Element. 


\section{Capítulo 1}

\section{Introdução}

O sistema brasileiro de transmissão de energia elétrica, além de ser um dos mais extensos do mundo, possui uma grande variedade de classes de tensão de operação, que variam de $34,5 \mathrm{kV}$ até $765 \mathrm{kV}$. Além dessa vasta quantidade de linhas, tem-se ainda as linhas de distribuição de energia elétrica que são, usualmente, utilizadas na classe de tensão de 13,8 kV.

De acordo com o site da Agência Nacional de Energia Elétrica (ANEEL), todo o conjunto de instalações e equipamentos elétricos que operam em tensões inferiores a $230 \mathrm{kV}$ são considerados como parte do sistema de distribuição. Porém, as concessionárias de energia elétrica, visando uma classificação mais detalhada, tratam como sistema de transmissão os que operam com tensões iguais ou superior a $230 \mathrm{kV}$, e como de sub-transmissão os sistemas que operam entre 69 e $230 \mathrm{kV}$. Como distribuição primária, tem-se os sistemas que operam entre 13,8 e 34,5 kV e, como distribuição secundária, tem-se os sistemas de baixa tensão, 220/127 V. Ressalta-se que os valores de tensão de distribuição secundária podem mudar de acordo com a região e a concessionária, estando disponíveis no site da ANEEL.

Nos dias atuais, com o aumento do consumo da energia elétrica e principalmente pela manutenção e conservação da rede elétrica de distribuição brasileira, é muito utilizada a madeira retirada de florestas tropicais para a construção de cruzetas. Com a grande preocupação ambiental surgem ideias como a construção de cruzetas de materiais diversos, como concreto, metal e, ainda outros que, assim como os citados, apresentam um balanço energético para sua fabricação com resíduos, gerados durante e após sua conclusão, que não condizem com as necessidades globais atuais.

Apesar da busca por outros materiais, acredita-se que a madeira ainda é o melhor material a 
ser usado na construção de cruzetas, pelo seu custo atraente e pela resistência mecânica e elétrica que esse material proporciona. Portanto, o que se busca com o presente trabalho, consiste em apresentar e justificar uma forma de se continuar a utilizar a madeira sem, no entanto, prejudicar o meio ambiente.

Sendo assim, buscou-se, por meio desta pesquisa, definir e apresentar uma metodologia para a obtenção de um novo padrão para as estruturas de redes de $15 \mathrm{kV}$, baseando-se nas atualmente empregadas. Foram avaliados vários tipos de padrões e suas variações. O principal intuito de se analisar padrões diferentes das estruturas utilizadas na distribuição foi o de proporcionar uma diminuição do tamanho das cruzetas hoje em dia utilizadas. O tamanho padrão corresponde a 2 metros. Pela redução do tamanho, reduz-se de forma direta a quantidade de matéria prima empregada, nesse caso, a madeira utilizada no processo de fabricação das cruzetas. Contudo, para a viabilização prática e técnica de um novo padrão de cruzeta, um completo estudo estrutural e elétrico de todos os componentes envolvidos como, por exemplo, os condutores, isoladores, pinos, entre outros, foi cuidadosamente realizado.

Sabe-se que diretamente associado a um novo padrão, com um menor tamanho da cruzeta, tem-se também alterações nos espaçamentos entre os condutores. Sendo assim, em função desta almejada redução, uma análise direcionada ao efeito de acoplamento mútuo entre os condutores foi realizada.

Outro ponto de motivação foi a possibilidade de um estudo mais aprofundado com relação às perdas técnicas/elétricas associadas ao sistema de distribuição. Pela redefinição de um novo padrão, com novos espaçamentos e demais componentes, espera-se contribuir para uma melhor eficiência do sistema de distribuição, diminuindo assim, as perdas técnicas/elétricas associadas.

Apenas para ilustrar, estima-se que as perdas elétricas em linhas de distribuição do interior do estado de São Paulo, sob concessão da Companhia Paulista de Força e Luz (CPFL), correspondam a aproximadamente $6,45 \%$ da energia total distribuída. Considerando então um montante de aproximadamente $25 \mathrm{GWh}$ de energia distribuída anualmente, têm-se perdas de 1,65 GWh/ano. Assim sendo, considerando a tarifa média de suprimento de R \$ 95,00/MWh, o potencial de ganhos anuais em relação às perdas técnicas é de $\mathrm{R} \$ 157.130 .000,00 /$ ano. Tais apontamentos foram colocados somente para evidenciar que pequenas reduções nas perdas elétricas, sobre um sistema de distribuição corretamente projetado e operado, resultarão em um montante que poderá ser diretamente revertido para a sociedade como melhorias no sistema como um todo. 
Outro aspecto relevante e motivador para a definição de um novo padrão foi com relação à quantidade de cruzetas utilizadas anualmente pela empresa supracitada, que atinge o número de 60.000 cruzetas ao ano. Este número refere-se às cruzetas anualmente necessárias para os projetos de expansão e de reposição.

Esta pesquisa foi concebida como parte de um projeto maior de Pesquisa e Desenvolvimento - P\&D, que teve como resultados, além dessa tese, a montagem e a instalação de cruzetas em linhas de distribuição para a realização de testes em campo. Este projeto de P\&D foi realizado através de uma parceria entre Laboratório de Madeiras e de Estruturas de Madeira (LaMEM), Laboratório de Sistemas de Energia Elétrica (LSEE), e CPFL.

No rumo do objetivo principal, ressalta-se que o LaMEM utiliza uma técnica chamada de Madeira Laminada Colada (MLC), que por si só já apresenta um ganho relevante no que diz respeito aos aspectos ambientais, uma vez que essa técnica utiliza madeiras provenientes de reflorestamentos de pinus e eucalyptus. O LaMEM já utiliza a técnica de MLC há algum tempo, e como exemplo, cita-se Zangiácomo (2003), que apresenta o emprego de espécies tropicais alternativas para sua produção. A aplicação das cruzetas com tecnologia de MLC, com maior vida útil e facilidades na montagem das estruturas, trará ganhos na confiabilidade e nos custos de manutenção das redes. Aliados a isso devem ser considerados os aspectos relativos às políticas de meio ambiente no tocante à preservação das florestas tropicais, bem como na contribuição para o "resgate de carbono" obtido através do uso de madeiras de reflorestamentos.

Tendo em vista esses aspectos, o desenvolvimento deste trabalho passou pela modelagem e análise de diversas estruturas de cruzetas, com geometrias distintas, a serem aplicadas em sistemas de distribuição na classe de $15 \mathrm{kV}$. O trabalho como um todo visa a adquirir um amplo conhecimento com relação aos efeitos dos campos elétricos a que estarão submetidas às estruturas em campo, desde as cruzetas propriamente ditas, isoladores, e até mesmo a influência da mão francesa de metal, buscando evidenciar um aumento do Nível Básico de Isolamento (NBI) da estrutura.

Neste cenário, para a realização das principais análises até se obter um novo padrão, utilizouse de poderosos softwares de simulação como é o caso do Alternative Transients Program (ATP), ATP (1987), para a análise tanto em regime permanente como transitória do sistema elétrico de potência, e o emprego do programa FLUX (Coulomb et al., 1985; Meunier et al., 1991), para análise do campo elétrico e das linhas equipotenciais observáveis sobre a estrutura de interesse. A concepção de aplicação deste último software é baseada na teoria de elementos finitos (Assan, 
2003). Através dessas simulações foi analisado, por exemplo, o NBI (IEEE-Std-1410, 2004) das estruturas modeladas, tomando-se como base os valores adotados pelas normas nacionais e internacionais específicas ao assunto, bem como os procedimentos e normas técnicas internas às concessionárias de energia.

Além desses softwares, outro utilizado foi o DIgSILENT PowerFactory, com o intuito de analisar e comparar o desempenho da linha operando com a estrutura atualmente empregada pela concessionária com a linha operando com a estrutura proposta neste trabalho. A análise de desempenho consistiu em simulações de fluxo de carga (Monticelli, 1983), observando a queda de tensão na linha de distribuição, as perdas de potência ativa e reativa, e o desequilíbrio de tensão no barramento da carga.

\subsection{Objetivos e Metas}

Como anteriormente apresentado, buscou-se, em parceria com o LaMEM, LSEE e CPFL, encontrar um modelo de estrutura mais econômico que os utilizados atualmente, diminuindo suas dimensões sem prejudicar o desempenho estrutural e elétrico da rede de distribuição.

O objetivo primordial desse trabalho é a redução do tamanho da cruzeta de madeira e, atrelados a esse objetivo, ressaltam-se o aumento do NBI da estrutura, a redução das perdas ativas e reativas da rede, diminuição da queda de tensão ao final da linha de distribuição e a redução do desequilíbrio da tensão fornecida.

Além desses objetivos, também foi meta a identificação e compilação dos conhecimentos técnicos internos existentes junto a CPFL, LaMEM e LSEE, bem como na literatura técnica sobre o assunto, organizando-os em uma base de dados comum ao sistema elétrico. Foram observados e registrados os requisitos técnicos mínimos a serem considerados nos estudos de viabilidade, na elaboração do projeto e na definição das especificações, nas características construtivas e nos aspectos de operação e manutenção das instalações da rede de distribuição. Tal banco de dados e resultados decorrentes, respeitando-se o domínio das informações contidas de propriedade exclusiva da CPFL, poderá ser de grande utilidade para o setor de energia, visto que a aplicação de um novo padrão poderá ser mais bem adaptada e empregada nas áreas de concessão das diversas concessionárias de energia existentes no território nacional. 


\section{$1.2 \quad$ Aspectos Inovadores}

Ressalta-se que o principal foco deste trabalho é a redução do tamanho da cruzeta de madeira utilizada nas linhas de distribuição da classe de $15 \mathrm{kV}$. Procura-se, também, reduzir as perdas na distribuição de energia e aumentar o NBI das estruturas, buscando sempre o mínimo de alteração nas peças já utilizadas pela concessionária, o que virá a facilitar a implementação da nova estrutura proposta neste trabalho.

Além de propôr uma nova estrutura de distribuição, ressalta-se como originalidade deste trabalho a utilização de um software baseado no Método dos Elementos Finitos (MEF) - FLUX 3D - em conjunto com um software bastante difundido na análise transitória de sistemas elétricos de potência, o ATP.

Cabe colocar que, apesar de os softwares baseados no MEF já serem bastante utilizados para análises de campos elétricos e linhas equipotenciais, este é utilizado de maneira bem pontual, analisando apenas um isolador, como por exemplo, em Queiroz et al. (2006).

Neste trabalho, utilizou-se o FLUX 3D na estrutura completa, o que poderá ser utilizado para complementar estudos referentes ao NBI de estruturas de distribuição e transmissão de energia elétrica.

\subsection{Metodologia aplicada}

O objetivo deste trabalho é estabelecer uma metodologia para o desenvolvimento de um novo padrão estrutural e elétrico de cruzeta para redes de $15 \mathrm{kV}$ utilizando-se de softwares disponíveis.

Os softwares utilizados nesse trabalho são: O ATP, para a análise de transitórios; o Flux 3D, para as simulações baseadas no MEF; e o DIgSILENT PowerFactory, para a análise do desempenho da linha através da análise do fluxo de potência.

Além destes, há outros que podem ser aplicados de forma semelhante e na ordem dos três programas acima citados, como, por exemplo, o PSCAD desenvolvido pela Manitoba-HVDC,o antigo Femlab, atualmente designado por COMSOL Multiphysics, e o CYMDIST - Distribution System Analysis, desenvolvido pela CYME International.

A metodologia aplicada neste trabalho é dividida em quatro partes principais:

- Simulações de transitórios eletromagnéticos; 
- Simulações de campos elétricos e linhas equipotenciais;

- Análise de desempenho da linha em estudo; e

- Ensaios elétricos e mecânicos.

Todas as etapas serão detalhadas no decorrer do trabalho. Porém, para melhor caracterizar a metodologia aplicada, alguns comentários serão apresentados no que segue.

\section{Simulações de transitórios eletromagnéticos}

As simulações de transitórios eletromagnéticos devem abordar a análise do sistema em regime permanente, bem como a análise dos transitórios eletromagnéticos devido aos curtos-circuitos a que a linha possivelmente estará sujeita em campo.

Para a análise dos transitórios, os curtos-circuitos podem ser monofásicos, bifásicos e trifásicos, envolvendo as fases A, B ou C, com e sem o envolvimento do terra (T), totalizando 11 tipos de curtos-circuitos, listados abaixo:

- Monofásico A-T;

- Monofásico B-T;

- Monofásico C-T;

- Bifásico AB;

- Bifásico BC;

- Bifásico AC;

- Bifásico AB-T;

- Bifásico BC-T;

- Bifásico AC-T;

- Bifásico ABC;

- Bifásico ABC-T. 
Após as simulações dos distúrbios em vários pontos da linha, devem ser selecionados os piores casos, ou seja, os casos que apresentaram as maiores diferenças de potencial entre as fases, para o registro dessas informações e posterior simulação dos campos elétricos e linhas equipotenciais.

\section{Simulações de campos elétricos e linhas equipotenciais}

Utilizando-se dos resultados obtidos através das simulações de transitórios eletromagnéticos, são realizadas as simulações estacionárias de campos elétricos e linhas equipotenciais e, através delas, busca-se uma avaliação da intensidade de campo elétrico e das diferenças de potenciais a que a estrutura será submetida.

Os resultados obtidos nessas simulações poderão complementar as análises do NBI das estruturas.

\section{Análise de desempenho da linha em estudo}

A análise de desempenho da linha deve apresentar uma comparação entre os modelos de estrutura propostos a fim de demonstrar que a sua modificação não prejudicará a operação e o desempenho do sistema de distribuição. Assim, na análise devem constar a influência da geometria da linha na queda de tensão, na potência transmitida e no desequilíbrio de tensão ocasionado pela linha.

\section{Ensaios elétricos e mecânicos}

Os ensaios elétricos e mecânicos devem ser realizados após a determinação da nova estrutura proposta com o intuito de comprovar os resultados obtidos nas simulações e certificar-se de que a estrutura possa suportar todos os esforços mecânicos e elétricos a que estará submetida.

\subsection{Estrutura do Documento}

O presente trabalho divide-se em seis partes.

No que diz respeito à sua organização, tem-se, respectivamente, a seguinte divisão, cada item correspondendo a um capítulo: introdução, revisão bibliográfica, modelagem do sistema de distribuição, modelagem da cruzeta e demais componentes com a utilização do método de 
elementos finitos, análise de desempenho da linha de distribuição, ensaios elétricos e mecânicos e a conclusão.

A introdução contextualiza o trabalho e projeta os resultados obtidos.

No capítulo 2, apresenta-se uma revisão bibliográfica referente a assuntos pertinentes ao tema da pesquisa, focando principalmente na utilização de softwares baseados no MEF e em análises de campos elétricos.

Na sequência, capítulo 3, é demonstrada a modelagem de uma linha de distribuição real e os piores resultados encontrados durante as simulações de transitórios eletromagnéticos devido aos curtos-circuitos aplicados na linha.

De posse dos resultados encontrados no capítulo supracitado, passou-se para as simulações utilizando o software FLUX 3D. Os resultados e as devidas análises são expostas no capítulo 4.

Depois de validada a nova estrutura, através de simulações, tem-se o capítulo de análise de desempenho da linha de distribuição (Capítulo 5), onde é feito o estudo do fluxo de potência para a linha que utiliza a estrutura atual comparando-a com a linha que utiliza a estrutura proposta neste trabalho.

O capítulo 6 apresenta alguns ensaios elétricos e mecânicos necessários para a validação da nova estrutura proposta para a sua posterior utilização.

Para finalizar o documento, no capítulo 7 são expostos aspectos conclusivos em relação ao trabalho realizado seguidos pelas referências bibliográficas que serviram de suporte teóricometodológico a este trabalho. 


\section{Capítulo 2}

\section{Pesquisas e Assuntos}

\section{Correlacionados}

Neste capítulo, tem-se uma revisão bibliográfica sobre assuntos correlacionados ao proposto neste trabalho, como alguns trabalhos referentes à análise de campos elétricos na determinação de parâmetros dos Sistemas Elétricos de Potência (SEPs) e à análise de seus elementos, como, por exemplo, no desempenho de isoladores em estado perfeito ou não (com defeitos) para o uso, dentre outras situações. O objetivo principal de tal apresentação é o de afirmar a aplicação do MEF para a análise de campos elétricos em um contexto direcionado para o desenvolvimento desta pesquisa.

Lusignan e Miller (1940) apresentam resultados obtidos durante ensaios de sobretensão para avaliar o comportamento da isolação adicionada pela madeira quando utilizada em conjunto com isoladores. Os ensaios foram realizados em um laboratório de alta tensão localizado em Barbeton, Ohio, e os resultados comprovam que a madeira traz ganhos significativos. Os autores realizaram ensaios com cruzetas de madeira retirada de 3 tipos de árvores, alternando os ensaios com madeiras tratadas e não tratadas. Para o tratamento da madeira foi utilizado o creosoto, um destilado do alcatrão de carvão mineral obtido pela carbonização do carvão betuminoso à alta temperatura, destinado à preservação de madeiras (Nestler, 1974). Os autores concluem que a madeira, corretamente selecionada, pode adicionar uma complementação à isolação da estrutura muito significativa, e que a magnitude dessa isolação adicional é mais ou menos proporcional ao comprimento da madeira. Outra constatação bastante significativa é com relação ao teor de umidade da madeira: quanto menor a umidade, maior será o incremento da isolação apresentada 
pelo conjunto. A madeira tratada não trouxe grandes benefícios com relação à isolação quando comparada com a madeira não tratada.

Ross (1947) analisa a queima de estruturas de madeiras devido às fugas de corrente. O autor apresenta um esquemático de um circuito elétrico com resistências em série para representar uma estrutura com isoladores e cruzeta de madeira. Nas análises o autor ressalta as zonas de maior concentração de tensão como os pontos mais favoráveis ao início do processo da queima da madeira devido às fugas de corrente. No trabalho são expostas diversas imagens de estruturas queimadas pelas fugas de corrente e são analisadas as possíveis causas.

Em AIEE (1956), os autores ressaltam a isolação adicionada aos impulsos atmosféricos pela utilização de estruturas de madeira. Colocam ainda que apesar de os resultados serem encorajadores, teriam necessariamente que realizar muitos testes sob condições controláveis. Os autores destacam que a madeira, quando submetida a impulsos de tensão, comporta-se mais como uma resistência elétrica do que como um isolador. Através dessa resistência, os mesmos modelaram um circuito equivalente representativo, utilizando resistores e capacitores, de uma estrutura composta de um trecho de madeira e um isolador. Ao variarem o valor da resistência que representa a madeira, os autores alteraram o teor de umidade na madeira utilizada e assim, obtiveram valores de isolação adicionada por unidade de comprimento ( $k V$ per Ft.) de madeira utilizada. Como conclusões os autores colocam que as estruturas devem ser concebidas sempre considerando o pior caso, ou seja, com a estrutura operando com a madeira em seu estado úmido, pois a madeira, nesse caso, não oferece quase nenhum incremento na isolação, seja para o sistema em regime, $60 \mathrm{~Hz}$, ou sob surtos de manobra e impulsos atmosféricos. Concluem, também, que a madeira oferece um maior incremento da isolação quando sob períodos mais curtos (as simulações foram realizadas para 4 e 16 microssegundos).

Em Asboll (1988), o autor ressalta a utilização da MLC em estruturas de transmissão como um material alternativo. Esse material era utilizado principalmente nas classes de 66 e $132 \mathrm{kV}$. O autor descreve as estruturas de madeira laminada como uma alternativa para postes de madeira tradicionais e torres de treliça no que diz respeito às propriedades mecânicas e de economia. $\mathrm{O}$ autor coloca algumas vantagens na utilização de postes de madeira laminada, como o menor risco das estruturas não serem homogêneas, o que permite que a carga mecânica possa ser entre 20 e $30 \%$ maior do que em postes naturais, além de serem $30 \%$ mais leves. Além desses pontos, o autor destaca o fator econômico e a preocupação ambiental.

Armstrong et al. (1967) destacam que as concessionárias de energia elétrica devem continuar 
se esforçando para melhorar a aparência das linhas de distribuição. Porém, devem, simultaneamente, considerar a resistência das estruturas com relação aos impulsos elétricos, evitando assim certos desligamentos. Foram analisadas várias configurações possíveis. A linha, montada ao ar livre, possuía aproximadamente 800 metros de comprimento e sua construção só foi possível devido ao laboratório estar localizado em uma fazenda. Um dos terminais da linha era localizado na parte interna do laboratório de alta tensão e o outro terminal na estação de testes de curtos-circuitos. Os autores buscaram pelos resultados permitir às concessionárias uma avaliação das suas linhas de distribuição com relação à suportabilidade frente as descargas atmosféricas. Além disso, as análises realizadas sob a linha em períodos chuvosos permitiram às concessionárias uma melhor estimativa do nível de isolamento de suas linhas quando submetidas a diversas circunstâncias.

Gustavsen et al. (2002) realizam estudos referentes às taxas de substituições e manutenções em postes de madeira. O estudo é feito com base em dados obtidos de uma concessionária norueguesa, e leva em consideração a resistência natural dos postes de madeira e as ações climáticas a que estão submetidos (vento e gelo). O trabalho demonstra como a abordagem utilizada pode ser considerada como ferramenta estratégica para o projeto mecânico de novas linhas aéreas de distribuição, avaliando o impacto econômico de diversas alternativas de manutenção nas linhas existentes. Os autores afirmam que a construção de linhas aéreas de distribuição com uma maior resistência mecânica geralmente reduz o número de substituições dos postes de madeira devido às ações climáticas e colocam como atividade futura, uma melhor investigação, comparando se a redução dos custos de substituição associados trarão ganhos considerando os custos de investimentos iniciais mais elevados.

Wong e Rahmat (2010) demonstram a utilização de um modelo de circuito elétrico para a realização de estudos referentes à distribuição de correntes em postes de madeira. Esse modelo foi criado com base em detalhes físicos reais de um poste feito com madeira de Pinus Resinosa, tratada com arseniato de cobre cromado, do inglês Chromated Copper Arsenate (CCA), com 12 metros de altura. Os autores ressaltam a facilidade em realizar as simulações computacionalmente, pois as resistências do cerne e do alburno podem ser representadas de maneira concentrada, o que já não seria possível por ensaios experimentais. Os autores modelam, também, um circuito equivalente para uma estrutura completa contendo a cruzeta, a mão francesa e o parafuso central, responsável por fixar a cruzeta ao poste. Com a modelagem completa da estrutura, os autores puderam avaliar o efeito das partes metálicas na estrutura, da resistência do ar e da umidade na madeira. 
Altafim et al. (2004) apresentam análises elétricas e mecânicas de duas espécies de madeira de reflorestamento, Pinus ellionii e Eucalyptus citriodora, revestidas com resinas à base de óleo de mamona poliuretano, tratando-as como um possível material alternativo para a construção de cruzetas em estruturas de distribuição em substituição às cruzetas feitas de madeira retirada de árvores nativas de florestas tropicais. Os ensaios mecânicos mostram que ambas apresentaram resultados satisfatórios, de acordo com a norma ABNT (1984). Porém, os autores ressaltam que os resultados obtidos com a utilização de Pinus ellionii foi superior. Os resultados dos ensaios elétricos das cruzetas revestidas com resina foram ainda mais animadores, pois o NBI das estruturas foi aumentado.

Darveniza et al. (1967) tratam da utilização da madeira devido às suas propriedades de isolamento, principalmente pela capacidade de extinção de arcos elétricos e resistência a impulsos. Tratam também dos possíveis efeitos danosos das fugas de correntes e das correntes devido à sobrecargas no sistema. Foram feitas análises levando em consideração linhas protegidas com cabos guarda e linhas desprotegidas. Os autores citam o American Institute of Electrical Engineers (AIEE) (AIEE, 1956), que conclui que a madeira em dias sem chuva combinada com isoladores de porcelana apresenta uma resistência a impulsos de 32,81 até $426,51 \mathrm{kV} / \mathrm{m}$. Já a madeira em dias chuvosos, de 0 até $196,85 \mathrm{kV} / \mathrm{m}$. Esses valores serão de grande importância para as análises dos resultados obtidos neste trabalho.

Yamashita et al. (1993), com o intuito de facilitar a observação dos resultados, desenvolveram um método de simulação do campo elétrico e das linhas de potencial através do método de análise por elementos finitos. Os autores desenvolveram uma forma de demonstrar os resultados em cores para a distribuição do campo elétrico. Já o potencial elétrico foi representado com linhas de força. Os autores confirmam que as exibições dos resultados da distribuição do campo elétrico, da distribuição do potencial elétrico e das linhas de força elétrica, ajudam o usuário a entender as características físicas do campo elétrico estático.

Em Pihler e Ticar (2005) são apresentados os resultados de uma pesquisa teórica sobre o comportamento de um sistema de transmissão de energia elétrica em média tensão com condutores revestidos. A pesquisa foi realizada com base nos cálculos computadorizados de campos elétricos. Foram verificadas medidas de descarga parcial para determinar se elas são mais intensas quando o condutor isolado está em uma braçadeira de metal ou plástico, e quando o isolador é de vidro ou porcelana. Segundo os autores, no caso do cálculo do campo elétrico na proximidade imediata do condutor com uma braçadeira de metal, melhores resultados são 
obtidos com o uso de um isolador de porcelana. No caso de uma braçadeira de material isolante, a magnitude do campo elétrico diminui cerca de cinco vezes em relação ao caso anterior. Nos sistemas com uma braçadeira isolada, o isolador de vidro apresenta magnitude de campo elétrico até duas vezes maior do que no caso da porcelana.

Em Queiroz et al. (2006) são realizadas simulações em isoladores poliméricos com tensão nominal de $69 \mathrm{kV}$ a fim de verificar as áreas com maior concentração de campo elétrico, dentro ou fora dos dispositivos, e desenvolver uma metodologia para o estudo do comportamento elétrico dos isoladores. As simulações foram realizadas no software Femlab (COMSOL, 2001; Zimmerman, 2004), tanto para isoladores perfeitos quanto para isoladores com defeitos previamente observados. Segundo os autores, as determinações do campo elétrico e de potenciais elétricos são importantes na caracterização dos pontos críticos de degradação. Altas concentrações de campos elétricos podem provocar descargas parciais, desgastando o material e ocasionando um envelhecimento precoce do isolador. O Femlab é um software desenvolvido para modelagem e simulação de processos físicos que podem ser descritos por equações diferenciais parciais. Ele apresenta uma interface gráfica que permite a visualização dos desenhos em escala e a caracterização das superfícies e dos contornos com os valores desejados. O programa faz uso do MEF e das equações diferenciais parciais para calcular os resultados, que podem ser observados em forma de linhas equipotenciais ou por mapa de cores. Para a resolução de problemas utilizando o software é necessário definir a geometria da região onde o problema deve ser resolvido, indicando-se as condições de contorno e as características elétricas da região. O programa discretiza a região e realiza os cálculos de campo e potenciais elétricos. Considerando os resultados obtidos nas simulações, os autores concluíram que a presença de corpos condutores no interior do isolador causa uma forte intensificação do campo elétrico. Contudo, esta ocorrência é incomum nos isoladores. Embora a simulação não tenha apresentado grandes concentrações de campo elétrico, este defeito pode evoluir para situações extremas, devido à carbonização de uma micro-região, causada pelas descargas elétricas ou presença de solução aquosa. A presença das descargas ou da solução aquosa no interior do isolador, promovendo uma intensificação do campo elétrico, fornece condições favoráveis à ocorrência do processo de trilhamento (tracking).

Grzybowski et al. (2006), desenvolveram um estudo sobre o nível de isolamento dos isoladores de distribuição da classe de $15 \mathrm{kV}$ dos padrões (American National Standards Institute (ANSI)) ANSI 55-4, ANSI 55-3, ANSI 52-9, ANSI 52-1, frente a uma onda de curta duração (do inglês Steep Front Short Duration (SFSD)), com tempo de subida e descida de 60/200 ns ao invés do padrão de 1.2/50 $\boldsymbol{\mu}$ s, usualmente apontada pela literatura para a simulação de descargas 
atmosféricas. Uma série de testes laboratoriais de alta tensão foi proposta para estabelecer o desempenho dos isoladores para o tipo de onda SFSD. Os testes tiveram como objetivo determinar a tensão crítica de flashover (do inglês Critical Flashover Voltage (CFO)) para isoladores de $15 \mathrm{kV}$ sozinhos, bem como para isoladores de $15 \mathrm{kV}$ com cruzeta de madeira. Verificou-se que as CFO para ondas SFSD são maiores que para descargas atmosféricas, ou seja, os isoladores suportam uma maior tensão para estas ondas mais curtas que para descargas atmosféricas. A CFO adicionada por $1 \mathrm{ft}$. $(0.3048 \mathrm{~m})$ de cruzeta de madeira para os isoladores avaliados é na faixa de 200-400 kV. O aumento do nível de isolamento em SFSD é muito maior para isoladores com cruzeta de madeira.

Kontargyri et al. (2006) apresentaram um estudo para o cálculo de potenciais e de campos elétricos aplicável em isoladores utilizados para a suspensão de linhas de transmissão aéreas de $400 \mathrm{kV}$. É utilizado o software OPERA (Fields, 1999, 2004), baseado no MEF, para realizar as análises dos isoladores. Foram analisados dois tipos de cadeias de isoladores, sendo a primeira composta por isoladores de porcelana e a segunda por isoladores de vidro. Segundo os autores, os níveis de campo elétrico obtidos para a cadeia de isoladores de vidro são maiores do que para os isoladores de porcelana. As características dielétricas da porcelana são tais que este tipo de cadeia de isoladores oferece uma distribuição suave do campo elétrico ao longo dela. Os maiores níveis de campo elétrico obtidos para os isoladores de vidro são, entretanto, ainda sustentáveis devido à maior força dielétrica do vidro. O campo elétrico produzido por linhas aéreas é frequentemente calculado com o uso de métodos numéricos através de um computador. Entretanto, o cálculo analítico oferece a vantagem de que leva a uma expressão matemática, que permite o cálculo direto do campo elétrico.

Em Tzinevrakis et al. (2008) é desenvolvido um método para obter fórmulas analíticas da intensidade do campo elétrico produzido por linhas contendo um único circuito. Este método é baseado na análise da intensidade do campo elétrico através da soma de duas expansões multipolares e no uso de números complexos duplos para a simplificação das expressões matemáticas. Devido à assimetria de cargas nos condutores, eles são analisados através de seus componentes simétricos. Utilizando este método, é dada a fórmula analítica precisa da intensidade do campo elétrico para linhas contendo um único circuito com condutores em arranjo triangular, que é válido em qualquer ponto na vizinhança destas linhas. Através da fórmula precisa, é obtida uma fórmula aproximada mais simples, a qual fornece, segundo os autores, o campo elétrico com precisão excepcional para cálculos a baixas alturas, ou para longas distâncias da linha. 
Weida et al. (2009) apresentam pontos importantes com relação as simulações baseadas no MEF de grandes estruturas tridimensionais. Elementos de segunda ordem são usados ao invés de elementos lineares, mantendo a malha e os parâmetros das simulações. Alguns nós adicionais foram adaptados sobre as bordas dos elementos para que pudessem refletir com maior precisão a geometria da superfície. A fim de validar a abordagem, os autores apresentaram os resultados da simulação de uma estrutura simples com geometria simplificada com uma solução analítica conhecida. Além disso, os resultados das simulações de uma estrutura de grande escala (isolador tridimensional) também foi apresentada nesse trabalho.

O trabalho realizado por Zemljaric (2011) busca uma rota de escalada ótima para a manutenção de torres de transmissão de energia com o mínimo de exposição do pessoal de manutenção aos efeitos do campo elétrico e magnético. O autor apresenta o cálculo de campos elétricos e magnéticos em 3 dimensões e a técnica utilizada é o método dos elementos de contorno, Boundary Element Method (BEM) (Wintle, 1998). As análises foram realizadas para dois tipos de estruturas, porém, o autor coloca que os cálculos realizados podem ser utilizados para qualquer tipo de torre.

Em Salari et al. (2009), realiza-se uma análise comparativa de métodos em 2 e 3-D (dimensões) para calcular o campo eletromagnético produzido por linhas de transmissão operando na frequência do sistema. O estudo foca no efeito da catenária de cabos e no efeito de cargas elétricas e correntes presentes nos elementos da torre. Os cálculos do campo elétrico na superfície dos cabos foram considerados observando-se os campos elétricos e magnéticos próximos à superfície da terra. São mostrados os resultados para uma típica linha trifásica de $138 \mathrm{kV}$, bem como o intervalo adequado de aplicação para uma modificada e rápida solução em 2-D. Segundo os autores, dos resultados obtidos, calculados na frequência do sistema, os efeitos da catenária dos cabos e os efeitos de cargas e correntes presentes nos elementos da torre na variação do campo eletromagnético ao longo de uma seção da linha ficam claros. Para cálculos em pontos onde os cabos estão em sua altura mínima (para terreno plano), como esperado, os resultados obtidos com uma metodologia tradicional em 2-D são satisfatoriamente precisos. Ao longo do vão das linhas e para pontos suficientemente distantes das torres (no mínimo uma vez a altura da torre), uma metodologia em 2-D modificada demonstrou ser razoavelmente precisa. Para analisar todos os pontos ao longo de todas as seções da linha, particularmente próximo das torres, um método em 3-D é inevitável. Vale colocar que, apesar da sobrecarga computacional, o método em 3-D é perfeitamente possível de ser aplicado pelos computadores pessoais atuais. 
Em Liebel e Mueller (1994) observa-se um forte indicativo da capacidade estrutural encontrada na utilização de cruzetas de madeira laminada. Segundo os autores, a laminação vertical apresenta maior resistência mecânica quando comparada à laminação horizontal, porém ambas podem atingir a meta proposta. A madeira utilizada nos testes é do gênero Pseudotsuga.

Em Xu et al. (2009) tem-se uma estrutura com um dos isoladores posicionados diretamente no topo do poste, fora da cruzeta. Tal estrutura foi testada em laboratório buscando-se evitar faltas subsequentes e decorrentes do balanço de um condutor após uma falta inicial ser observada. Os cálculos apresentados e analisados buscam fornecer as distâncias mínimas entre os condutores para que as probabilidades de uma falta subsequente sejam minimizadas.

Em Youngquist et al. (1977) encontra-se a aplicação de uma estrutura de cruzeta em madeira laminada com um isolador também posicionado no topo do poste. Essas cruzetas eram laminadas e tiveram aferida a sua viabilidade estrutural, alcançando, segundo o autor, resultados satisfatórios.

No presente capítulo apresentou-se alguns trabalhos referentes à utilização do MEF em isoladores e estruturas, afirmando a possibilidade da realização das análises que serão mostradas no capítulo 4. Além disso, foram apresentados trabalhos que demonstram os aspectos isolantes da madeira, indicando sua utilização em sistemas elétricos. Com relação à MLC, coloca-se que concessionárias norueguesas já as utilizam a mais de 40 anos em estruturas de distribuição e transmissão de energia elétrica e suas condições climáticas não são tão favoráveis como as condições brasileiras, principalmente pelos esforços mecânicos a que estão sujeitas as estruturas norueguesas, devido a ação dos ventos fortes e da neve.

Ressalta-se como contribuição deste trabalho, em relação aos apresentados nesse capítulo de revisão bibliográfica, a exposição de uma metodologia em que se utiliza três importantes softwares para a análise de uma nova estrutura de distribuição. A metodologia deste trabalho poderá ser também utilizada para auxiliar na análise do NBI das estruturas. 


\section{Capítulo 3}

\section{Modelagem do Sistema de}

\section{Distribuição Teste através do software ATP}

As simulações de transitórios eletromagnéticos tiveram seu início a partir da década de 60 através do desenvolvimento de um programa chamado ElectroMagnetic Transients Program (EMTP), criado inicialmente por Dommel (1969), com base no trabalho de Frey e Althammer (1961). Herman W. Dommel com a ajuda de colaboradores desenvolveu vários modelos durante os anos (1964 - 1973) em que trabalhou na Boneville Power Administration (BPA) - USA. Após 1973, Dommel foi trabalhar na Universidade de Britsh Columbia (UBC) - Canadá e a coordenação do EMTP passou a ser de responsabilidade de Scott Meyer.

Vendo as potencialidades do programa, em 1984 o Electric Power Research Institute (EPRI) USA passou a investir no EMTP através de um grupo criado para essa atividade, o Development Coordination Group (DCG), visando principalmente a melhoria dos modelos e da documentação já existentes.

A versão do EMTP denominada ATP foi desenvolvida por Scott Meyer, após divergências entre ele e o DCG. A versão base utilizada no ATP é a versão M39 do EMTP. O ATP foi instalado no Leuven EMTP Center-Leuven-Bélgica (LEC), que centralizou e distribuiu o ATP até 1992. Após essa data, Scott Meyer e a BPA voltaram a exercer a coordenação e o desenvolvimento do programa (Ametani, 2007).

Cabe firmar que as simulações computacionais realizadas nesta pesquisa, com relação a um 
sistema elétrico de interesse, foram feitas dispondo de dados reais de uma linha de distribuição da CPFL, utilizando-se do programa ATP. Os procedimentos adotados serão detalhados nas seções que seguem.

\subsection{A Modelagem do Sistema Elétrico}

O sistema de distribuição modelado neste trabalho é responsável pela alimentação de uma pequena cidade localizada no interior do estado de São Paulo, com uma população aproximada de 11 mil habitantes.

A cidade é atendida através de uma Subestação de Energia (SE) com capacidade de 12,5 MVA, com tensão de entrada de $138 \mathrm{kV}$ e 13,8 kV de saída. O alimentador responsável pela interligação da saída da SE com a cidade foi caracterizado por um cabo com bitola de 350 MCM, possuindo um comprimento de $14,6 \mathrm{~km}$.

A figura 3.1 representa o sistema modelado. Cada item que o compõem, será melhor detalhado nas subseções seguintes.

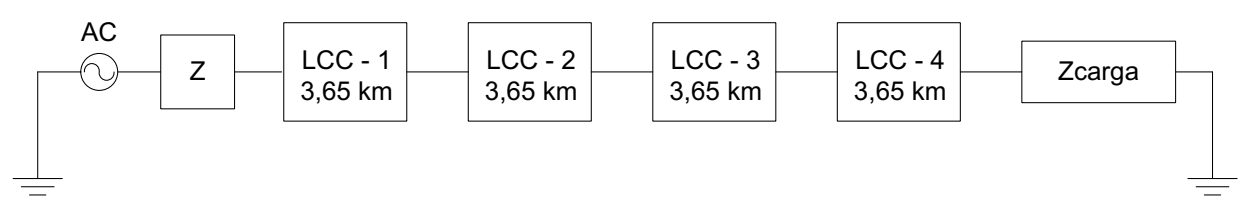

Figura 3.1: Diagrama representando o sistema elétrico simulado.

\subsubsection{Subestação}

Para representar a SE rebaixadora, localizada a 14,6 km de distância da cidade, foi utilizada uma fonte trifásica configurada com uma tensão eficaz de saída de 14,932 kV entre fases, frequência fundamental de $60 \mathrm{~Hz}$, com as impedâncias de sequência positiva e zero conectadas na saída da fonte. As impedâncias foram calculadas a partir dos valores das potências de curto-circuito do sistema e são mostradas na tabela 3.1.

Tabela 3.1: Valores das impedâncias de sequência zero e positiva do sistema, representadas na figura 3.1 por "Z").

\begin{tabular}{|c|c|c|c|}
\hline $\mathrm{R}+(\mathrm{ohms})$ & $\mathrm{X}+(\mathrm{ohms})$ & $\mathrm{R} 0$ (ohms) & $\mathrm{X} 0$ (ohms) \\
\hline 0,0650 & 2,1293 & 0,0006 & 1,9501 \\
\hline
\end{tabular}




\subsubsection{Linha de Distribuição}

Para modelar a linha de distribuição, optou-se por subdividi-la em 4 partes, com o intuito de facilitar a aplicação dos curtos-circuitos e a análise dos transitórios. Assim, os parâmetros elétricos foram calculados utilizando-se da rotina Line Cable Constants (LCC), disponível no software ATP, para quatro trechos de linha, cada um com $3,65 \mathrm{~km}$, totalizando os 14,6 km da linha de distribuição em análise.

Para a execução da rotina LCC foram utilizados os dados do condutor de alumínio 350 MCM, com diâmetro externo de $17,25 \mathrm{~mm}$ e resistência $\mathrm{CC}$ do condutor de $0,18796 \mathrm{ohm} / \mathrm{km}\left(\mathrm{a} 20^{\circ} \mathrm{C}\right)$.

Com relação à geometria da estrutura, foram utilizadas as medidas conforme apresentadas na figura 3.2, com uma altura de 11 metros em relação ao solo. Para a simulação da linha foi utilizado o modelo representado por parâmetros distribuídos e constantes (Wedepohl, 1963), o que forneceu resultados semelhantes aos reais, conforme será posteriormente apresentado.

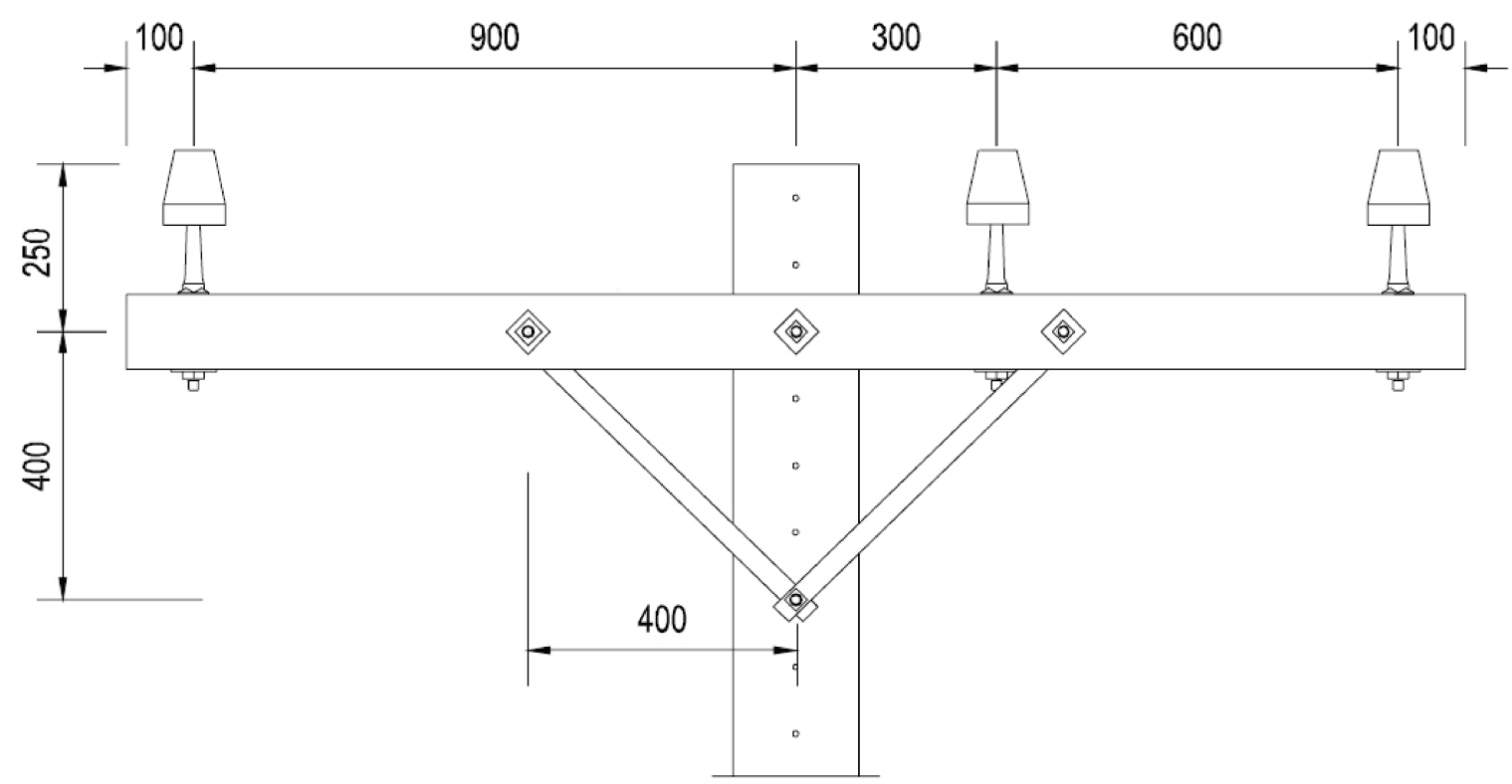

Figura 3.2: Modelo de uma estrutura de cruzeta (N1), contendo alguns dos componentes comumente agregados. (Fonte:CPFL (2009))

\subsubsection{Carga}

A impedância modelada para representar a carga do sistema foi calculada a partir da potência ativa $(4.200 \mathrm{~kW})$, da potência reativa $(1.661 \mathrm{kVAr})$, e da corrente $(193,4 \mathrm{~A})$. Todos os dados foram fornecidos pela concessionária. Os valores encontrados para representar a impedância da carga podem ser observados na tabela 3.2 . 
Tabela 3.2: Resistência e indutância da carga calculados a partir das potências ativa e reativa.

\begin{tabular}{|c|c|}
\hline $\mathrm{R}$ (Ohms) & $\mathrm{Xl}$ (Ohms) \\
\hline 119,997 & 0,78876 \\
\hline
\end{tabular}

Um aspecto importante para verificar os desequilíbrios de tensão causados pela própria assimetria da linha de distribuição, foi a consideração da carga equilibrada no terminal final do circuito.

A figura 3.3 representa a curva de carga da cidade no período de 14 à 27 de fevereiro de 2011. Através desta curva, pode-se notar que os valores máximos não ultrapassam a corrente de 193,4 A, que foi utilizada na modelagem da carga. Desta maneira, considera-se que o modelo atende ao período em que o sistema alimentará a máxima carga conectada.

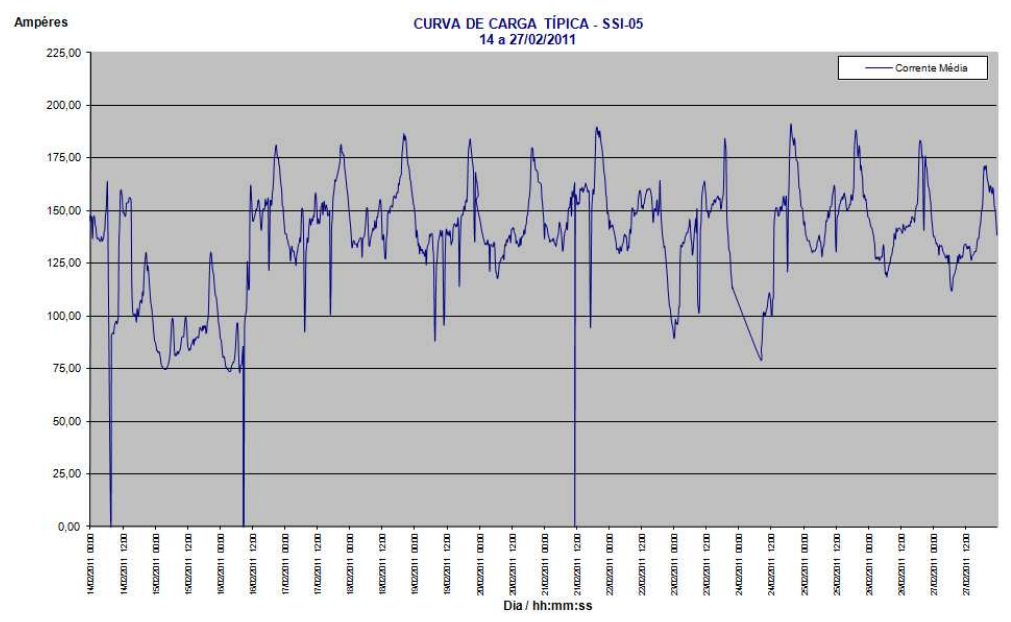

Figura 3.3: Curva de carga típica no período de 17 à 27 de fevereiro de 2011 (Fonte: Santos et al. (2008)).

A figura 3.4 apresenta as formas de onda das três fases de tensão na saída da SE para uma situação normal de operação do sistema.

Após a modelagem completa do sistema, os valores simulados foram confrontados com os valores fornecidos pela concessionária. As tensões de saída na subestação e de alimentação na carga são mostradas na tabela 3.3 . 


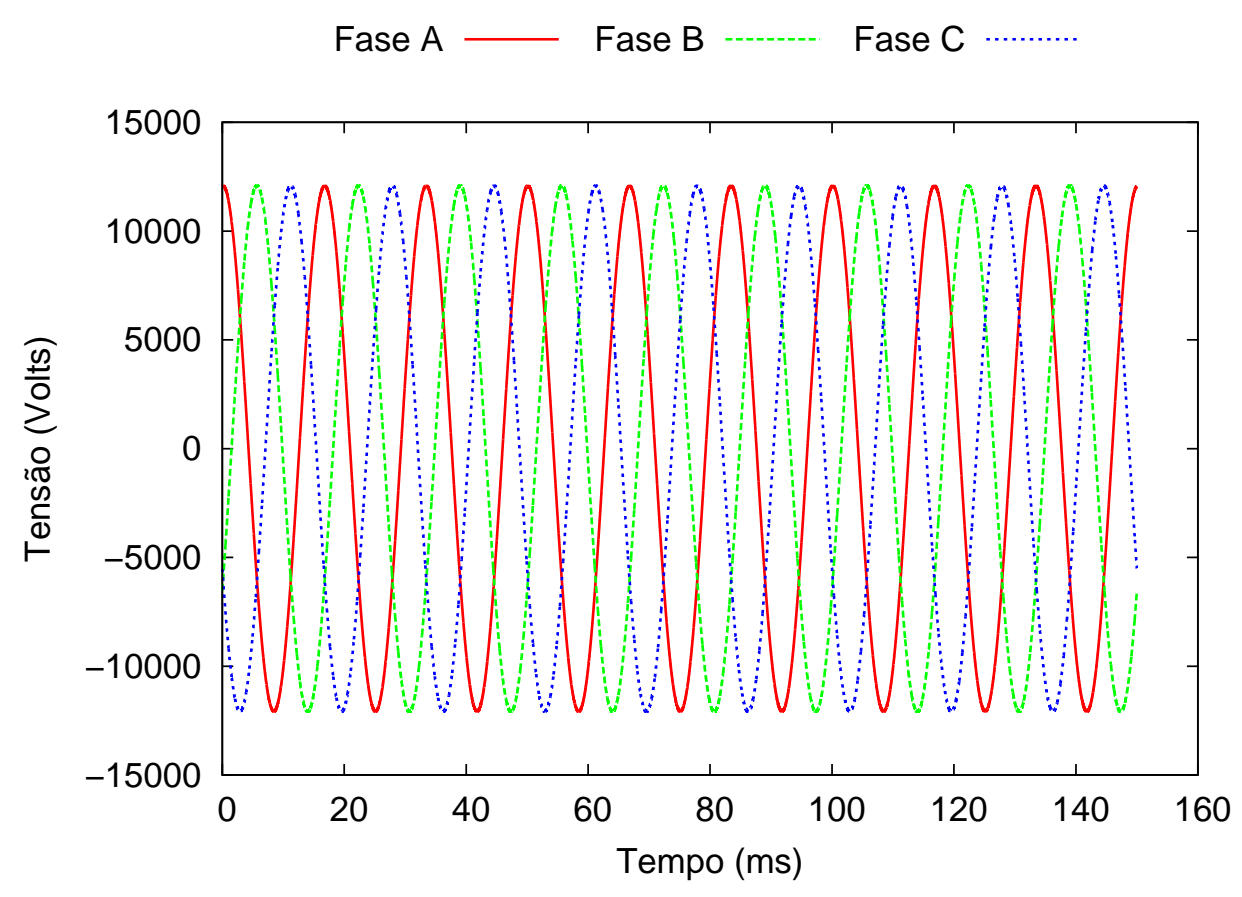

Figura 3.4: Tensão nas três fases do sistema na saída da SE.

Tabela 3.3: Valores de tensão real e simulados na saída da subestação e na entrada da cidade.

\begin{tabular}{|c|c|c|}
\hline & Real $(\mathrm{kV})$ & Simulado $(\mathrm{kV})$ \\
\hline Tensão de saída & 14,932 & 14,932 \\
\hline Tensão na carga & 13,474 & 13,435 \\
\hline
\end{tabular}

\subsection{Simulação dos Transitórios: Curtos-Circuitos}

Realizou-se a simulação da linha em regime permanente, para a validação do modelo e, em seguida, a simulação dos distúrbios passíveis de ocorrência em campo. Foram contemplados os curtos-circuitos monofásicos, bifásicos e trifásicos, com e sem a presença do terra. Foram simulados 55 distintos curtos-circuitos, variando-se o tempo de inserção do curto, 4 vezes, resultando em um total de 220 situações.

Após a realização das simulações dos transitórios eletromagnéticos, utilizando-se do programa ATP, foi necessário criar uma metodologia para resgatar os valores que alimentarão o programa baseado no MEF, o FLUX 3D.

Foi criado um algoritmo para verificar o instante em que as diferenças de potencial eram as maiores para aquela simulação. Detectado o instante, os valores instantâneos para as fases A, B 
e C foram armazenados.

Para ilustrar a coleta dos dados que serão utilizados no programa FLUX 3D, foi considerada uma linha tracejada (figura 3.5) de referência. No instante onde foi detectada a maior diferença de potencial entre as fases, foram registrados os valores, em Volts, das três fases neste mesmo instante. Vale frisar que para o caso em regime permanente, tem-se que os valores das fases $\mathrm{A}$ e C são iguais para o instante em que a fase B atinge seu pico. Esta metodologia também foi utilizada em Biasotto et al. (2010) e em de Oliveira et al. (2011).

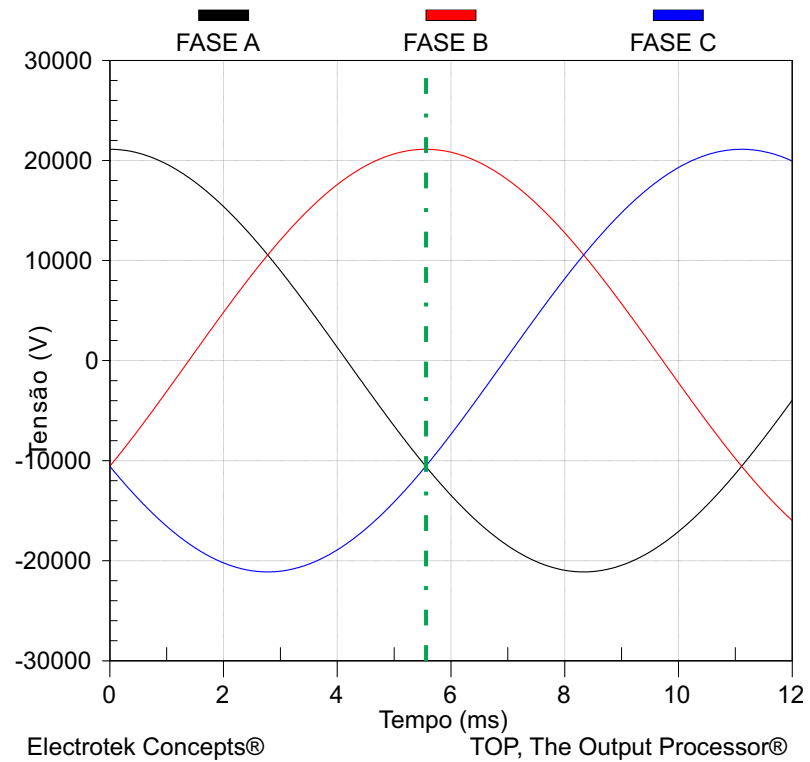

Figura 3.5: Regime permanente - método para o registro dos valores de tensão nas três fases do sistema.

Todas as situações foram analisadas, caso-a-caso, sendo as piores selecionadas. Ressalta-se que os piores casos foram os que apresentaram os maiores picos de tensão no momento da entrada do curto-circuito caracterizado.

Para as subseções 3.2.1, 3.2.2 e 3.2.3 que seguem, é importante esclarecer que a fase A encontra-se à esquerda da figura 3.2, a fase $\mathrm{B}$ ao centro, e a fase $\mathrm{C}$ à direita.

\subsubsection{Diferença de potencial entre as fases A e B}

A maior diferença de potencial encontrada entre as fases A e B, durante os curtos-circuitos, foi devido à um curto monofásico aplicado a 10,95 km da SE e medida na saída da própria SE. $\mathrm{O}$ pico de tensão na fase $\mathrm{A}$ foi de aproximadamente $-15 \mathrm{kV}$, sendo a diferença de potencial entre as fases A e B, de 24,514 kV. A figura 3.6 apresenta a forma de onda das tensões na três fases do sistema para esta situação. 


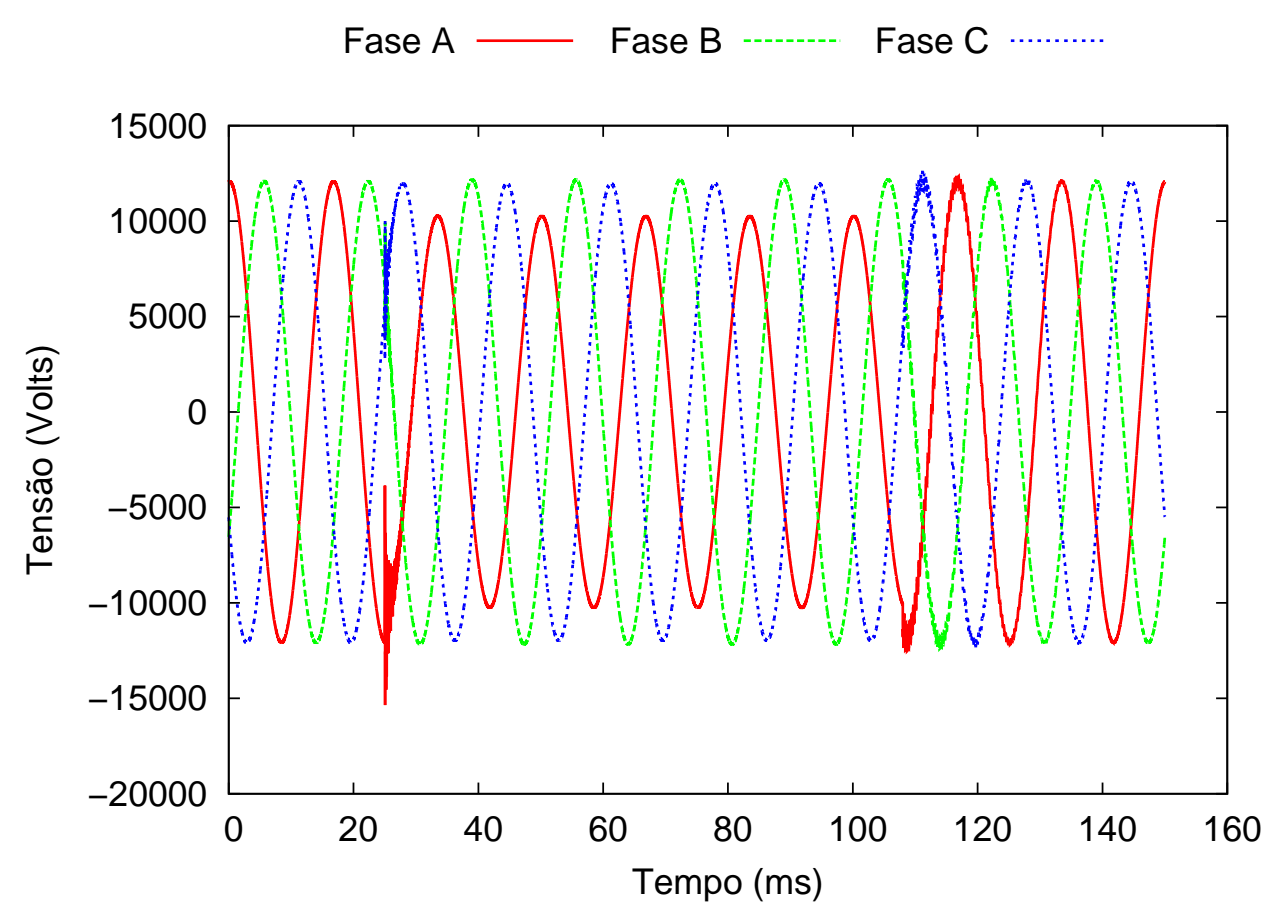

Figura 3.6: Transitório eletromagnético devido a um curto-circuito monofásico, envolvendo a fase A e o terra, localizado a 10,95 km da SE, com um tempo de inserção da falta de 24,98 ms.

\subsubsection{Diferença de potencial entre as fases A e C}

Pela disposição das fases A e C na estrutura apresentada na figura 3.2, nota-se que uma boa distância as separa $(1,8 \mathrm{~m})$. Assim, infere-se que as maiores e prováveis diferenças de potencial encontradas entre estas fases, não irão causar rupturas nos dielétricos existentes. Porém, as simulações foram conduzidas no sentido de buscar a comprovação desta afirmação.

A maior diferença de potencial encontrada neste caso foi devido à um curto-circuito monofásico aplicado a 10,95 km da SE e medido na saída da própria SE. O pico de tensão encontrado foi um pouco superior a $15 \mathrm{kV}$, sendo a diferença de potencial encontrada entre as fases A e C, de $24,79 \mathrm{kV}$. A figura 3.7 apresenta a forma de onda das três fases do sistema para esta situação.

\subsubsection{Diferença de potencial entre as fases $\mathrm{B}$ e $\mathrm{C}$}

É importante ressaltar que, neste caso, tem-se a menor distância entre as fases. Pela figura 3.2, a distância é de $0,6 \mathrm{~m}$. Portanto, esta região apresenta maiores possibilidades de ocorrência do rompimento do dielétrico. Além disso, outro aspecto que deve ser levado em consideração é a posição do isolador da fase $\mathrm{B}$, localizado muito próximo da conexão da cruzeta com a mão francesa, o que diminui o NBI da estrutura, uma vez que a mão francesa é feita de metal e possui 


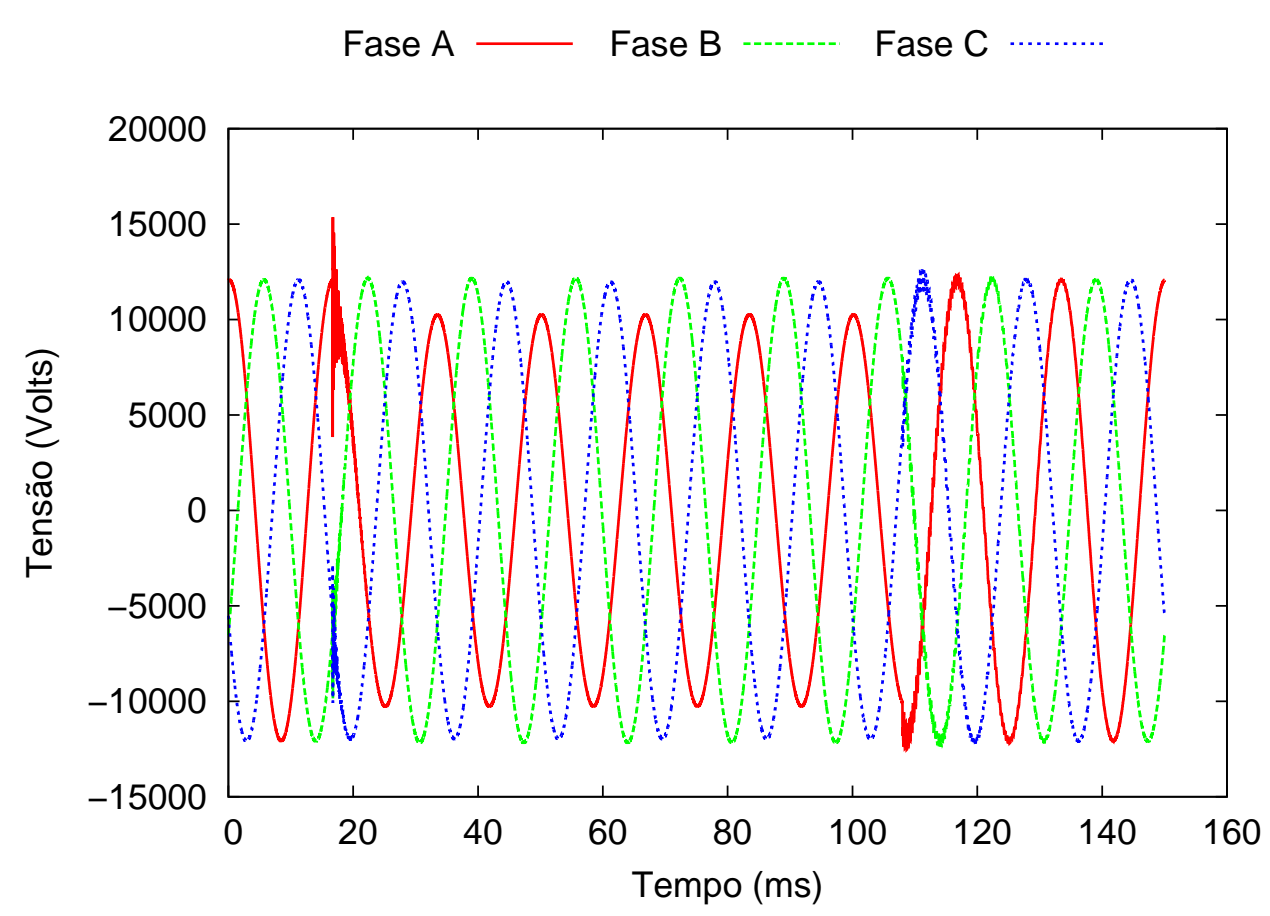

Figura 3.7: Transitório eletromagnético devido a um curto-circuito monofásico, envolvendo a fase A e o terra, localizado a 10,95 km da SE, com um tempo de inserção da falta de 16,66 ms.

uma condutividade elétrica alta.

A figura 3.8 representa a maior diferença de potencial encontrada entre as fases B e C. Este curto-circuito foi aplicado entre as fases B e C, sem resistência de falta, a 7,3 km de distância da SE, após 29,14 ms de simulação. O pico máximo de tensão foi um pouco menor que $15 \mathrm{kV}$ e ocorreu na fase B. O valor da diferença de potencial encontrado entre as fases B e C foi de $27,752 \mathrm{kV}$.

Os resultados das simulações realizadas neste capítulo demonstram os transitórios eletromagnéticos devido a curtos-circuitos aplicados ao sistema. Conforme a metodologia apresentada na seção 3.2, esses resultados serão aplicados nas estruturas modeladas no software FLUX 3D (capítulo 4) a fim de verificar os efeitos causados (pelas maiores diferenças de potencial encontradas) na estrutura atualmente utilizada e na nova estrutura proposta por esta pesquisa. 


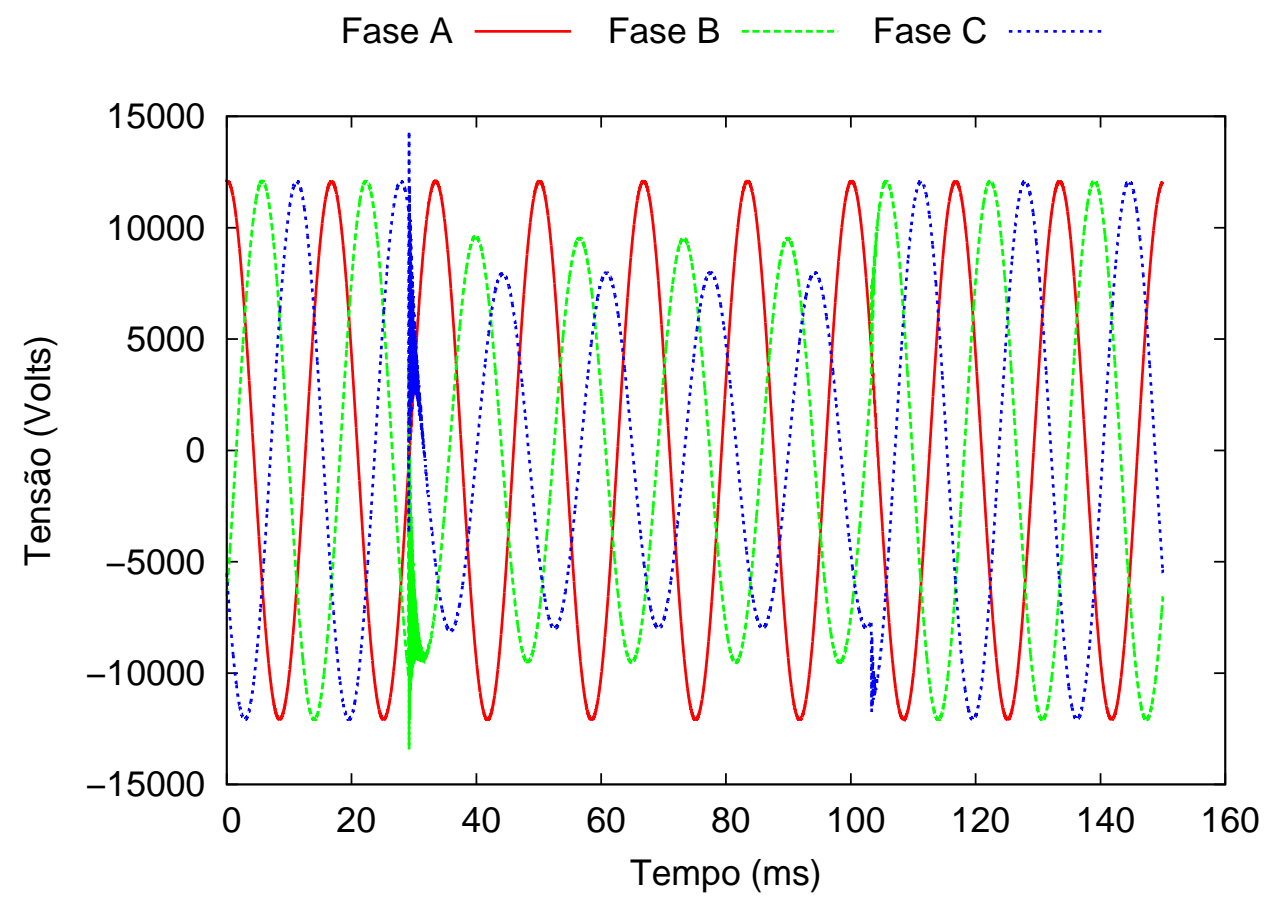

Figura 3.8: Transitório eletromagnético devido a um curto-circuito bifásico, envolvendo as fases B e C, localizado a $7,3 \mathrm{~km}$ da SE. 


\section{Capítulo 4}

\section{Modelagem da Cruzeta e demais}

\section{Componentes pelo Método de}

\section{Elementos Finitos}

A teoria de Maxwell (Maxwell, 1865, 1873; Simpson, 1997) permite descrever o conjunto dos fenômenos eletromagnéticos e, a partir das equações de Maxwell, consideradas como postulados, podem ser deduzidas todas as leis clássicas e previstos outros fenômenos. A aplicação deste conjunto de equações de maneira analítica é restrita a casos particulares, e até mesmo inexplicáveis em outros. Este fato foi um dos que contribuíram para que alguns problemas em eletromagnetismo fossem modelados e estudados por circuitos elétricos equivalentes como, por exemplo, o estudo de máquinas elétricas.

Como fato, tem-se que a geometria e a distribuição das grandezas eletromagnéticas nos casos reais, a interface entre meios com características diferentes e os fenômenos não lineares, ocasionam certa complexidade na resolução e no entendimento de certos problemas. Em consequência, torna-se necessário recorrer aos métodos numéricos, utilizando técnicas de discretização. Estes métodos transformam as equações de derivadas parciais em sistemas de equações algébricas cuja solução fornece uma aproximação dos campos eletromagnéticos.

Da literatura observada, encontra-se que com o advento dos computadores digitais, métodos numéricos puderam ser usados para resolver problemas de eletromagnetismo, tais como o cálculo dos campos elétricos e das linhas de potencial entre um conjunto de isoladores (Rasolonjanahary et al., 1992; Sebestyn, 2002). Entre eles, o MEF (Vlastos e Gubanski, 1991) é um dos mais utili- 
zados, pois se adapta facilmente às geometrias complexas. Este é baseado em uma discretização do domínio geométrico estudado e dos campos escalares e vetoriais incógnitos. A precisão da solução obtida fornece uma aproximação das grandezas locais que são os campos magnéticos e elétricos. Estas grandezas são exploradas para determinar as grandezas globais, tais como fluxo magnético, corrente, tensão, etc.

Cabe colocar que o MEF pertence a uma classe de modernas técnicas aplicadas em análises numéricas. É um método de análise numérica de modelos matemáticos de problemas físicos em meios contínuos. Esses modelos, tradicionalmente, são determinados através de equações diferenciais ou equações integrais com suas respectivas condições de contorno. Antes do aparecimento do MEF, a análise dos meios contínuos era efetuada por resolução direta dos sistemas de equações diferenciais parciais que regem o fenômeno, tendo em consideração as necessárias condições de contorno. Assim, o MEF é uma análise matemática que consiste na divisão do domínio de integração em um número finito de pequenas regiões básicas, denominadas elementos finitos, mantendo as mesmas propriedades do meio original (Zienkiewicz e Taylor, 2000).

A utilização do método dos elementos finitos para o cálculo dos campos elétricos e linhas equipotenciais tem trazido resultados importantes nos estudos de desempenho de linhas perante os curtos-circuitos causados pelo rompimento de dielétricos (Kontargyri et al., 2006).

Além do método dos elementos finitos (Zienkiewicz e Taylor, 2000), existem outros métodos numéricos utilizados para a solução de problemas de eletromagnetismo, como o método dos elementos de contorno (BEM) utilizado em Rasolonjanahary et al. (1992).

Para uma melhor organização do Capítulo 4, este foi dividido em duas seções. Na seção 4.1 trata-se das simulações utilizando os dados obtidos nas simulações de transitórios eletromagnéticos (Capítulo 3), aplicando-os na estrutura utilizada atualmente pela concessionária (CPFL). Na seção 4.2 são aplicadas as mesmas simulações realizadas e apresentadas na seção 4.1, porém com os valores aplicados na nova estrutura proposta por este trabalho.

\subsection{Simulações no Programa FLUX 3D: Modelo atual da Cru- zeta}

Para iniciar as simulações no programa FLUX 3D (três dimensões), fez-se necessário a modelagem da estrutura N1, ilustrada na figura 3.2, através do ambiente CAD disponível no próprio programa. 
Ressalta-se que é possível desenhar a estrutura em outros ambientes, pois o programa permite a importação de geometrias. Porém, o FLUX 3D exige uma certa experiência para criação dessas geometrias, pois a importação pode gerar problemas como, por exemplo, o cruzamento de linhas e de linhas com faces. Esses defeitos são minimizados quando se utiliza o próprio ambiente CAD disponível no software FLUX 3D, principalmente por ele exigir que os pontos sejam criados antes de criar as linhas, faces e volumes.

A figura 4.1 apresenta a geometria final da estrutura N1 modelada no programa FLUX 3D. A estrutura foi modelada considerando o poste quadrado para simplificar a fixação da cruzeta no poste. As diferenças de cores demonstradas, visam não só melhorar a apresentação, como também diferenciar as regiões. Neste programa são caracterizadas as regiões a partir de dados dos materiais envolvidos. A estrutura modelada é composta por três materiais distintos que apresentam valores de permissividades diferentes.

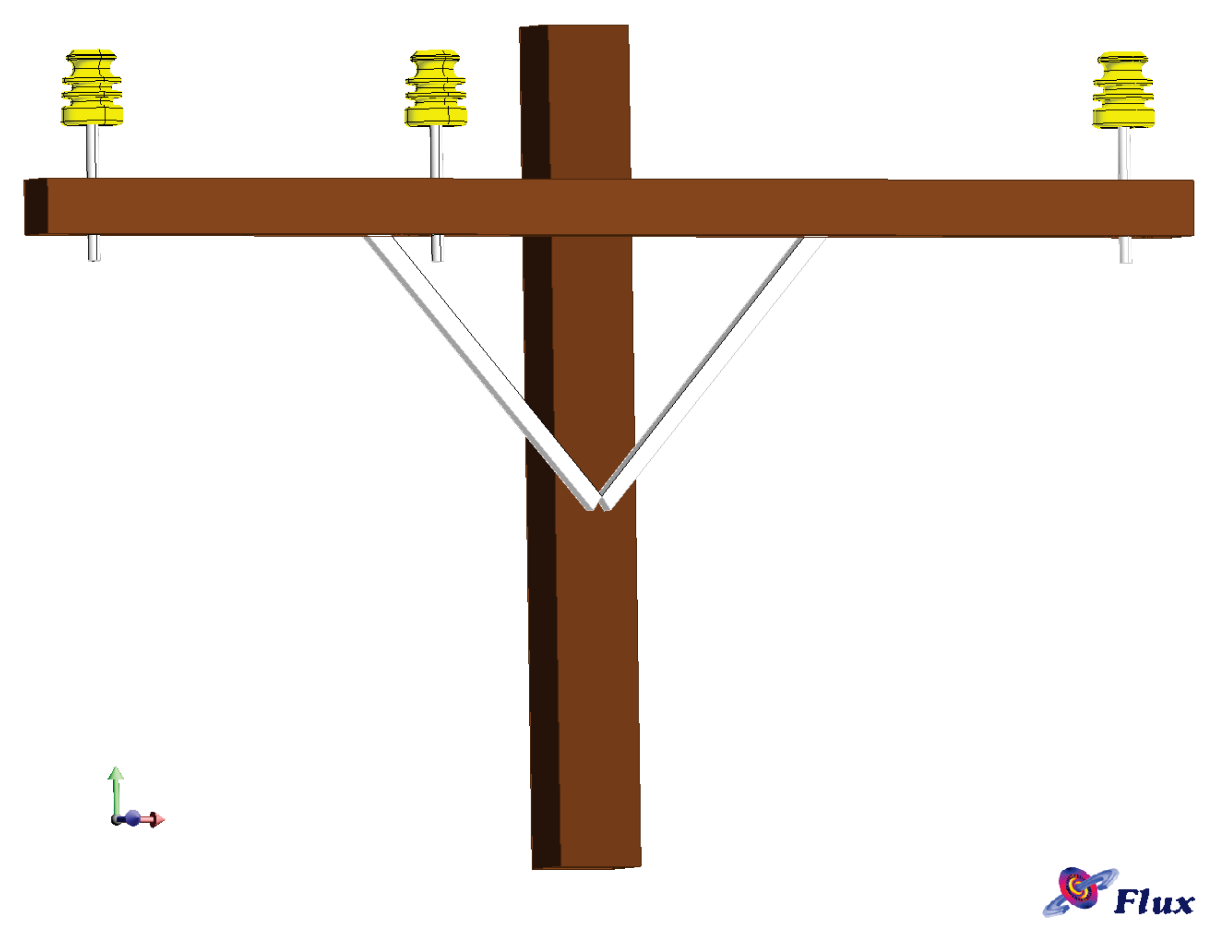

Figura 4.1: Estrutura N1 modelada no software FLUX 3D.

A permissividade de um material é usualmente dada com relação à do vácuo, denominandose permissividade relativa. A permissividade relativa é uma constante física que descreve como um campo elétrico afeta, e é afetado por um meio. Esta é determinada pela habilidade de um material de polarizar-se em resposta a um campo elétrico aplicado. A tabela 4.1 apresenta as permissividades relativas (Schimidt, 1979) dos materiais utilizados. 
Tabela 4.1: Permissividade relativa dos materiais utilizados.

\begin{tabular}{|c|c|}
\hline Material & Permissividade Relativa $\left(\varepsilon_{\boldsymbol{r}}\right)$ \\
\hline $\mathrm{Ar}$ & 1,00054 \\
\hline Isolador & 5,4 \\
\hline Cruzeta e Poste (Madeira) & $1,129-6,776$ \\
\hline Pino e Mão Francesa (Ferro) & 1 \\
\hline
\end{tabular}

Após a modelagem da estrutura é necessária a criação da malha de elementos finitos que é composta, para o caso em três dimensões, por tetraedros conectados através de nós (figura 4.3). O MEF transforma o meio contínuo em discreto, e a essa divisão do domínio se dá o nome de "malha" (grid em inglês). A malha é formada por elementos compostos de arestas (faces), nós (pontos de interseção das arestas) e de volumes, no caso em 3 dimensões, formando os tetraedros, que foram escolhidos para a criação da malha neste trabalho. Vale ressaltar a possibilidade da criação da malha utilizando outras figuras geométricas, como, por exemplo, cubos.

A geração da malha é feita automaticamente pelo programa FLUX 3D, porém, é necessário que o usuário configure a quantidade de segmentos e a quantidade de nós desejados em cada linha do modelo. Essa configuração reflete na qualidade final da malha gerada, o que fornecerá resultados mais precisos de acordo com sua qualidade.

A qualidade da malha e os elementos são avaliados e classificados pelo próprio programa de maneira automática. Mas, para melhor ilustrar os elementos de baixa qualidade, foi gerada uma malha com qualidade baixa. A figura 4.2 apresenta a malha de elementos finitos, em uma estrutura modelada em duas dimensões, para facilitar a visualização de elementos de baixa qualidade. Ressalta-se que os pontos da imagem onde a malha não é homogênea, por exemplo, entre os isoladores mais próximos (Fases B e C), são os mais problemáticos e podem interferir no resultado final das simulações. 


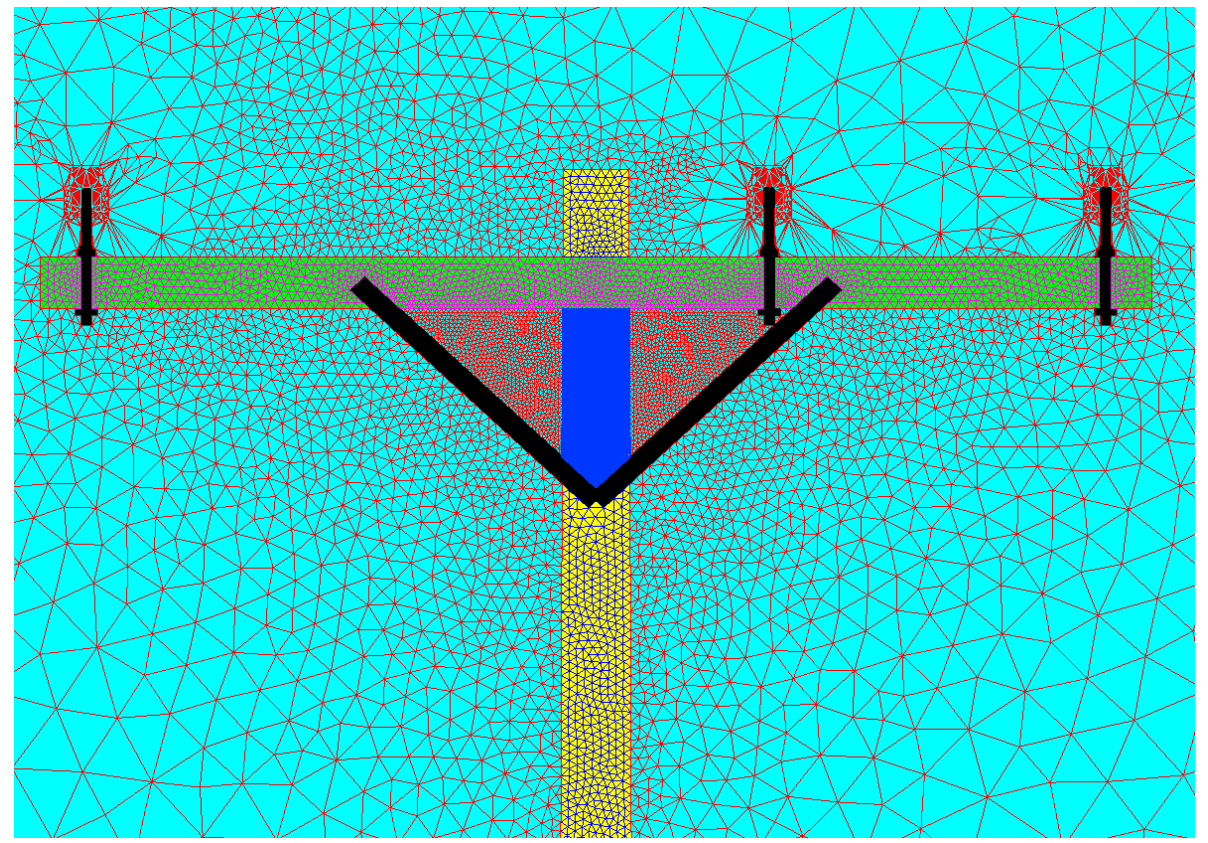

Figura 4.2: Malha de elementos finitos criada para ilustrar os elementos de baixa qualidade.

Foram realizadas diversas tentativas de geração da malha. Na tabela 4.2, ilustra-se a diferença na qualidade alcançada quando se comparou a primeira malha gerada e a malha final utilizada neste trabalho (figura 4.3).

Tabela 4.2: Evolução na qualidade da malha de elementos finitos para a estrutura atual da cruzeta (valores em porcentagem).

\begin{tabular}{|c|c|c|}
\hline & Primeira Geração & Geração Atual \\
\hline Elementos não avaliados & 0 & 0 \\
\hline Elementos de excelente qualidade & 9,69 & 61,24 \\
\hline Elementos de boa qualidade & 18,39 & 29,18 \\
\hline Elementos de qualidade média & 29,75 & 7,68 \\
\hline elementos de má qualidade & 42,17 & 1,9 \\
\hline
\end{tabular}

Na figura 4.3, é possível perceber a diferença na densidade da malha nas extremidades e nas partes próximas do modelo da estrutura. Isto ocorre pois na solução do problema é necessário que se tenha uma maior precisão nas partes onde serão avaliados os campos elétricos. Além disso, quanto mais complexas as geometrias criadas, caso dos isoladores, mais densa deverá ser a malha. 


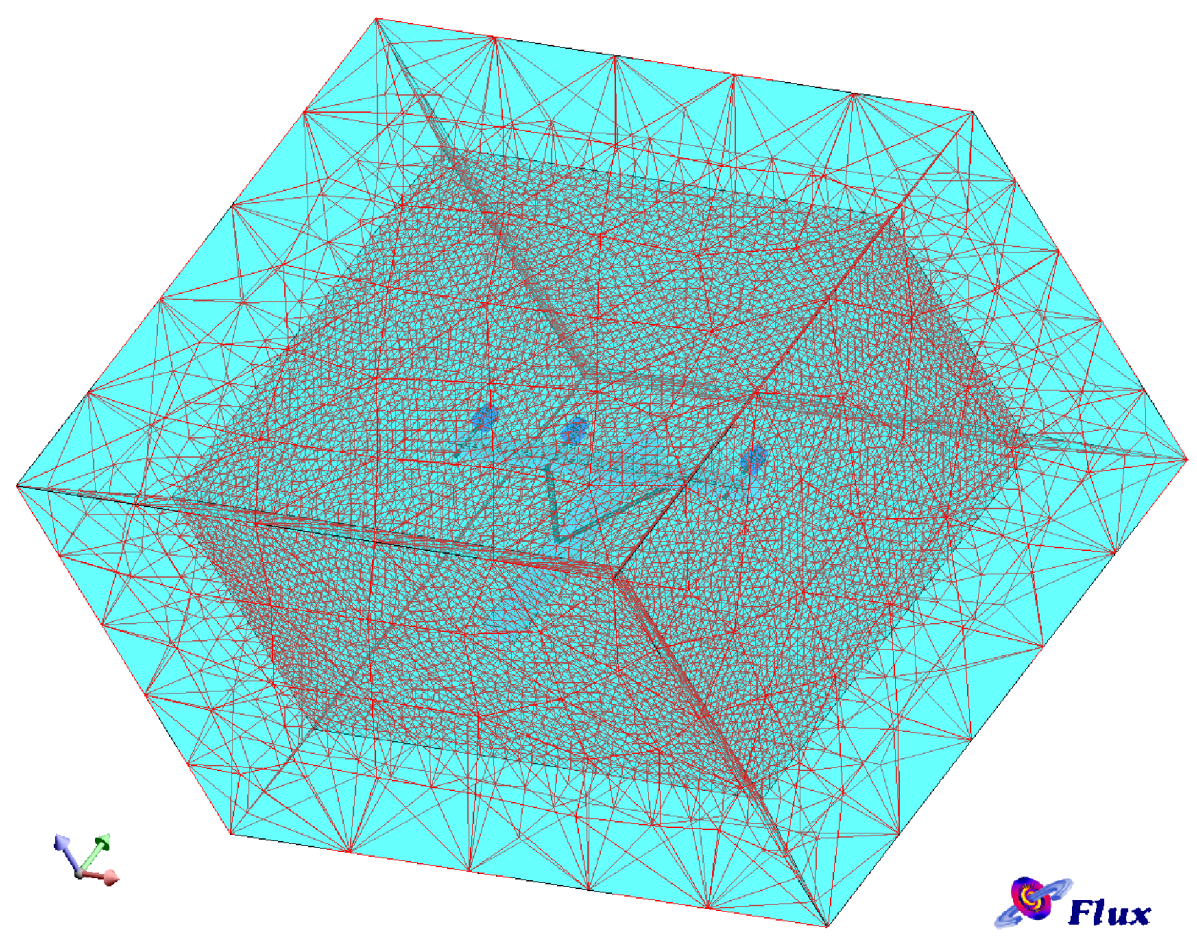

Figura 4.3: Malha de elementos finitos criada para a simulação dos campos elétricos e linhas equipotenciais.

Com os valores registrados da tensão nas três fases no instante em que foi detectada a maior diferença de potencial entre as fases críticas, criou-se uma região na superfície do isolador para caracterizar o contato com o condutor energizado. Nestas regiões foram impostos os valores registrados para as fases A, B e C, respectivamente. Essa região criada com os valores de tensão das fases A, B e C pode ser vista no detalhe em amarelo na superfície do isolador, figura 4.4.

O programa FLUX 3D permite que o usuário visualize os resultados através de imagens que contemplam os valores do campo elétrico e de linhas equipotenciais.

A figura 4.5 apresenta a estrutura atual, vista por trás, com a visualização do campo elétrico devido à operação nominal do sistema. O instante em que foram armazenados os valores é o instante em que a tensão da fase B atinge seu máximo valor. Esse caso é o mesmo mostrado no exemplo da figura 3.5 .

Optou-se por mostrar as imagens do campo elétrico de duas formas. Uma por trás da estrutura, e a outra pela frente. Estas formas são importantes para visualizar o aumento da intensidade do campo elétrico provocado pela influência da mão francesa, que é feita de metal.

Assim, a vista por trás (figura 4.5) permite a visualização da elevação do campo elétrico na 


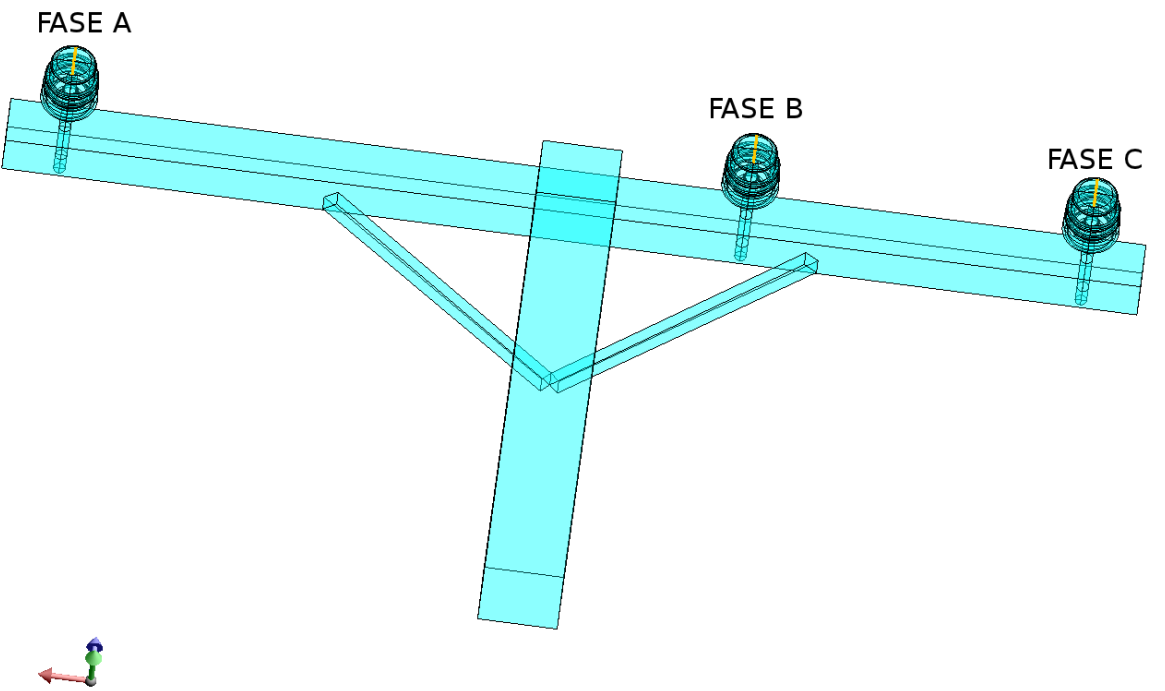

Flux

Figura 4.4: Detalhe das Fases A, B e C.

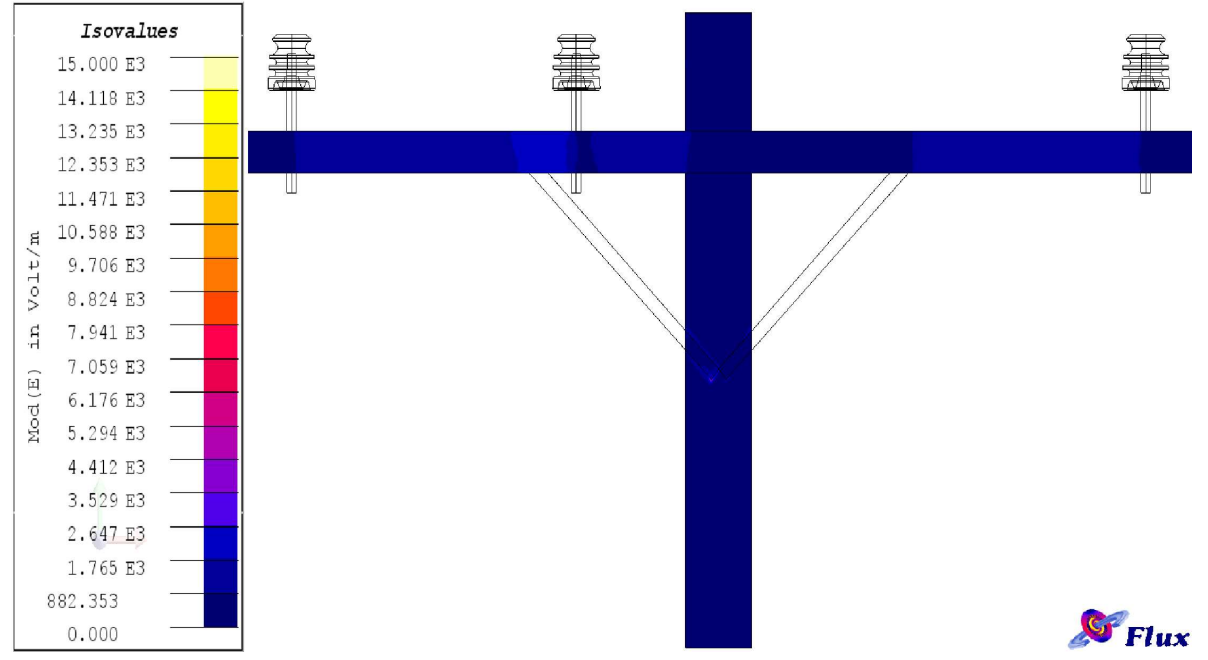

Figura 4.5: Campo elétrico devido à operação nominal do sistema apresentado na figura 3.4 (vista posterior).

conexão da mão francesa com o poste. Já a vista de frente (figura 4.6), permite visualizar a conexão da mão francesa com a cruzeta. Para uma interpretação melhor das imagens de campo elétrico, optou-se por fixar a escala para as vistas posteriores entre 0 e $15 \mathrm{kV} / \mathrm{m}$, e as vistas frontais entre 0 e $20 \mathrm{kV} / \mathrm{m}$. Essa padronização favorece a percepção do aumento da intensidade de campo elétrico devido aos transitórios. 


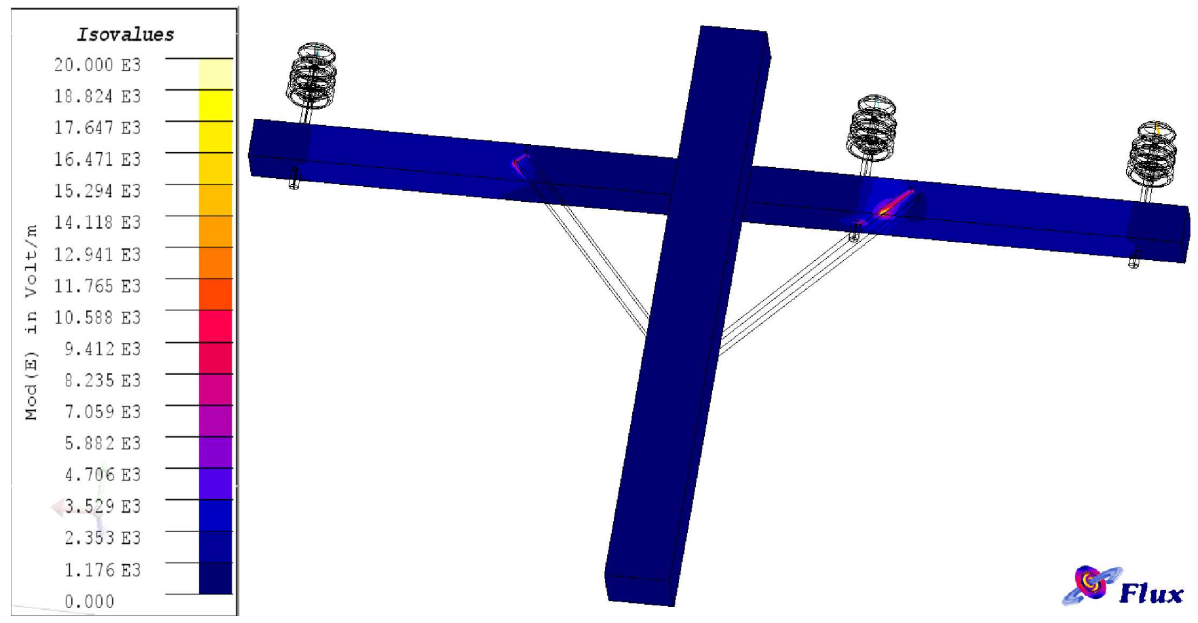

Figura 4.6: Campo elétrico devido à máxima diferença de potencial encontrada no transitório apresentado na figura 3.4 (vista frontal).

A figura 4.7 apresenta as linhas equipotenciais referentes ao regime nominal de operação do sistema, no instante em que a tensão da fase B é máxima. Ressalta-se que para a análise das linhas não é necessária a visualização da imagem por vários ângulos. Assim, as demais visualizações das linhas equipotenciais serão todas das costas da estrutura, não mais nessa perspectiva frontal demonstrada na figura 4.7, que tem o intuito de facilitar a percepção de que as linhas equipotenciais circulam todo o volume da cruzeta e do poste.

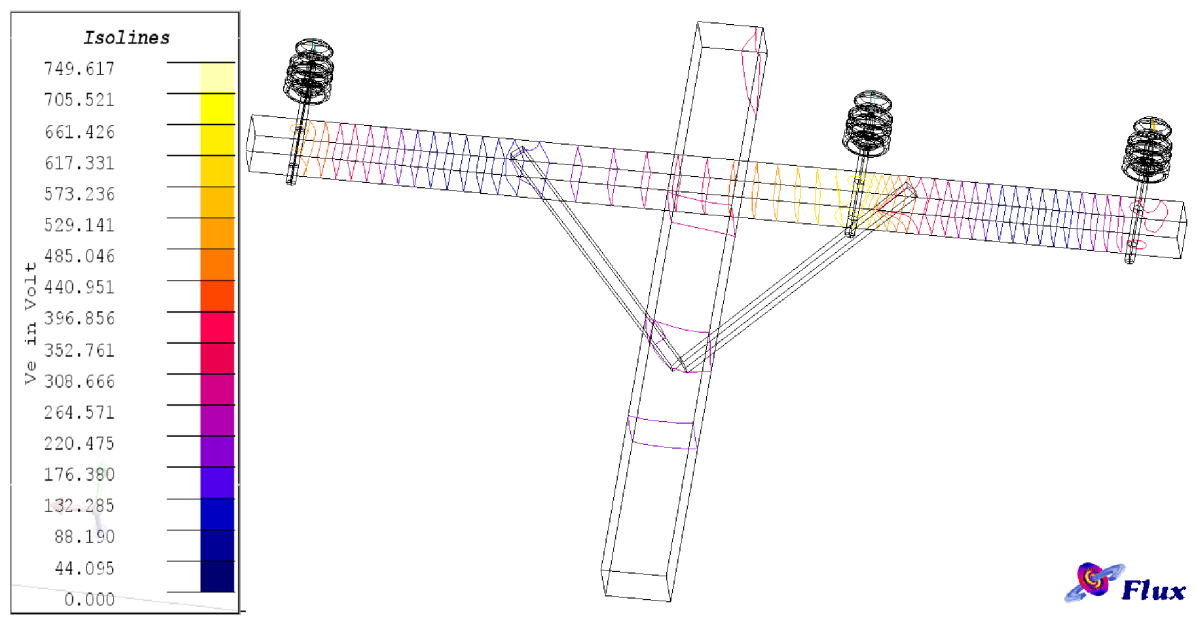

Figura 4.7: Linhas equipotenciais devido à máxima diferença de potencial encontrada no transitório apresentado na figura 3.4 (vista frontal).

Cabe adiantar que a análise das linhas equipotenciais será feita entre as fases B e C, pois são as fases mais próximas fisicamente e as que mais facilmente podem sofrer um curto-circuito devido ao rompimento do dielétrico que as separa. Sendo assim, exitem dois caminhos onde pode acontecer o rompimento do dielétrico. Um deles é o próprio ar, que de acordo com IEEE- 
Std-1410 (2004), suporta até $600 \mathrm{kV} / \mathrm{m}$. O segundo caminho onde pode ocorrer o rompimento do dielétrico é pela cruzeta de madeira que, para esse caso em questão, suporta $250 \mathrm{kV} / \mathrm{m}$ (IEEE-Std-1410, 2004).

\subsubsection{Campo elétrico e linhas equipotenciais devido ao distúrbio que apre- sentou a máxima DDP entre as fases A e B}

A figura 4.8 apresenta uma vista frontal em perspectiva do campo elétrico na estrutura devido à máxima diferença de potencial encontrada durante o curto-circuito monofásico apresentado na seção 3.2.1.

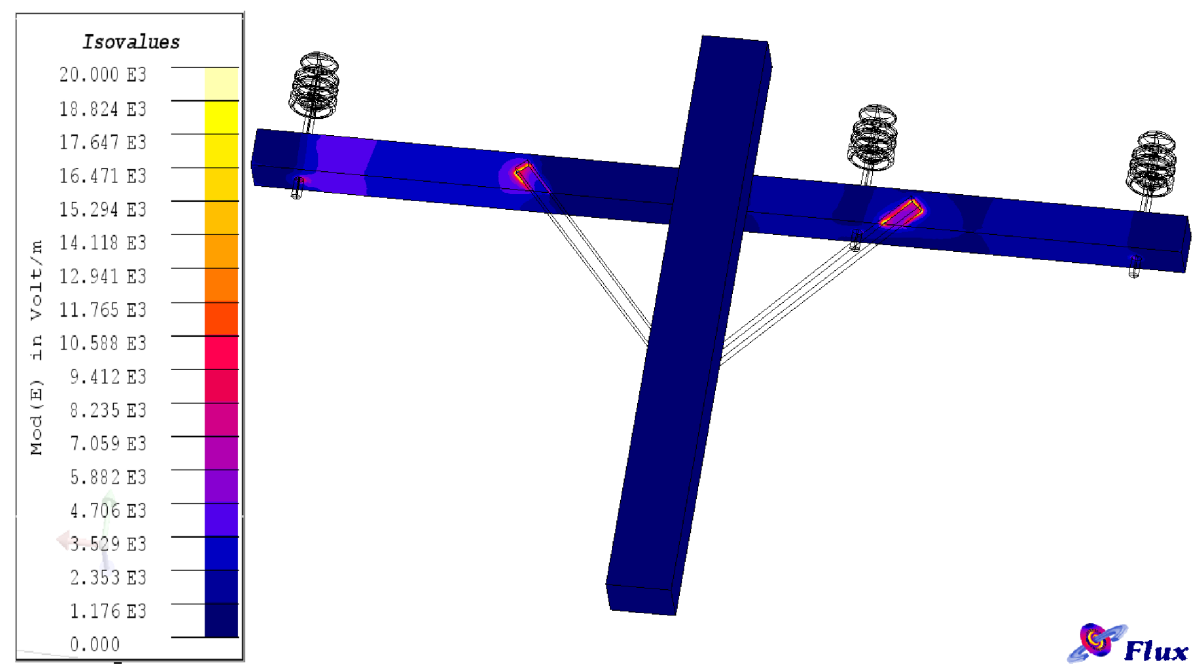

Figura 4.8: Campo elétrico devido à máxima diferença de potencial encontrada no transitório apresentado na figura 3.6 (vista frontal).

A figura 4.9 apresenta o campo elétrico para a mesma situação, porém agora vista posteriormente. Apesar de surgirem cores mais quentes, ressalta-se que o maior valor apresentado na escala é de $20 \mathrm{kV} / \mathrm{m}$, sendo esse valor muito inferior ao valor suportado pela cruzeta de madeira, que é de $250 \mathrm{kV} / \mathrm{m}$ (IEEE-Std-1410, 2004).

Analisando a figura 4.10, pode-se notar a diferença de potencial entre as linhas equipotenciais. Entre as fases B e C (esquerda da estrutura), onde temos a região mais crítica, essa diferença é de $481 \mathrm{~V}$. Tendo em vista que a distância entre o isolador da fase C (esquerda da estrutura) é de $0,5 \mathrm{~m}$ do ponto de conexão da mão francesa com a cruzeta, a isolação proporcionada pela cruzeta será de $125 \mathrm{kV}(250 \mathrm{kV} / \mathrm{m}$ x 0,5 m). 


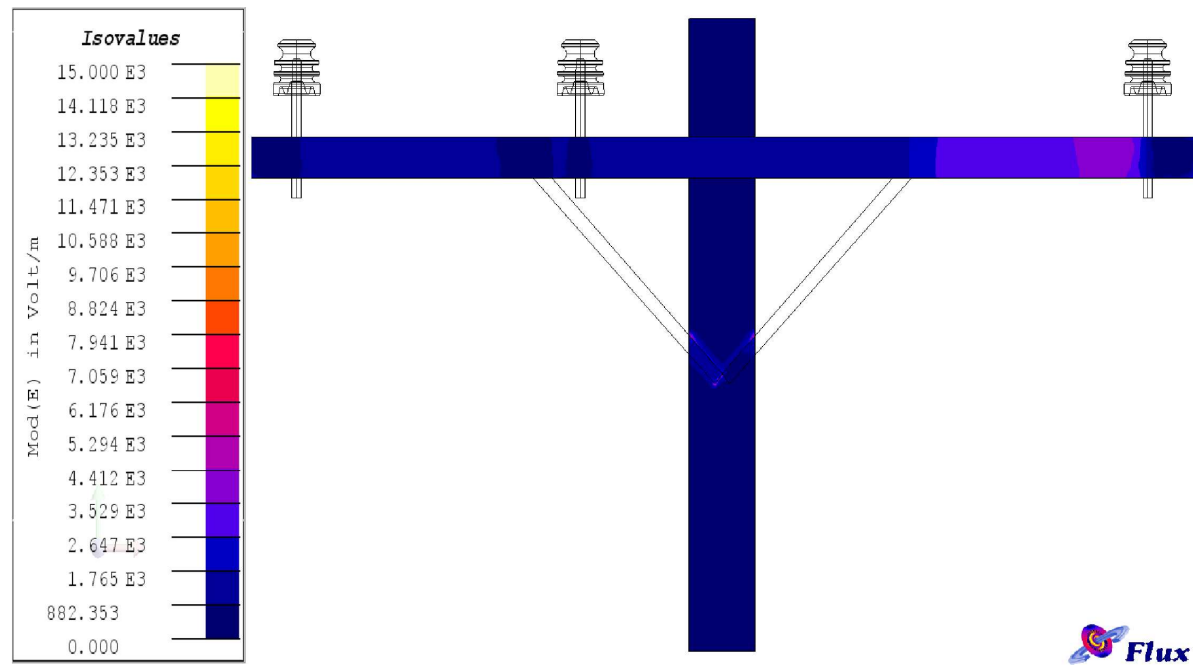

Figura 4.9: Campo elétrico devido à máxima diferença de potencial encontrada no transitório apresentado na figura 3.6 (vista posterior).

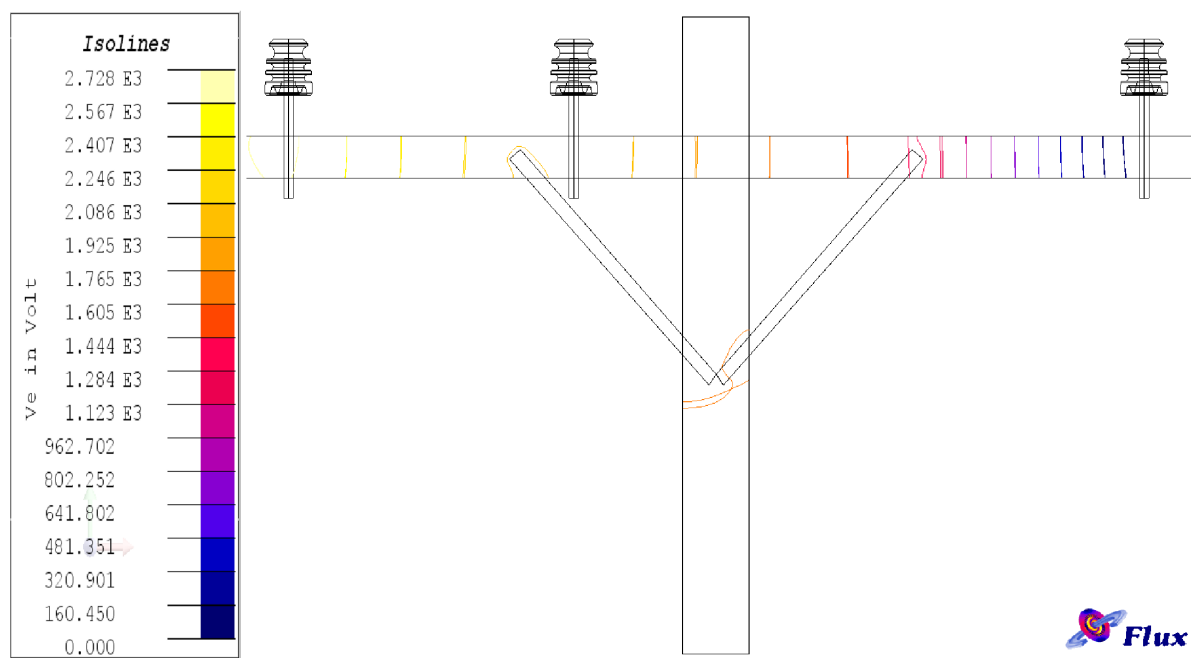

Figura 4.10: Linhas equipotenciais devido à máxima diferença de potencial encontrada no transitório apresentado na figura 3.6 (vista posterior).

\subsubsection{Campo elétrico e linhas equipotenciais devido ao distúrbio que apre- sentou a máxima DDP entre as fases A e C}

Os resultados apresentados nesta seção são referentes à máxima diferença de potencial, entre as fases A e C, encontrada durante as simulações dos transitórios eletromagnéticos (seção 3.2.2).

A figura 4.11 apresenta o campo elétrico na estrutura, vista em perspectiva frontal. Nota-se, assim como no caso anterior, um aumento da intensidade de campo elétrico nas proximidades da mão francesa e dos pinos do isolador (partes metálicas). Contudo, os valores encontrados não são suficientemente altos para causar a ruptura do dielétrico (cruzeta de madeira). 


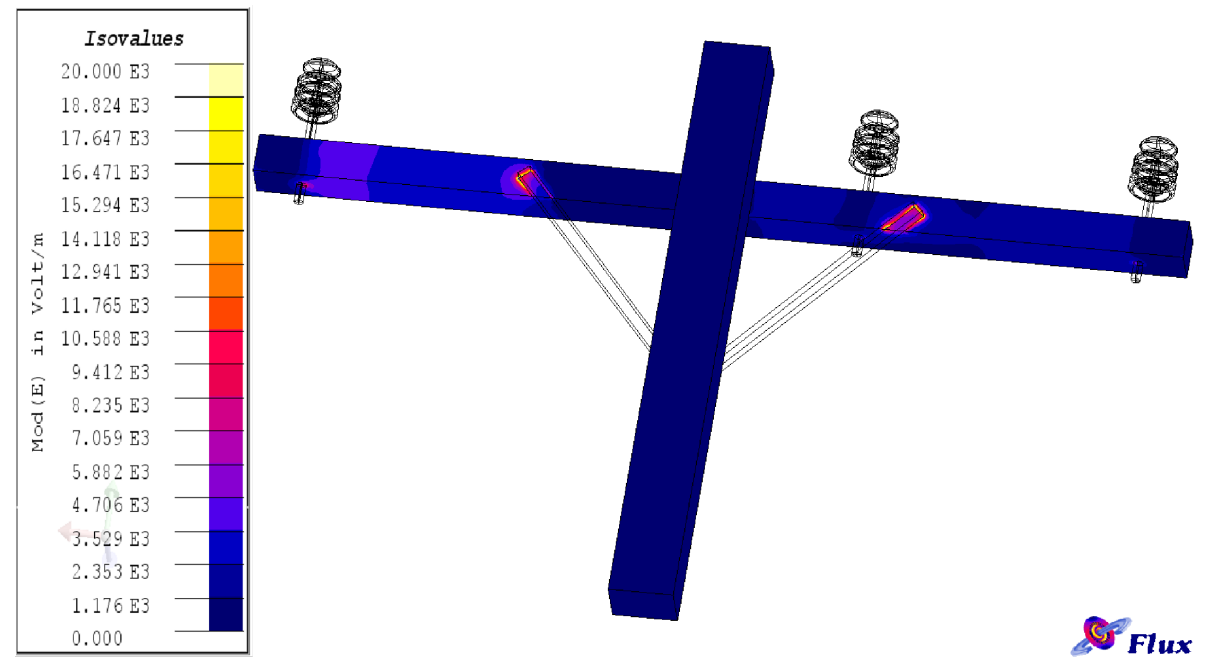

Figura 4.11: Campo elétrico devido à máxima diferença de potencial encontrada no transitório apresentado na figura 3.7 (vista frontal).

A figura 4.12 apresenta o campo elétrico na estrutura vista posteriormente. Novamente, destaca-se o aumento da intensidade de campo elétrico nas partes próximas aos objetos metálicos. Mesmo com esse aumento, não será evidenciado nenhum problema de isolação da estrutura.

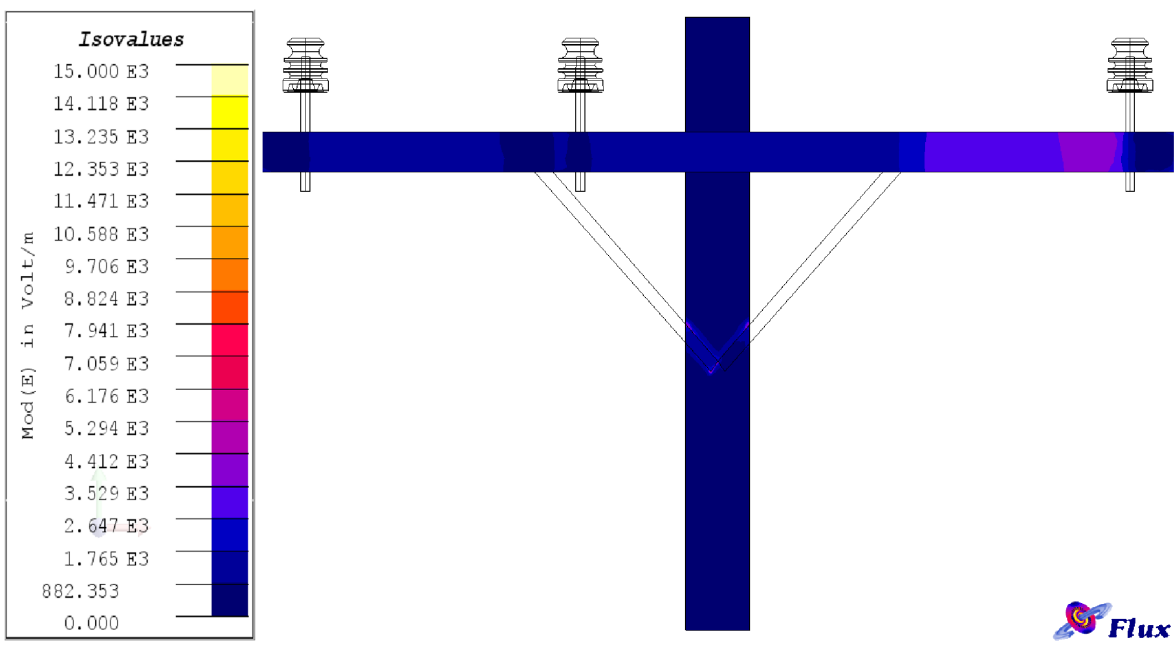

Figura 4.12: Campo elétrico devido à máxima diferença de potencial encontrada no transitório apresentado na figura 3.7 (vista posterior).

A figura 4.13 ilustra que as linhas equipotenciais e as diferenças de potencial encontradas para esta situação são incapazes de causar a ruptura da isolação da cruzeta de madeira. Ressaltase que a diferença de potencial entre cada linha apresentada é de aproximadamente $160 \mathrm{~V}$, o que traz uma diferença de potencial entre os isoladores das fases $\mathrm{B}$ e $\mathrm{C}$ de aproximadamente $480 \mathrm{~V}$. A diferença de potencial entre a fase A (à direita da figura 4.13) e a mão francesa é de aproximadamente $900 \mathrm{~V}$. Todos valores bem inferiores aos necessários para que haja a ruptura. 


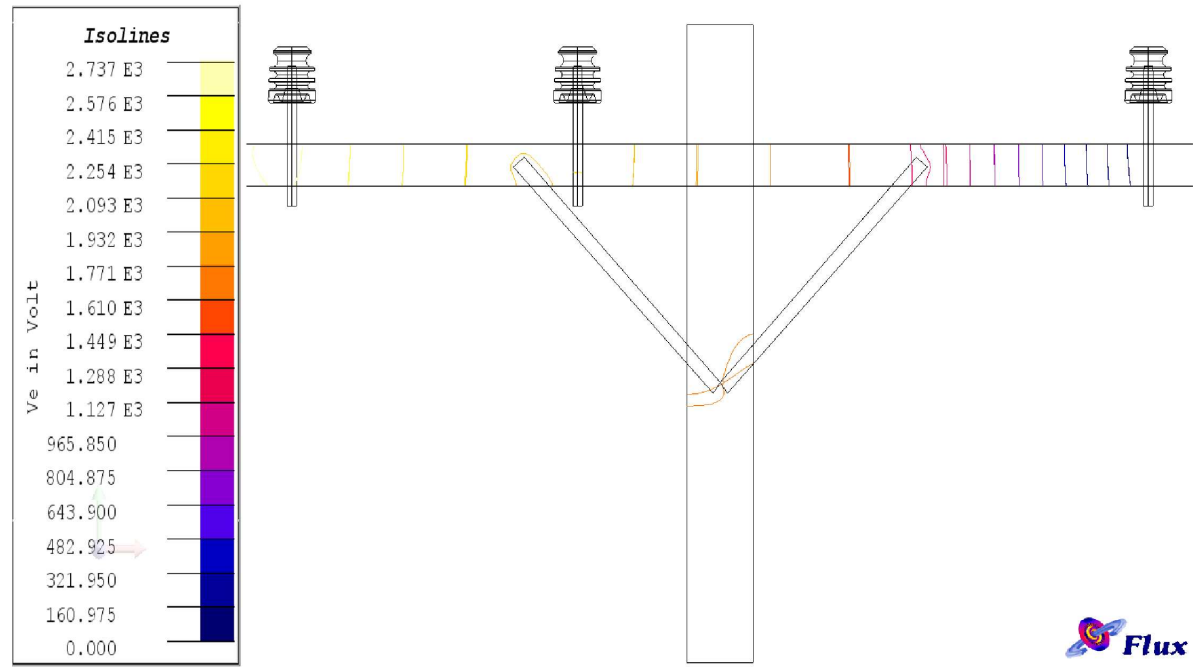

Figura 4.13: Campo elétrico devido à máxima diferença de potencial encontrada no transitório apresentado na figura 3.7 (vista posterior).

\subsubsection{Campo elétrico e linhas equipotenciais devido ao distúrbio que apre- sentou a máxima DDP entre as fases B e C}

Conforme evidenciado na seção 3.2.3, para esta situação, tem-se a análise mais crítica, pois os isoladores referentes às fases $\mathrm{B}$ e $\mathrm{C}$ são os mais próximos, estando separados por $0,6 \mathrm{~m}$ de distância. A análise se dará, assim como nos casos anteriores, pelas vistas frontal e posterior do campo elétrico e a vista posterior das linhas equipotenciais.

A figura 4.14 apresenta a vista frontal em perspectiva do campo elétrico devido à máxima diferença de potencial encontrada durante um curto-circuito bifásico envolvendo as fases B e C, apresentado na seção 3.8. Nota-se um aumento da intensidade de campo elétrico na região da cruzeta entre os isoladores B e C.

A figura 4.15 apresenta a vista posterior da estrutura e, assim como nas demais figuras representando o campo elétrico, esta também apresenta uma elevação do campo elétrico na região da cruzeta, entre os isoladores. O valor predominante neste caso é de $3,529 \mathrm{kV} / \mathrm{m}$, valor inferior ao suportado pela cruzeta de madeira conforme exposto em IEEE-Std-1410 (2004) e em Darveniza et al. (1967).

A figura 4.16 apresenta as linhas equipotenciais pela vista posterior da estrutura. Observase por esta figura um aumento considerado do número de linhas entre os isoladores B e C. Isto acontece em função do aumento da intensidade de campo elétrico (medido em $\mathrm{V} / \mathrm{m}$ ), que será refletido por uma maior variação da diferença de potencial neste local. Mesmo assim, a 


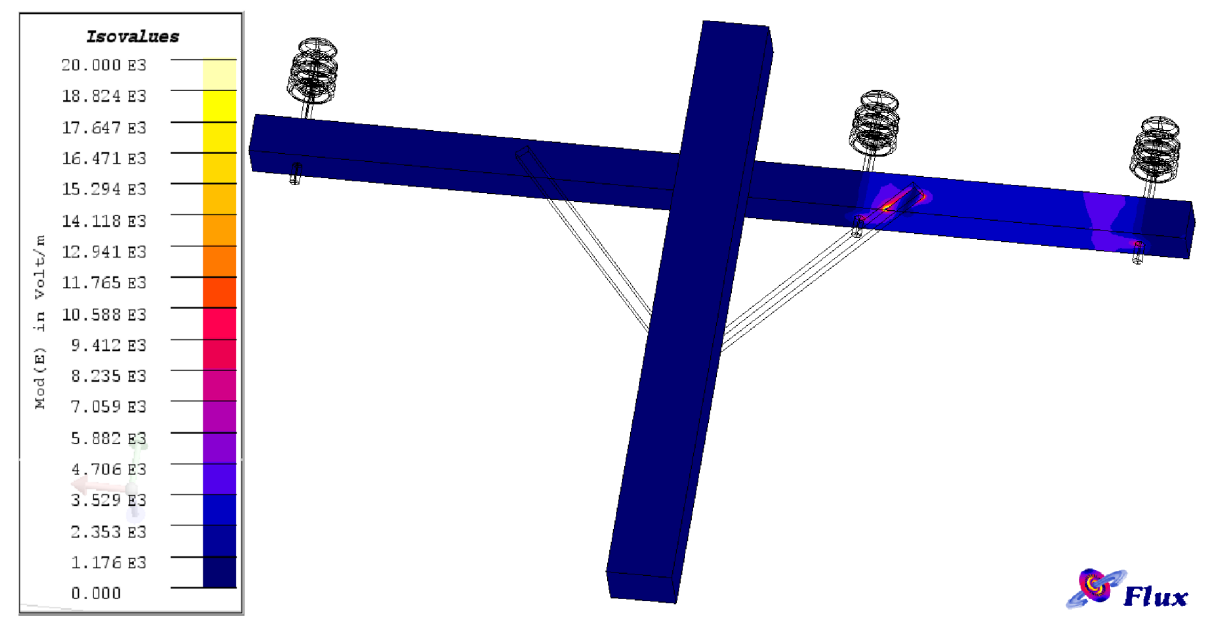

Figura 4.14: Campo elétrico devido à máxima diferença de potencial encontrada no transitório apresentado na figura 3.8 (vista frontal).

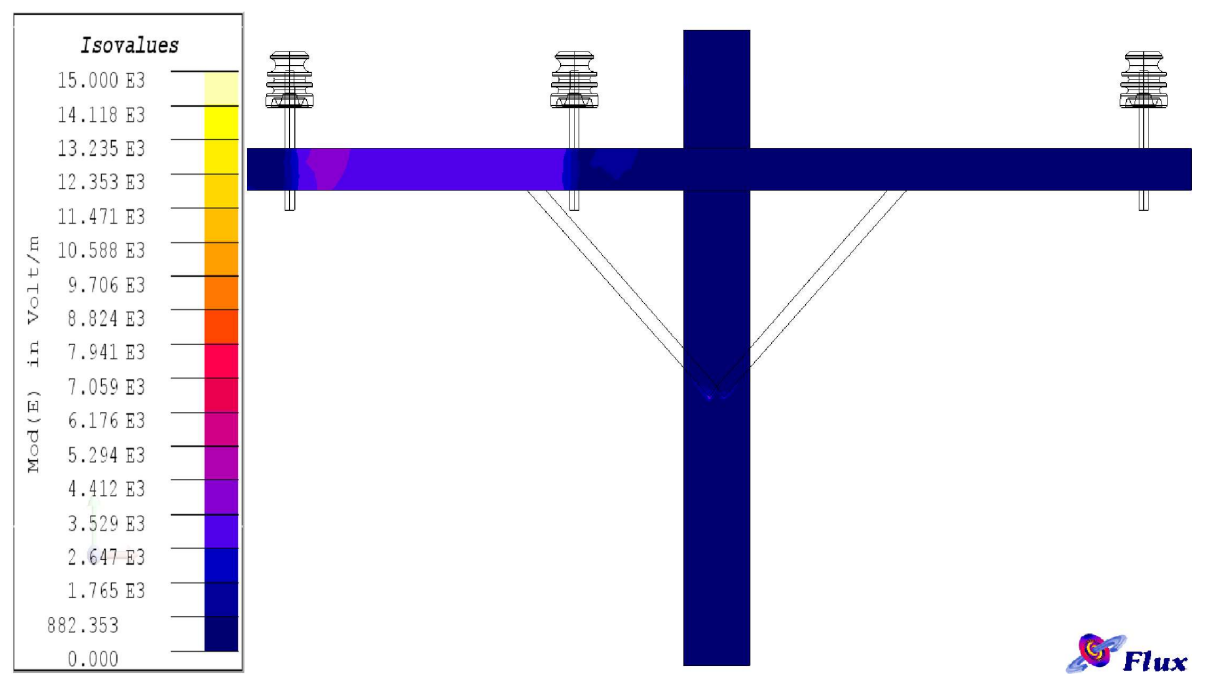

Figura 4.15: Campo elétrico devido à máxima diferença de potencial encontrada no transitório apresentado na figura 3.8 (vista posterior).

diferença de potencial entre o isolador da fase $\mathrm{C}$ (isolador à esquerda) e a mão francesa, próxima ao isolador central (Fase B) é de aproximadamente $900 \mathrm{~V}$, valor inferior ao suportado pela cruzeta de madeira (IEEE-Std-1410, 2004).

As análises realizadas nesta seção mostraram a suportabilidade da estrutura atualmente empregada com relação aos curtos-circuitos e à operação normal do sistema que a linha de distribuição está sujeita. Tais resultados já eram esperados e, até certo ponto, foram e estão constantemente sendo validados em campo, uma vez que esta estrutura em específico é utilizada por grande parte das concessionárias de distribuição de energia elétrica no Brasil. 


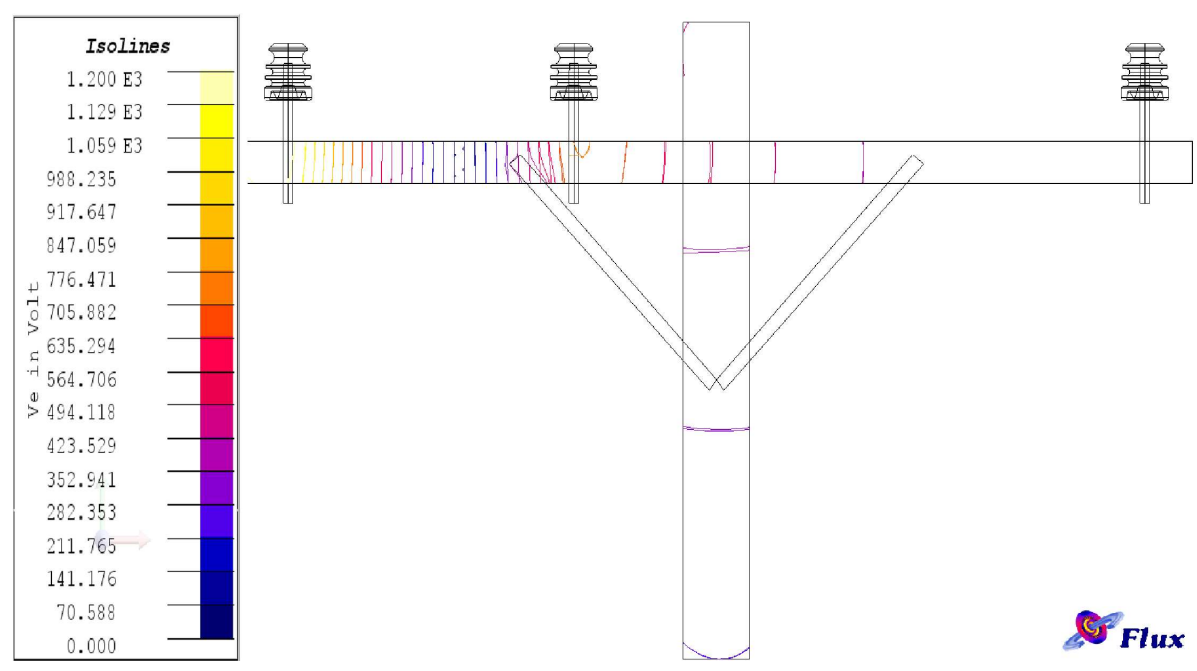

Figura 4.16: Campo elétrico devido à máxima diferença de potencial encontrada no transitório apresentado na figura 3.8 (vista posterior).

\subsection{Simulações no Programa FLUX 3D: Modelo Novo da Cru- zeta}

Assim como na seção 4.1, que trata das simulações referentes à atual estrutura utilizada pela concessionária em suas linhas de distribuição, para as simulações da nova estrutura foi necessária a sua modelagem no ambiente CAD disponível no programa FLUX 3D.

Alguns aspectos principais foram considerados para se obter a nova estrutura proposta para esta pesquisa.

Ressalta-se que um destes aspectos, além da redução do comprimento da cruzeta, foi o de posicionar o pino que sustenta um dos isoladores um pouco mais afastado do ponto de conexão da mão francesa com a cruzeta. Desta maneira, de forma direta, o NBI da estrutura seria aumentado, pois o trecho de cruzeta de madeira acrescentaria isolação à estrutura Darveniza et al. (1967).

Outro requisito pré estabelecido foi a procura por uma nova estrutura sem alterar muito os componentes já utilizados pela concessionária em campo. Com isso, pretende-se facilitar a substituição e adaptação da concessionária para a utilização do novo padrão estrutural. Neste sentido, todos os modelos idealizados nesta pesquisa foram compostos por elementos (componentes) já utilizados pela concessionária.

A Figura 4.17 apresenta um possível modelo de estrutura, idealizado sobre a estrutura "N1" (CPFL, 2009) convencional, apresentada na Figura 3.2. Esse modelo de estrutura apresenta 
uma redução de 0,4 metros no comprimento da cruzeta. Porém, percebe-se que além do pino central permanecer no mesmo local da Figura 3.2, o isolador à esquerda da Figura 4.17 também ficou próximo ao ponto de conexão da mão francesa com a cruzeta. Assim, a estrutura não trará ganhos com relação à isolação.

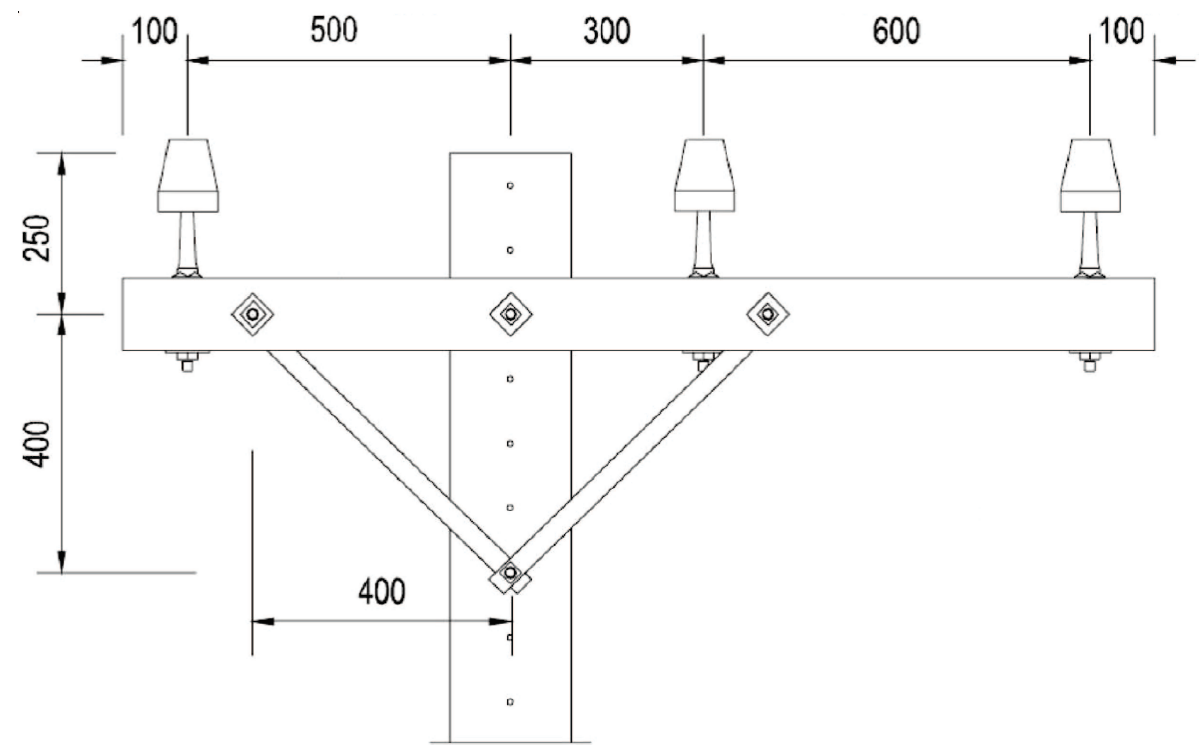

Figura 4.17: Modelo de cruzeta baseado na estrutura N1.

A Figura 4.18 apresenta um modelo baseado na estrutura "M1" (CPFL, 2009), conhecida também como "meio beco". Esta estrutura apresenta uma redução, assim como a estrutura da Figura 4.17, de 0,4 metros e apresenta um ganho com relação à anterior. Nesta estrutura, percebe-se que os pinos que sustentam os isoladores estão afastados do ponto de conexão da mão francesa com a cruzeta, e essa distância traz um aumento do NBI da estrutura.

Pela alternativa ilustrada na Figura 4.19, tem-se uma combinação das vantagens anteriormente ressaltadas pelas duas configurações anteriores (Figuras 4.17 e 4.18). Nesta composição, os isoladores não estão posicionados próximos ao ponto de conexão da mão francesa com a cruzeta. A estrutura apresenta simetria, que melhora o desempenho mecânico e elétrico, uma vez que os esforços a que a estrutura estará submetida são equilibrados e será possível uma redução das indutâncias mútuas da linha de distribuição (Fuchs, 1977; Kersting, 2012). Além desses pontos, o objetivo principal do projeto também será contemplado, visto que será possível obter uma redução no tamanho da cruzeta de 0,5 metros.

Assim, o modelo apresentado na Figura 4.19 foi escolhido para a continuação dos estudos. Outras vantagens proporcionadas por esta escolha serão demonstradas no decorrer do trabalho.

O novo modelo de cruzeta está representado pelas figuras 4.20 e 4.21, que apresentam, 


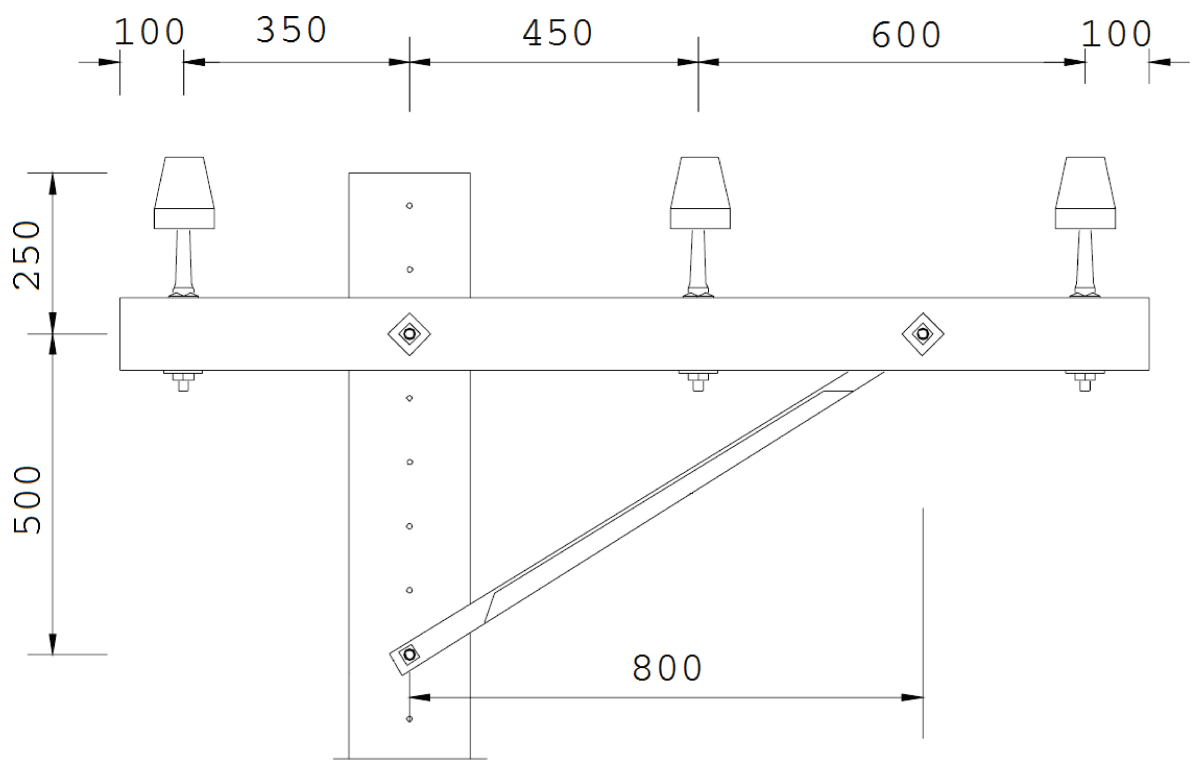

Figura 4.18: Modelo de cruzeta baseado na estrutura M1.

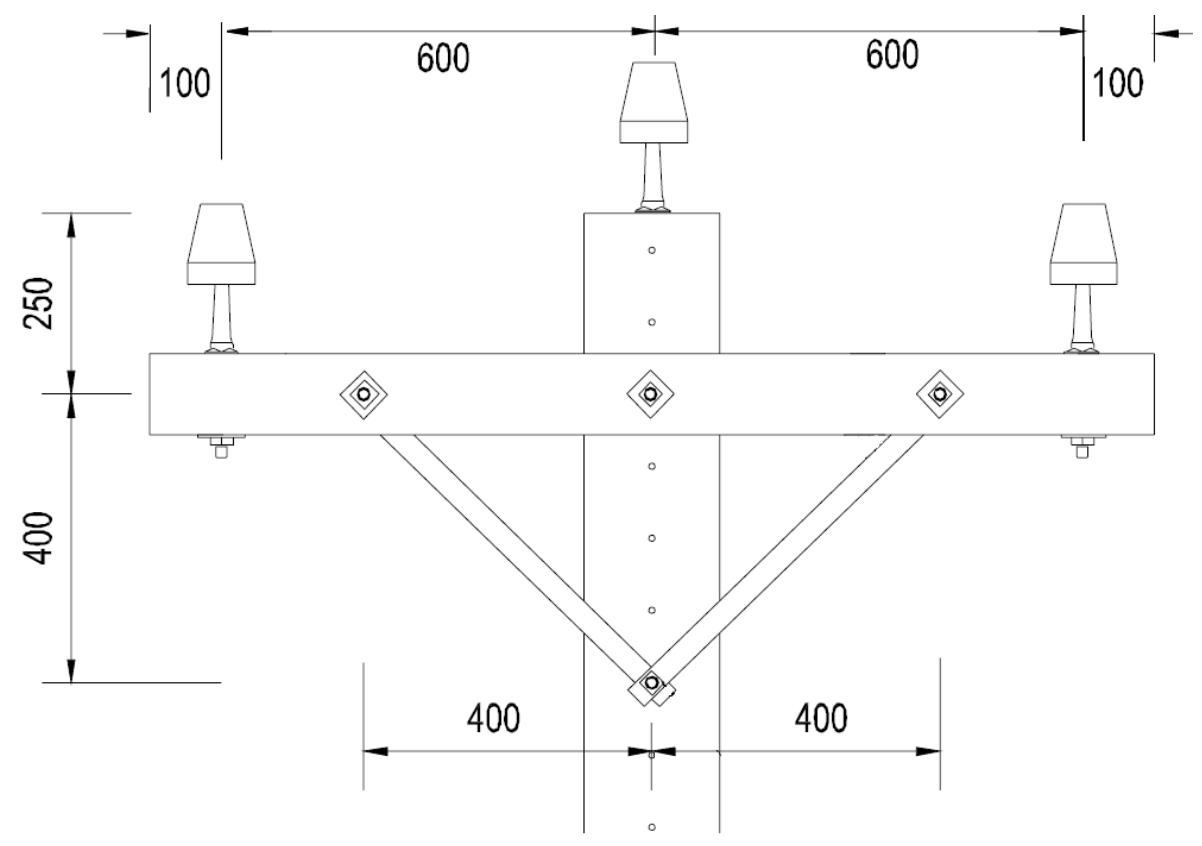

Figura 4.19: Modelo proposto final baseado na estrutura N1.

respectivamente, a vista frontal e lateral com suas devidas dimensões.

Vale frisar que este modelo proposto apresenta uma redução de $0,5 \mathrm{~m}$ de cruzeta que, multiplicado pela quantidade de cruzetas utilizadas em uma linha de distribuição passa a ser um valor muito significativo com relação à economia e à redução da madeira utilizada.

Ressalta-se que apesar da redução do tamanho da cruzeta, as distâncias entre os condutores são maiores do que na atual estrutura utilizada (figura 3.2) pela concessionária. No modelo 


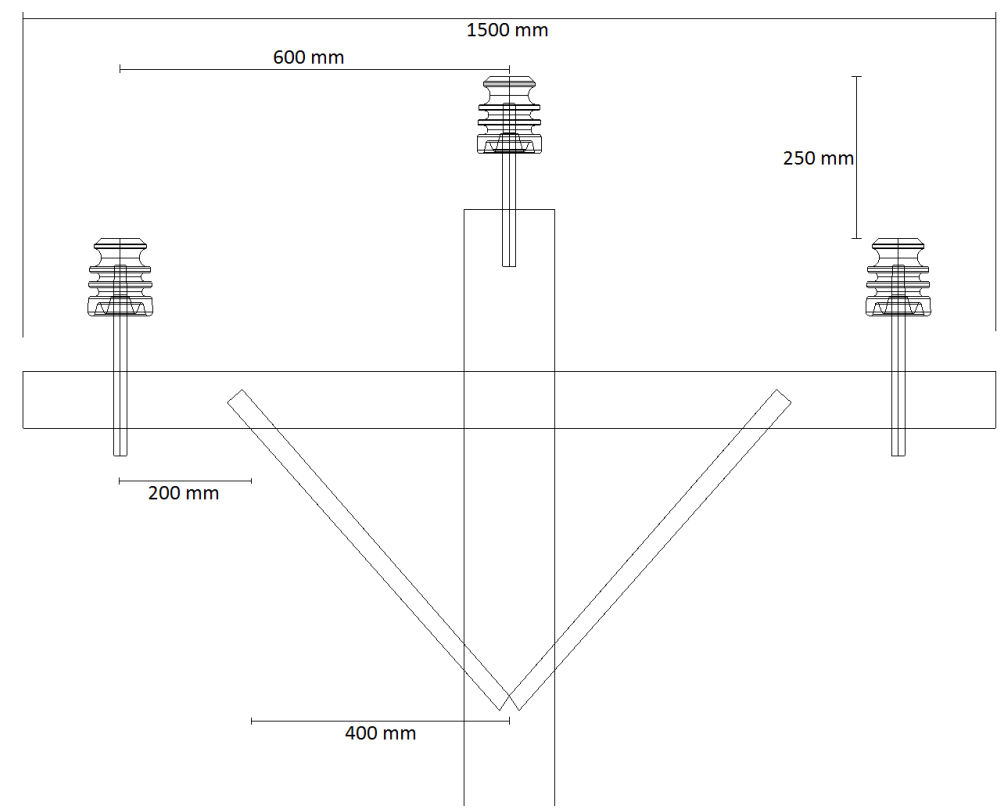

Figura 4.20: Vista frontal da nova composição.

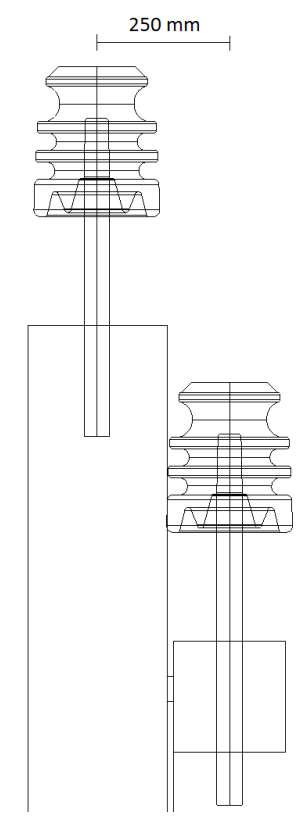

Figura 4.21: Vista lateral da nova composição.

empregado em campo, a distância entre as fases $\mathrm{B}$ e $\mathrm{C}$ é de 0,6 metros no eixo X. Agora, no novo modelo, a distância no eixo $\mathrm{X}$ foi mantida. Porém, devido à elevação do isolador central, a distância entre os condutores passa a ser um pouco superior, em torno de 0,65 m.

Outro aspecto significativo desta nova proposição é a distância entre o pino do isolador central e a mão francesa. Na figura 3.2 tem-se que o pino do isolador central se encontra praticamente sobre a conexão da mão francesa com a cruzeta. Isso faz com que o NBI da estrutura seja 
reduzido, pois este é dado pelo ponto mais vulnerável da estrutura (IEEE-Std-1410, 2004). Na nova estrutura proposta (figura 4.20), a distância entre o pino dos isoladores das fases A e C (localizados nas extremidades da cruzeta), e os pontos de conexão da mão francesa com a cruzeta, é de 0,2 m. Isso traz um aumento no CFO da estrutura de $50 \mathrm{kV}$.

A figura 4.22 apresenta a nova estrutura modelada no ambiente CAD do programa FLUX $3 \mathrm{D}$.

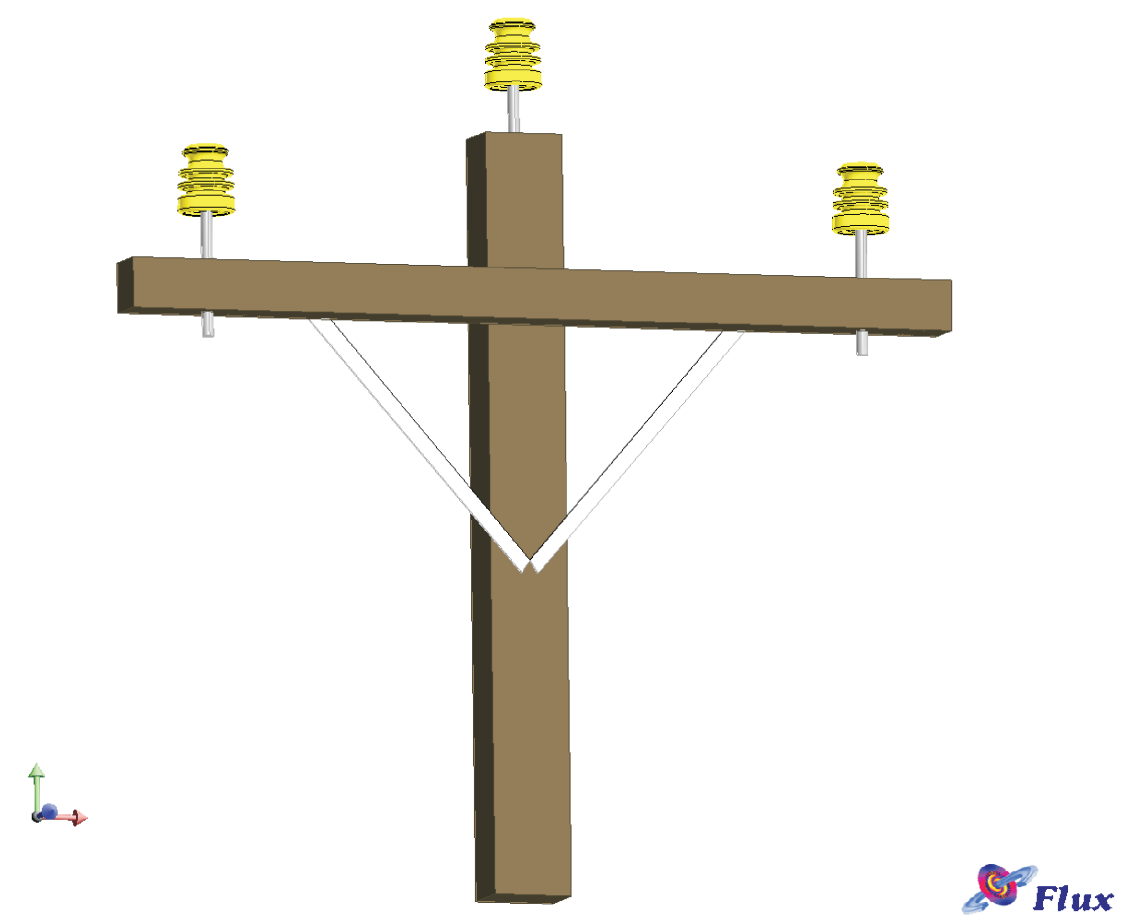

Figura 4.22: Vista frontal da nova composição modelada no FLUX 3D.

Depois de modelada a estrutura, passa-se para a etapa de geração da malha de elementos finitos. A tabela 4.3 apresenta os valores, em porcentagem, referentes à qualidade da primeira malha criada, bem como da malha atual, com a qual realizou-se as simulações que serão apresentadas nas seções subsequentes. Percebe-se a diferença entre a primeira malha criada para a estrutura atualmente utilizada (tabela 4.2), e a primeira malha criada para a estrutura proposta (tabela 4.3). A melhora observada é decorrente da experiência adquirida na execução do projeto, com relação aos valores das quantidades de nós e de segmentos que serão utilizados para a criação da malha.

A primeira análise da nova estrutura foi realizada para o caso de regime permanente (nominal) de operação do sistema. Assim, os valores utilizados são os mesmos empregados para o caso mostrado no exemplo da figura 3.5. 
Tabela 4.3: Evolução na qualidade da malha de elementos finitos para a estrutura proposta(valores em porcentagem).

\begin{tabular}{|c|c|c|}
\hline & Primeira Geração & Geração Atual \\
\hline Elementos não avaliados & 0 & 0 \\
\hline Elementos de excelente qualidade & 46,45 & 54,86 \\
\hline Elementos de boa qualidade & 30,5 & 30,05 \\
\hline Elementos de qualidade média & 13,55 & 16,67 \\
\hline elementos de má qualidade & 9,5 & 3,42 \\
\hline
\end{tabular}

A figura 4.23 apresenta o campo elétrico devido à operação normal do sistema no instante em que a fase B (fase central) atinge seu valor máximo (figura 3.5). A mesma escala utilizada nas imagens apresentadas na seção 4.1 será usada nesta seção com o intuito de facilitar as análises e a percepção.

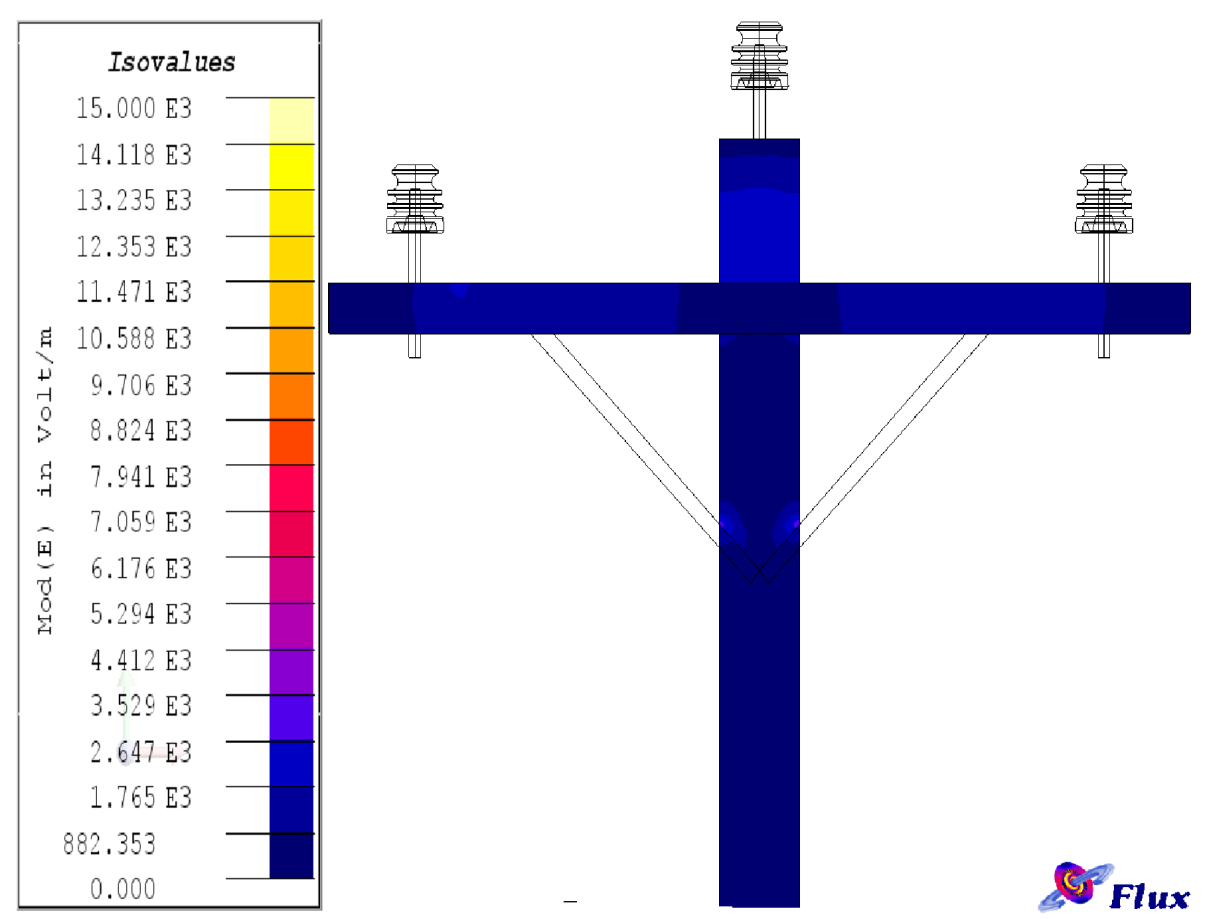

Figura 4.23: Campo elétrico devido à operação nominal do sistema, apresentado na figura 3.4, para a nova estrutura proposta (vista posterior).

A figura 4.24 apresenta o campo elétrico na estrutura proposta vista em uma perspectiva frontal. É possível notar que, assim como nos demais casos já apresentados, há um aumento do valor do campo elétrico nas proximidades dos objetos metálicos. Porém, ressalta-se que para a 
operação nominal do sistema, os valores de campo elétrico ficaram mais elevados na estrutura atual (figuras 4.64 .5 ) do que na nova estrutura (figuras 4.24 e 4.23).

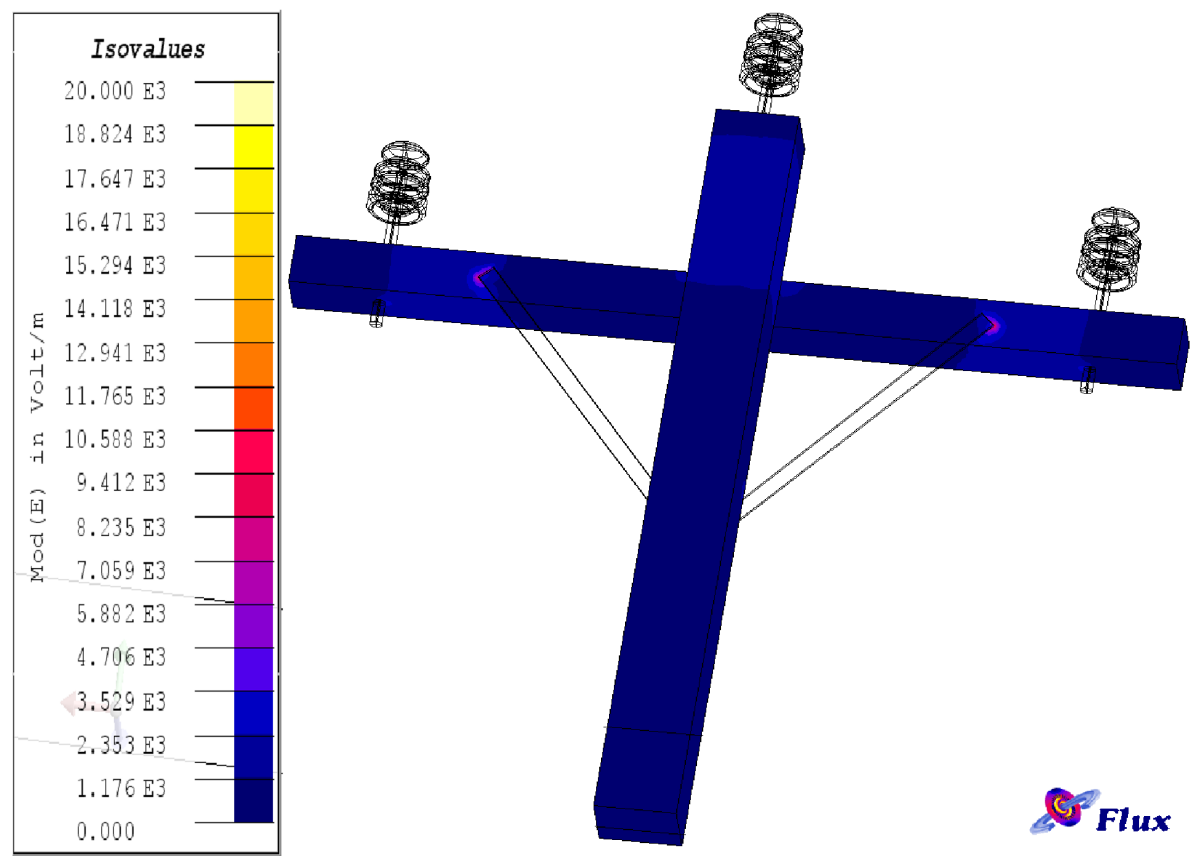

Figura 4.24: Campo elétrico devido à operação nominal do sistema, apresentado na figura 3.4, para a nova estrutura (vista frontal).

A figura 4.25 apresenta as linhas equipotenciais na estrutura devido à operação nominal do sistema. Ressalta-se que distância que separa as fases externas (A e C) da fase interna, é superior à da estrutura atualmente utilizada pela concessionária. E para que haja o rompimento do dielétrico entre as mesmas será necessária uma diferença de potencial de $190 \mathrm{kV}$.

Esse valor é encontrado multiplicando $250 \mathrm{kV} / \mathrm{m}$ (IEEE-Std-1410, 2004) pelo comprimento de madeira entre os isoladores externos do isolador central. Esse comprimento é referente ao trecho da cruzeta $(0,6 \mathrm{~m})$ e do poste $(0,16 \mathrm{~m})$ que interligam os pinos, formando um possível caminho para o arco-elétrico.

Outro aspecto que deve ser considerado é a possibilidade de aumentar ainda mais a distância entre os isoladores das fases A e C, mantendo o tamanho da cruzeta em 1,5 m. Assim, os isoladores ficariam distantes $1,3 \mathrm{~m}$ um do outro, e não mais 1,2 $\mathrm{m}$. Isto é possível, pois na estrutura utilizada atualmente, a distância entre os isoladores A e C e a extremidade da cruzeta é de 0,10 m. Já no novo modelo esta distância é de $0,15 \mathrm{~m}$. Outra alternativa é manter as distâncias como estão no modelo proposto (figura 4.20) e reduzir 0,10 metros de cruzeta. Assim, o comprimento da cruzeta não mais seria de 1,5 m, mas sim de 1,4 m. 


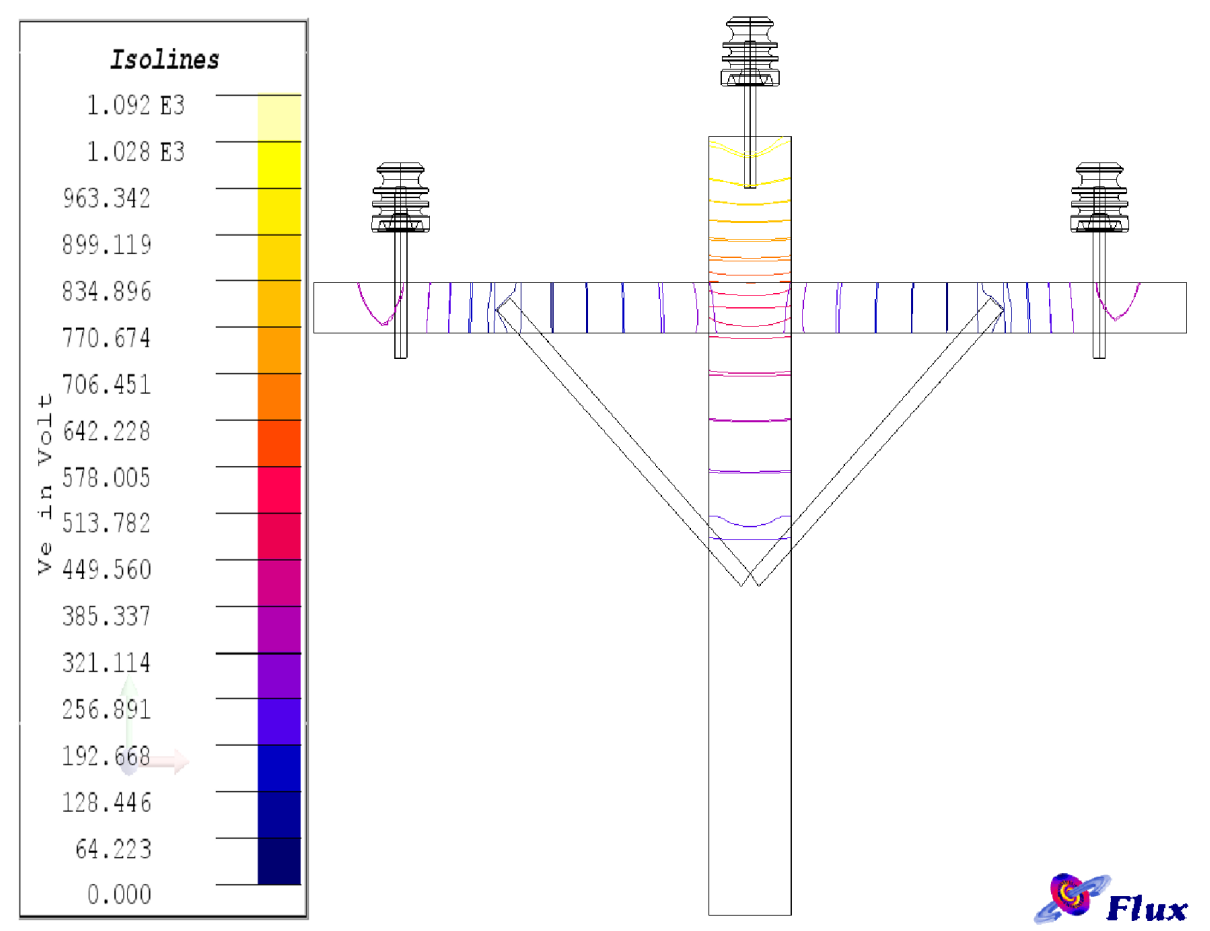

Figura 4.25: Linhas equipotenciais devido à operação nominal do sistema, apresentado na figura 3.4 , para a nova estrutura proposta (vista posterior).

Feitas as análises iniciais da estrutura com o sistema operando em regime permanente, seguem as análises dos mesmos distúrbios apresentados nas subseções da seção 4.1, porém agora para o novo modelo da estrutura.

\subsubsection{Campo elétrico e linhas equipotenciais devido ao distúrbio que apre- sentou a máxima DDP entre as fases A e B}

Nesta seção, apresentam-se o campo elétrico e as linhas equipotenciais devido ao curtocircuito apresentado na seção 3.2.1. A figura 4.26 apresenta a vista frontal, em perspectiva, do campo elétrico devido a esse distúrbio.

É possível notar na figura 4.26 o aumento da intensidade de campo elétrico entre o isolador mais à direita da estrutura e o ponto de conexão da mão francesa com a cruzeta, próxima a ele. Apesar deste aumento de intensidade, o valor do campo elétrico, $5,882 \mathrm{kV} / \mathrm{m}$, permanece abaixo do valor suportado pelo trecho da cruzeta (IEEE-Std-1410, 2004).

A figura 4.27 apresenta o campo elétrico (vista a posterior) para a mesma situação. Nota-se um aumento na mesma região, onde a intensidade de campo apresenta um valor de $5,294 \mathrm{kV} / \mathrm{m}$.

A figura 4.28 apresenta as linhas equipotenciais para a nova estrutura (vista posterior). Assim 


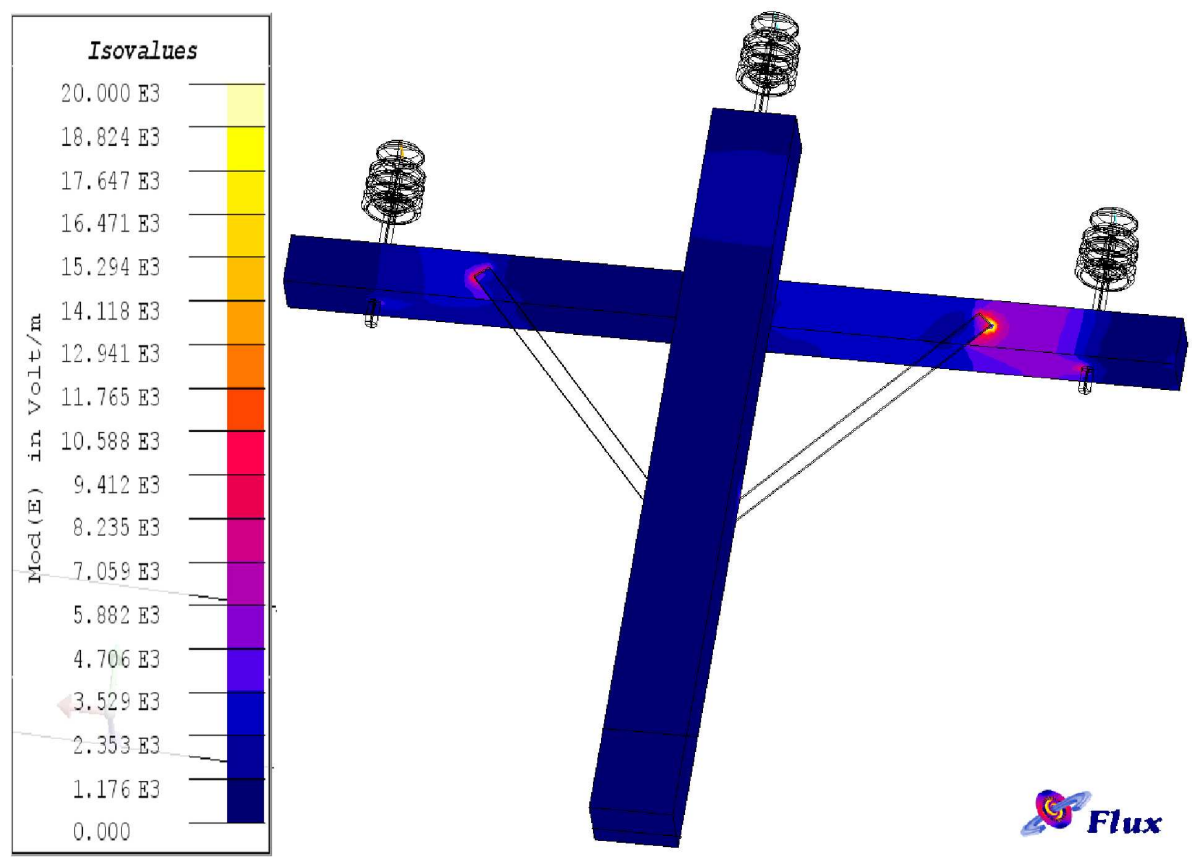

Figura 4.26: Campo elétrico devido à máxima diferença de potencial encontrada no transitório apresentado na figura 3.6, para a nova estrutura (vista frontal).

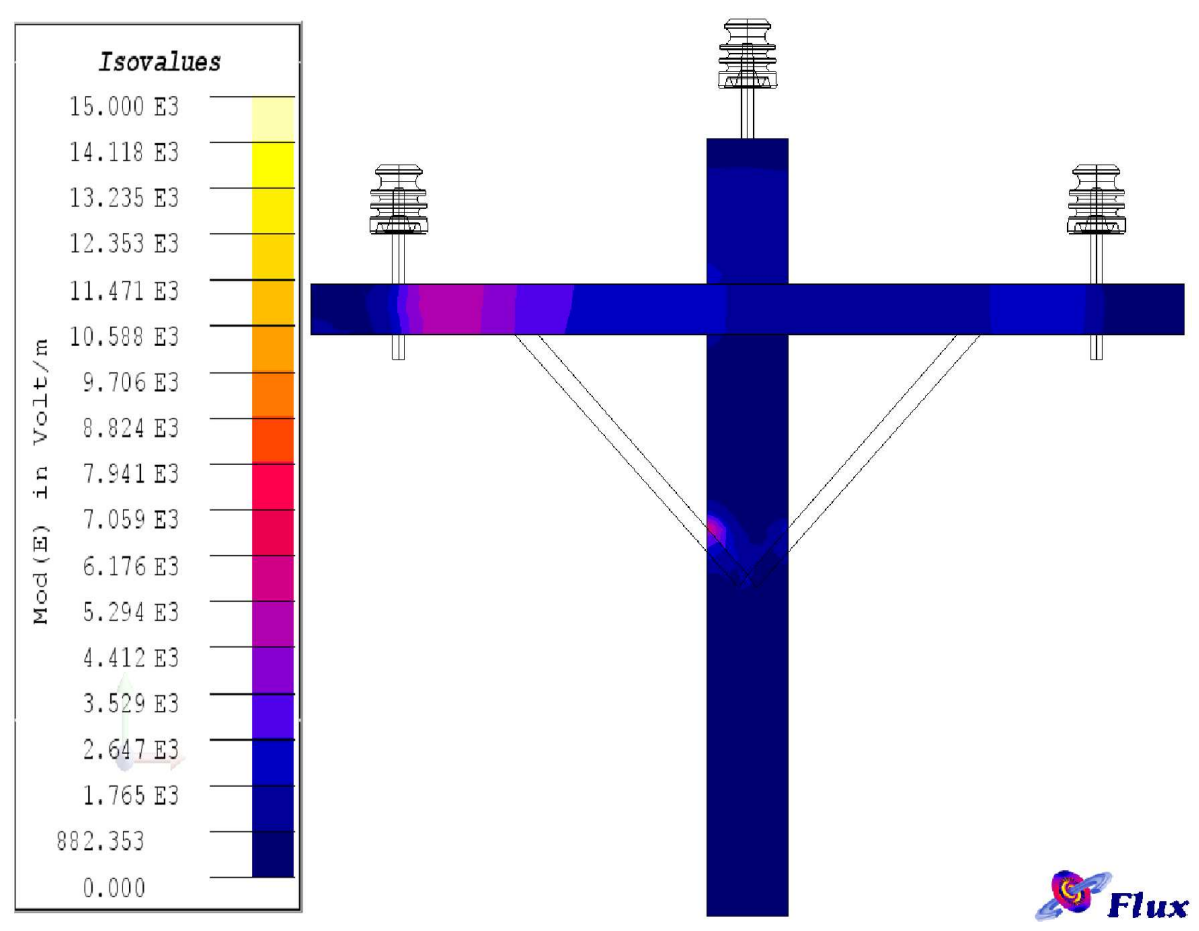

Figura 4.27: Campo elétrico devido à máxima diferença de potencial encontrada no transitório apresentado na figura 3.6, para a nova estrutura (vista posterior).

como na figura 4.27, a diferença de potencial entre o pino do isolador mais à esquerda da estrutura e o ponto de conexão da mão francesa com a cruzeta próximo a ele é de aproximadamente 770 V. O trecho de madeira que os divide acrescenta uma isolação, de acordo com IEEE-Std-1410 
(2004), de $50 \mathrm{kV}(\mathbf{2 5 0} \boldsymbol{k} \boldsymbol{V} / \boldsymbol{m} * \mathbf{0}, \mathbf{2} \boldsymbol{m}=\mathbf{5 0} \boldsymbol{k} \boldsymbol{V})$.

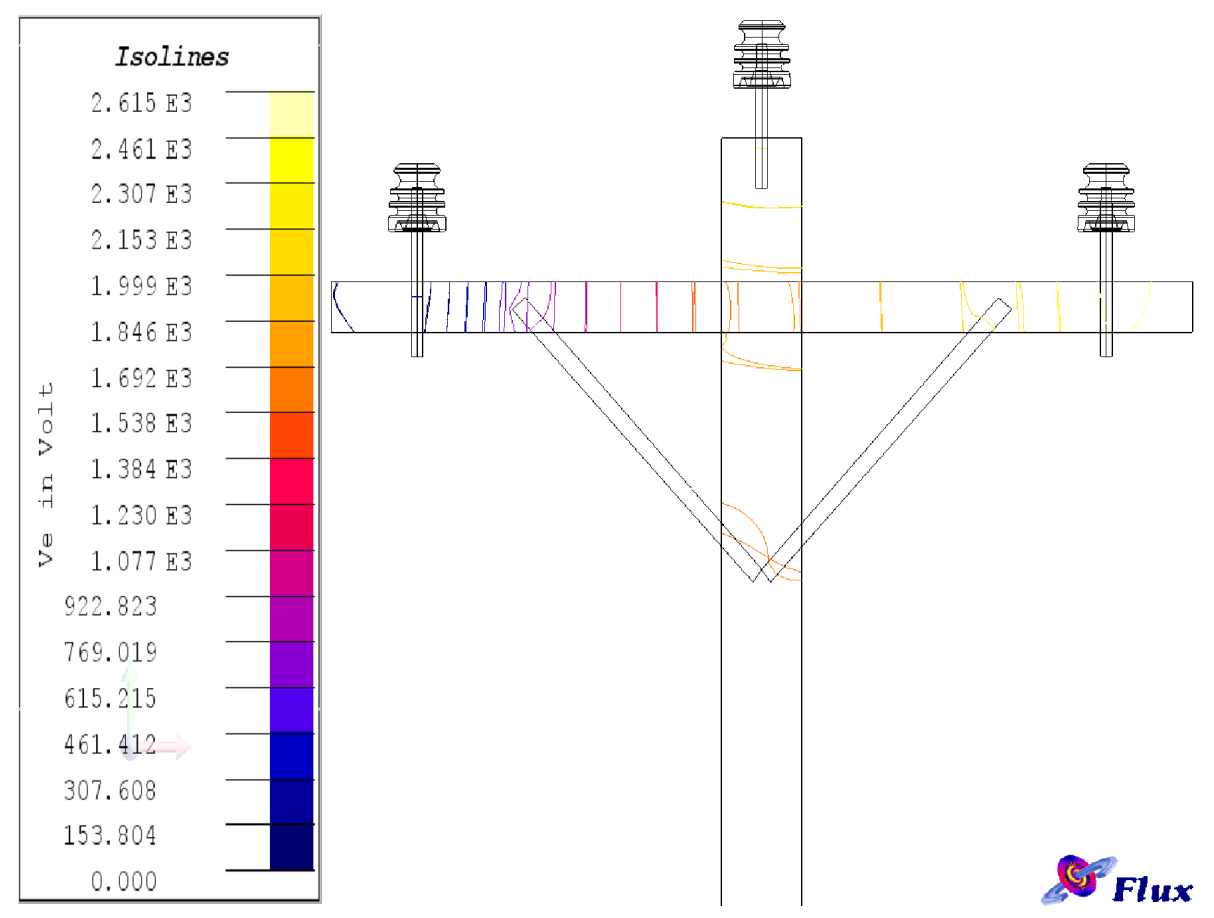

Figura 4.28: Linhas equipotenciais devido à máxima diferença de potencial encontrada no transitório apresentado na figura 3.6, para a nova estrutura proposta (vista posterior).

\subsubsection{Campo elétrico e linhas equipotenciais devido ao distúrbio que apre- sentou a máxima DDP entre as fases A e C}

Com base na seção 3.2.2 e nas figuras anteriores a este item, a figura 4.29 apresenta um aumento da intensidade de campo elétrico entre o isolador à direita da estrutura e o ponto de conexão da mão francesa com a cruzeta. O valor do campo elétrico nessa região é de $5,882 \mathrm{kV} / \mathrm{m}$, assim como no caso anterior, pois os valores de tensão deste caso são próximos dos utilizados para o caso anterior.

A figura 4.30 apresenta uma vista posterior da nova estrutura para a situação anteriormente mencionada.

A figura 4.31 apresenta as linhas equipotenciais para a estrutura - vista posterior. A região onde ocorre uma maior variação do potencial é a mesma notada no caso anterior (figura 4.28), porém, com um leve aumento nesse valor. Para o caso em questão, a diferença foi de aproximadamente $805 \mathrm{~V}$. Valor este, também inferior ao suportado pelo trecho. 


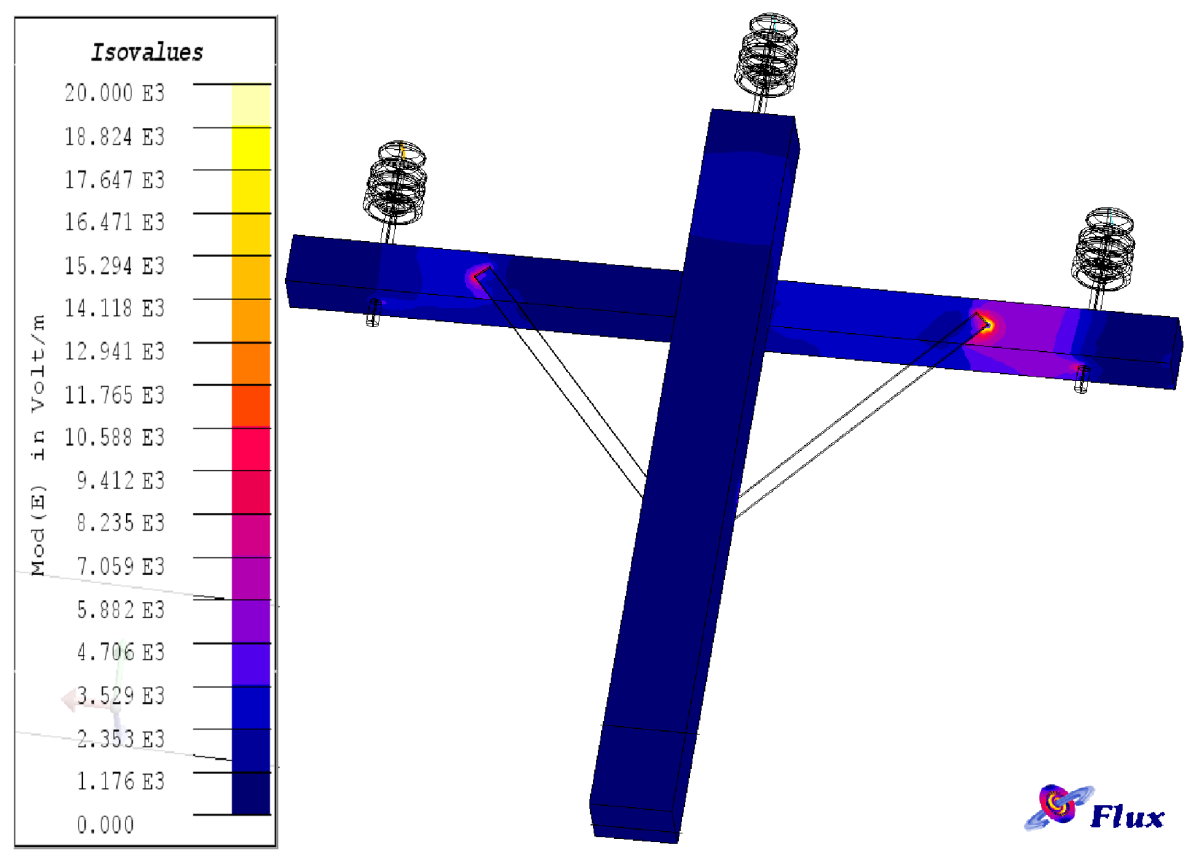

Figura 4.29: Campo elétrico devido à máxima diferença de potencial encontrada no transitório apresentado na figura 3.7, para a nova estrutura proposta (vista frontal).

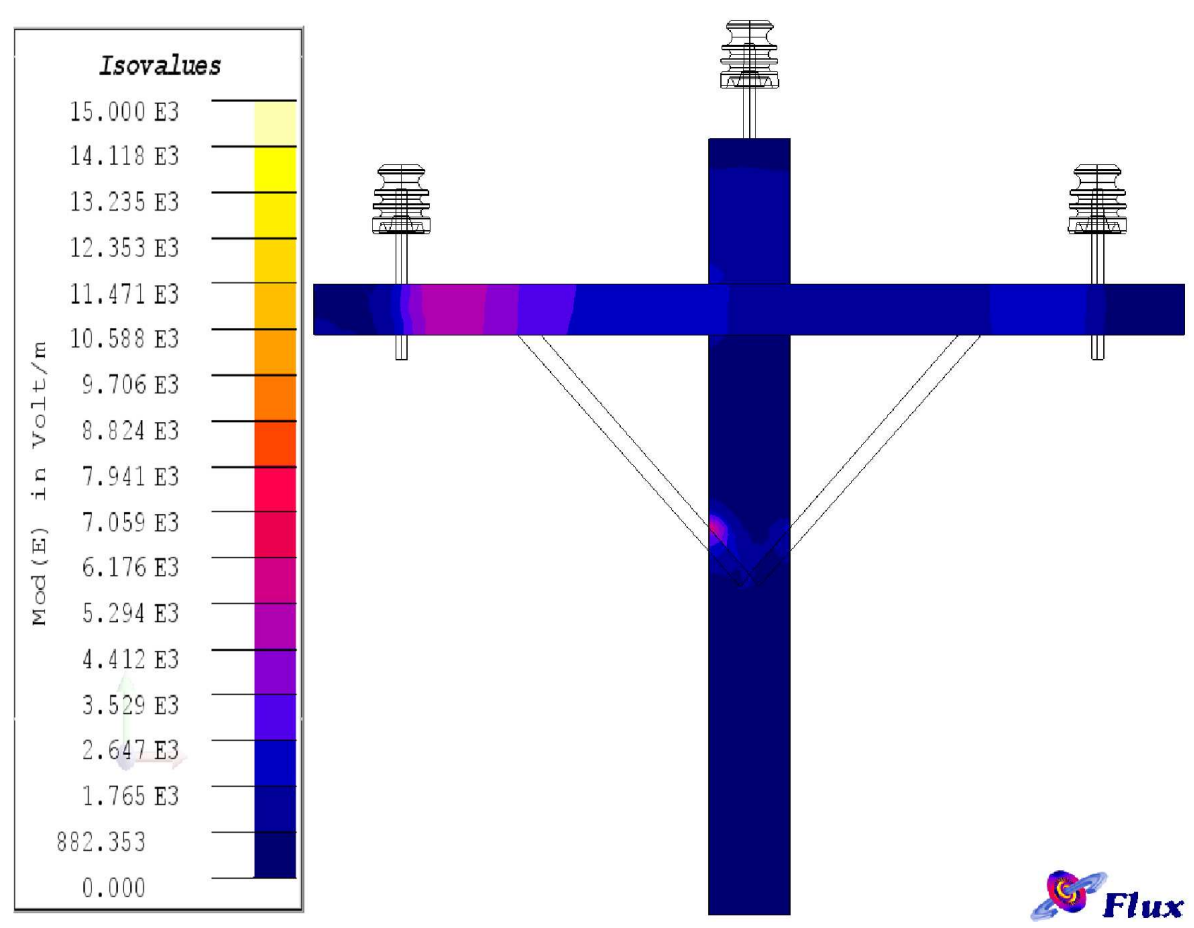

Figura 4.30: Campo elétrico devido à máxima diferença de potencial encontrada no transitório apresentado na figura 3.7, para a nova estrutura (vista posterior). 


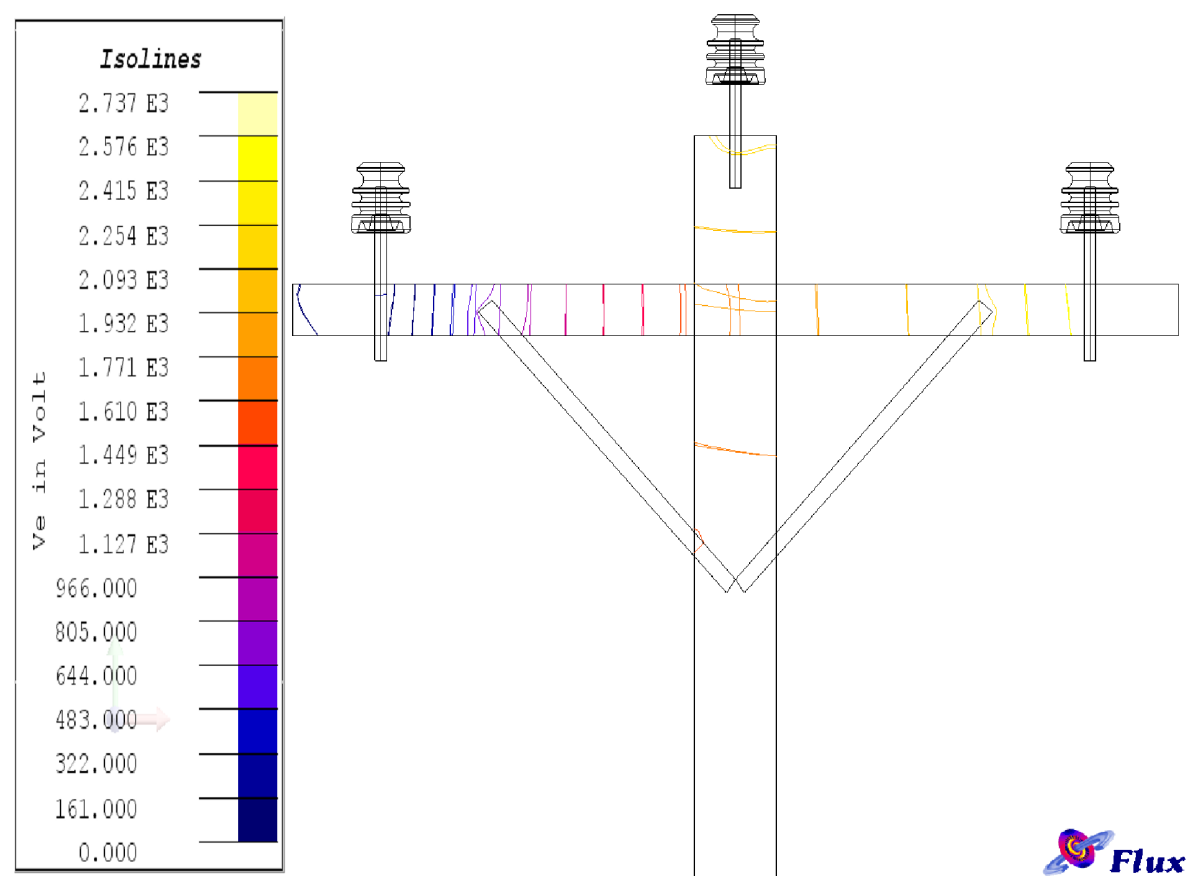

Figura 4.31: Linhas equipotenciais devido à máxima diferença de potencial encontrada no transitório apresentado na figura 3.7, para a nova estrutura proposta (vista posterior).

\subsubsection{Campo elétrico e linhas equipotenciais devido ao distúrbio que apre- sentou a máxima DDP entre as fases B e C}

Vale lembrar que esse mesmo distúrbio, quando analisado sobre a estrutura atualmente utilizada pela concessionária (seção 3.2.3), foi classificado como sendo o mais crítico, pois as distâncias entre os isoladores das fases B e C eram menores do que os isoladores associados as fases A e B. Contudo, para o novo modelo proposto, todos os casos apresentam a mesma importância, uma vez que a estrutura proposta é simétrica.

Assim como nos casos analisados nas subseções anteriores, nesta subseção não foi diferente, e a figura 4.32 ilustra o campo elétrico devido à máxima diferença de potencial encontrada durante o curto-circuito apresentado na seção 3.2.3. Nota-se um aumento na intensidade do campo elétrico. Porém, os valores permanecem bem abaixo do valor limite (IEEE-Std-1410, 2004). Na figura 4.32 o valor do campo elétrico na região entre o isolador à esquerda da estrutura e o ponto de conexão da mão francesa com a cruzeta próximo a ele é de $4,706 \mathrm{kV} / \mathrm{m}$.

A figura 4.33 apresenta o campo elétrico para a mesma situação (vista posterior).

A figura 4.34 apresenta uma vista posterior das linhas equipotenciais na estrutura. Podese notar que do lado esquerdo da figura não aparecem linhas, isso ocorre pois a variação do 


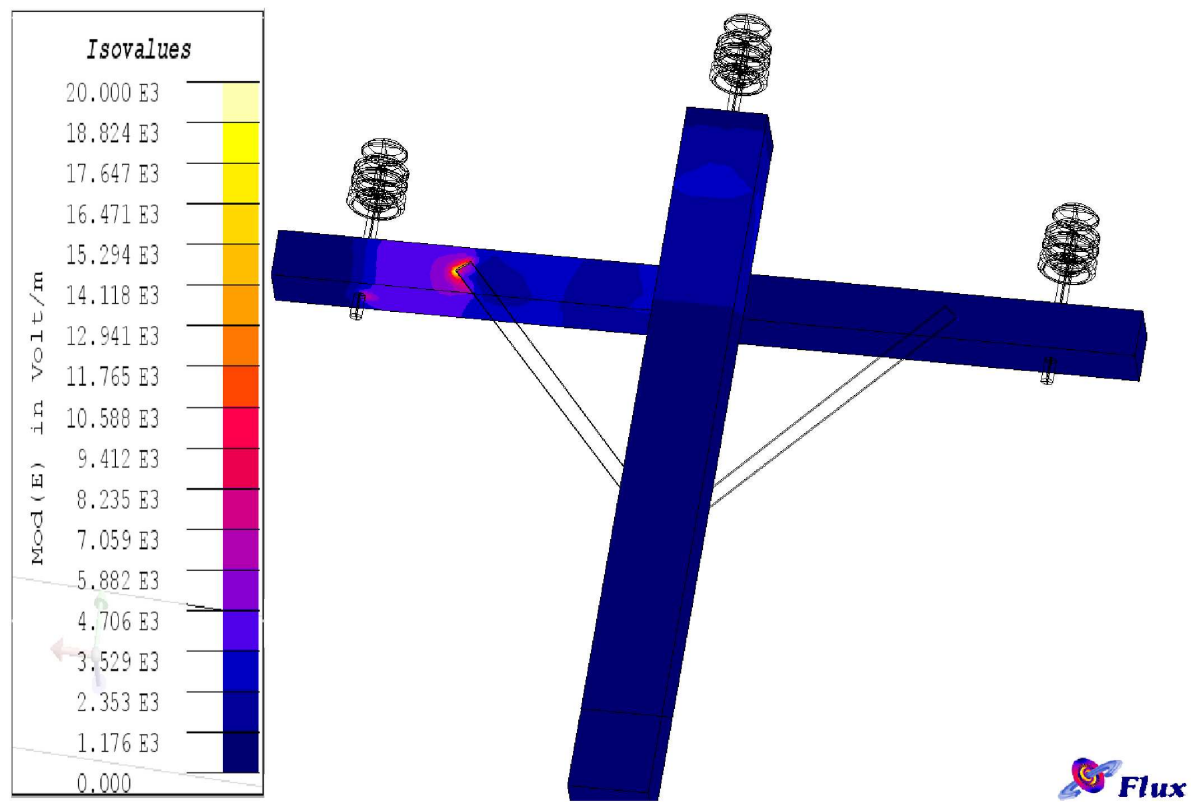

Figura 4.32: Campo elétrico devido à máxima diferença de potencial encontrada no transitório apresentado na figura 3.8, para a nova estrutura proposta (vista frontal).

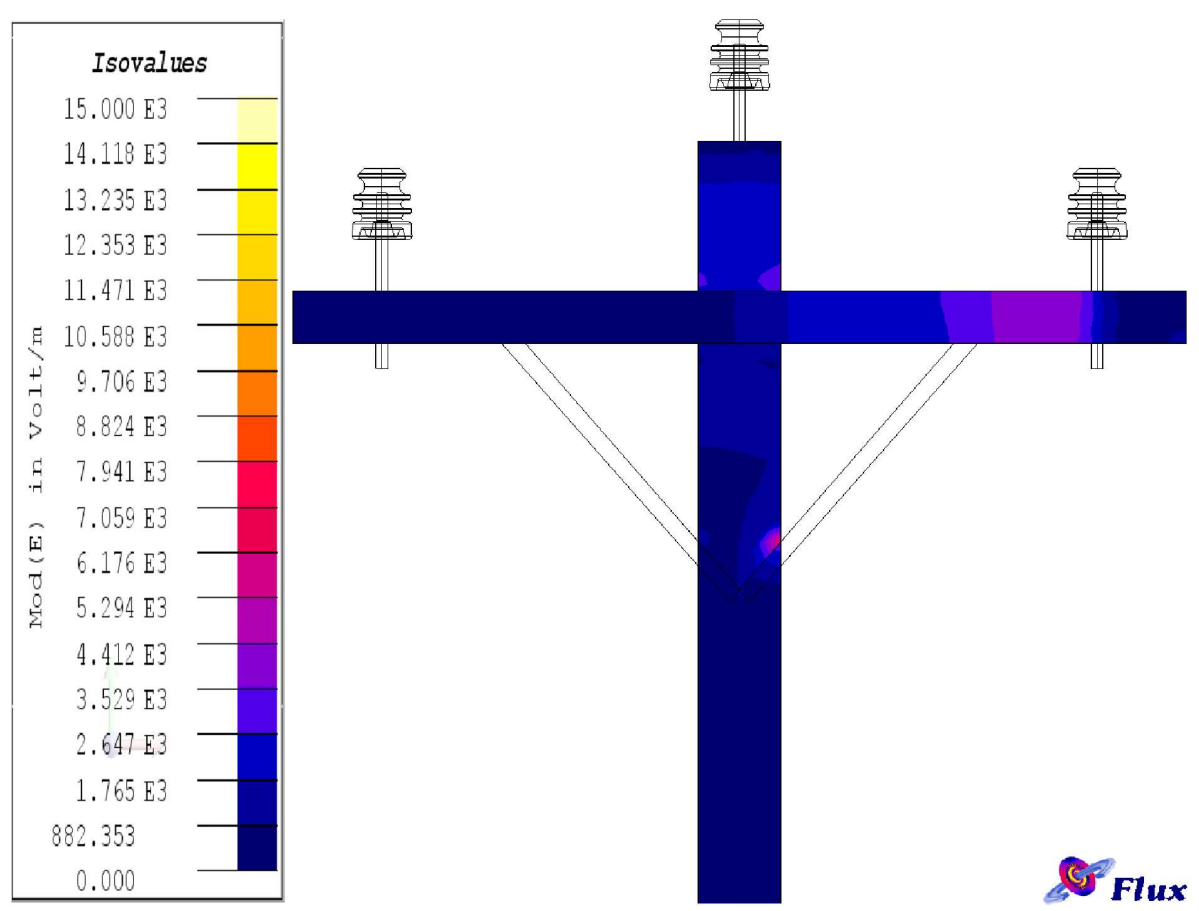

Figura 4.33: Campo elétrico devido à máxima diferença de potencial encontrada no transitório apresentado na figura 3.8, para a nova estrutura proposta (vista posterior).

potencial nesta região é muito pequena. Já do lado direito, existe uma variação no potencial elétrico. Porém, esse valor de aproximadamente $735 \mathrm{~V}$ permanece inferior ao valor suportado por este trecho de madeira. 


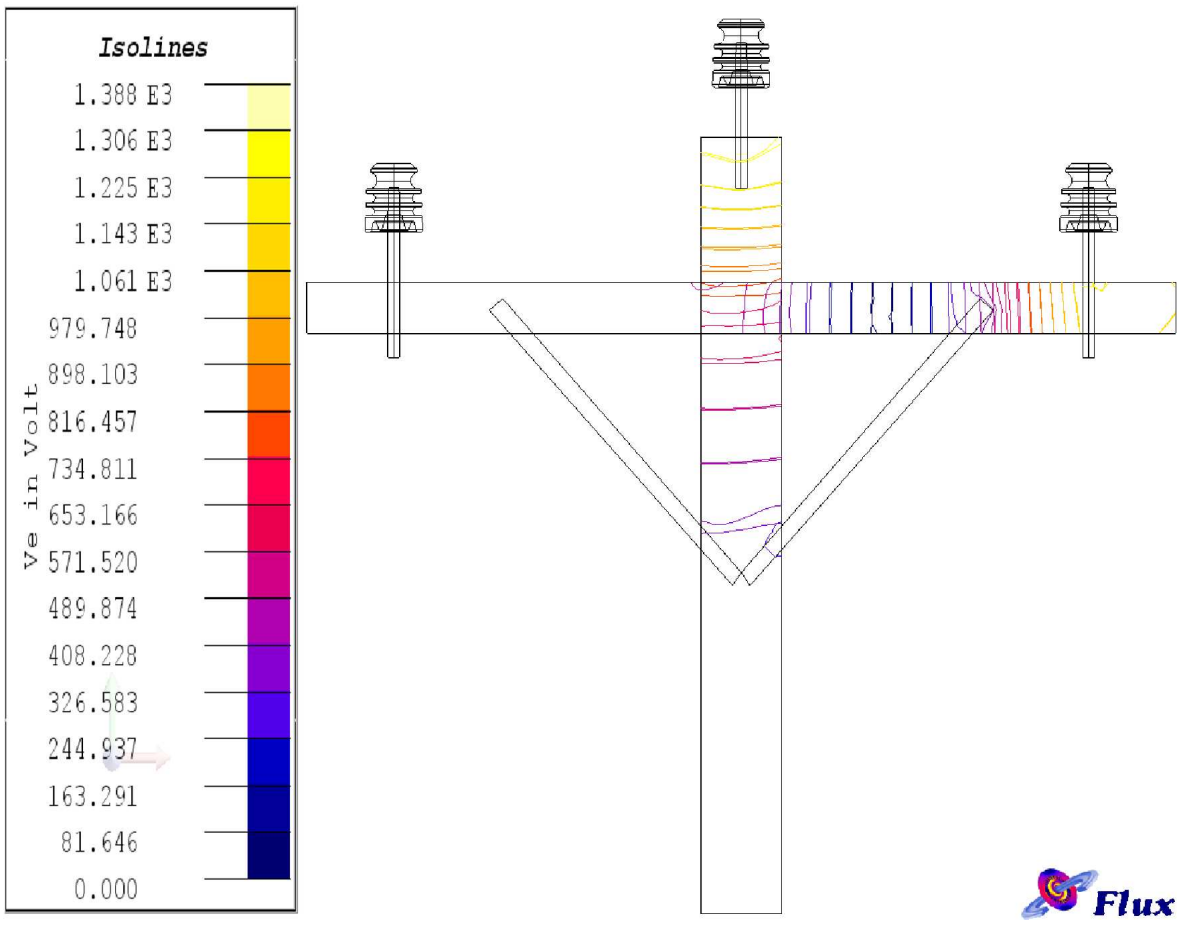

Figura 4.34: Linhas equipotenciais devido à máxima diferença de potencial encontrada no transitório apresentado na figura 3.8, para a nova estrutura proposta (vista posterior).

\subsubsection{Análise simplificada da nova estrutura em postes de madeira, concreto e de ferro}

Nas linhas de distribuição de energia elétrica são usualmente utilizados os postes de concreto e, além deles, existem também os postes de madeira e os postes de aço. Assim, de maneira simplificada e para efeitos comparativos, apresentam-se nessa seção os resultados das simulações de campos elétricos para a nova estrutura, utilizando-se de postes de madeira, concreto e de ferro. Vale enfatizar que para melhor caracterizar as diferenças entre os materiais empregados para a confecção dos postes, a condutividade elétrica do material associado também será considerada, como apresentado na tabela 4.4 .

Todas as análises serão feitas utilizando-se os valores de tensão registrados para o regime nominal de operação do sistema no instante em que o valor de tensão da fase central (fase B) é o máximo, assim como o primeiro caso apresentado na seção 4.1 e na seção 4.2. A escala utilizada para refletir o campo elétrico em cada configuração foi reajustada para uma melhor percepção das diferenças apresentadas.

A figura 4.35 apresenta o campo elétrico na estrutura modelada com poste de madeira.

Na figura 4.36, modelou-se a estrutura utilizando os valores de condutividade e da permis- 
Tabela 4.4: Condutividade elétrica dos materiais utilizados.

\begin{tabular}{|c|c|}
\hline Material & Condutividade elétrica $-\sigma_{o}(\mathrm{~S} / \mathrm{m})$ \\
\hline Ar & $\approx \mathbf{0}$ \\
\hline Isolador & $\approx \mathbf{0}$ \\
\hline Cruzeta (Madeira) & $\approx \mathbf{0}$ \\
\hline Concreto & $\approx \mathbf{0}$ \\
\hline Ferro & $\approx \mathbf{1 0}^{\mathbf{1 2}}$ \\
\hline
\end{tabular}

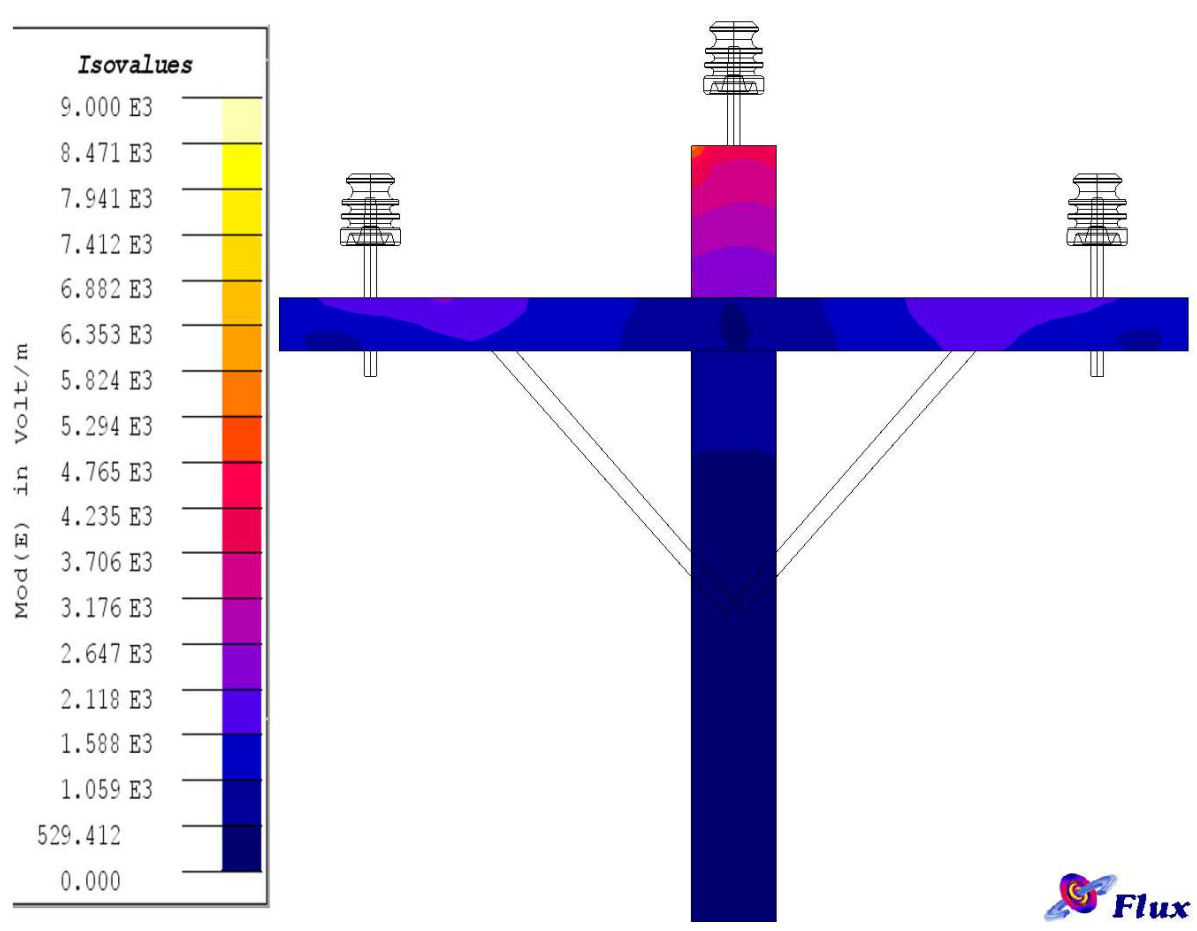

Figura 4.35: Campo elétrico na estrutura - poste de madeira.

sividade elétrica do concreto. Ressalta-se que os valores são próximos dos valores apresentados pela madeira.

Deve ser lembrado que o concreto utilizado isoladamente apresenta resistência mecânica muito baixa, por isso as estruturas são feitas de concreto armado. Ou seja, o concreto é utilizado juntamente com vergalhões de aço para que as estruturas de concreto apresentem resistência mecânica.

Para demonstrar a interferência que os vergalhões de aço podem causar na estrutura, foi modelado o poste de concreto com um vergalhão atravessando o poste. A figura 4.37 apresenta 


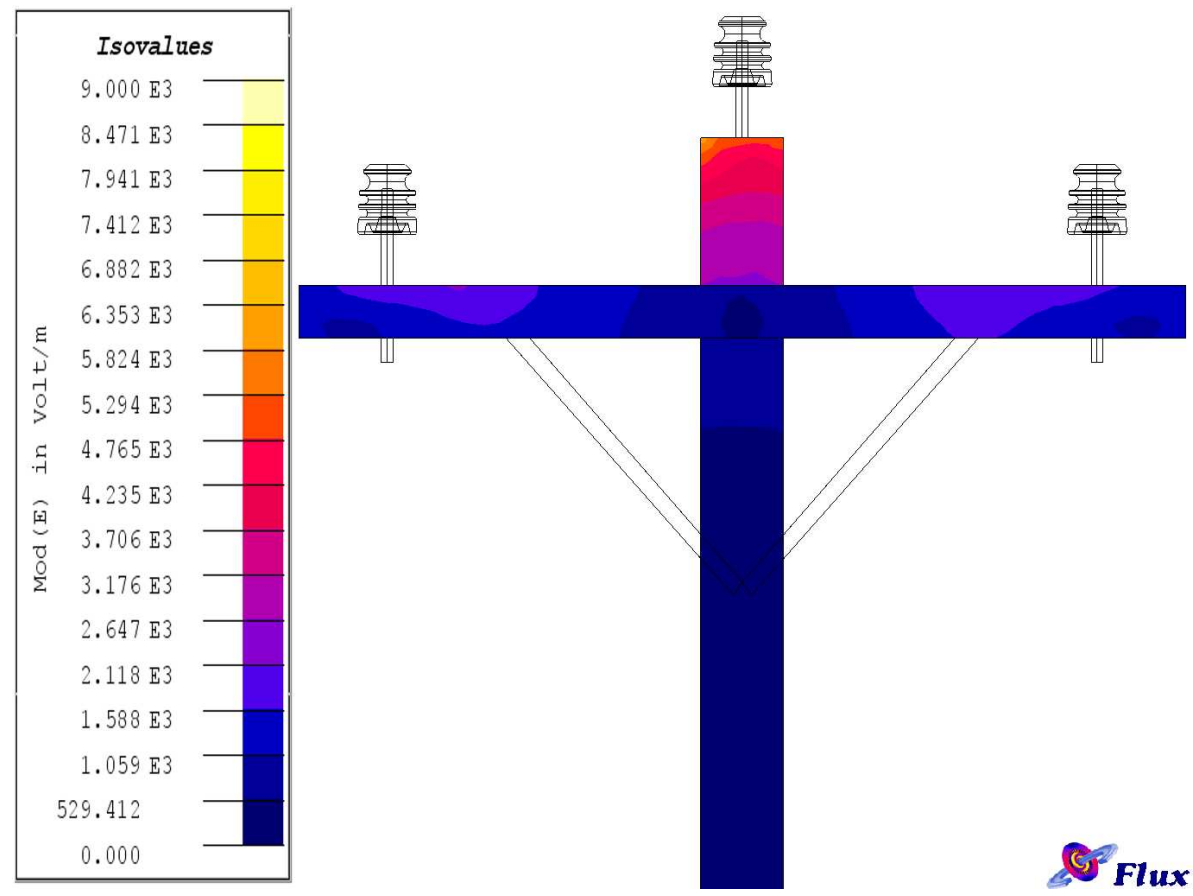

Figura 4.36: Campo elétrico na estrutura - poste de concreto.

uma vista em perfil da parte de baixo do poste e, nela é possível perceber que a intensidade de campo elétrico no canto superior direito da base do poste é um pouco maior do que a intensidade do campo elétrico no canto superior esquerdo. Isso acontece principalmente pela influência do vergalhão, que foi configurado com a permissividade elétrica igual a 1, assim como o pino e a mão francesa (tabela 4.1).

A figura 4.38 apresenta os valores da intensidade do campo elétrico para a estrutura com poste de ferro. Os valores do campo elétrico são um pouco superiores aos valores apresentados para a estrutura com o poste de concreto puro (sem a armação feita com vergalhões) e para a estrutura com o poste de madeira. Porém, ressalta-se o valor da condutividade elétrica do poste de ferro e do poste de concreto armado (com armação feita com vergalhões), que não acrescentam isolação alguma à estrutura, fazendo com que os isoladores e o trecho de cruzeta de madeira sejam os únicos componentes responsáveis pela isolação do sistema elétrico. Já pela utilização do poste de madeira temos uma situação contrária, visto que a mesma acrescenta uma isolação de 250 kV/m (IEEE-Std-1410, 2004). 


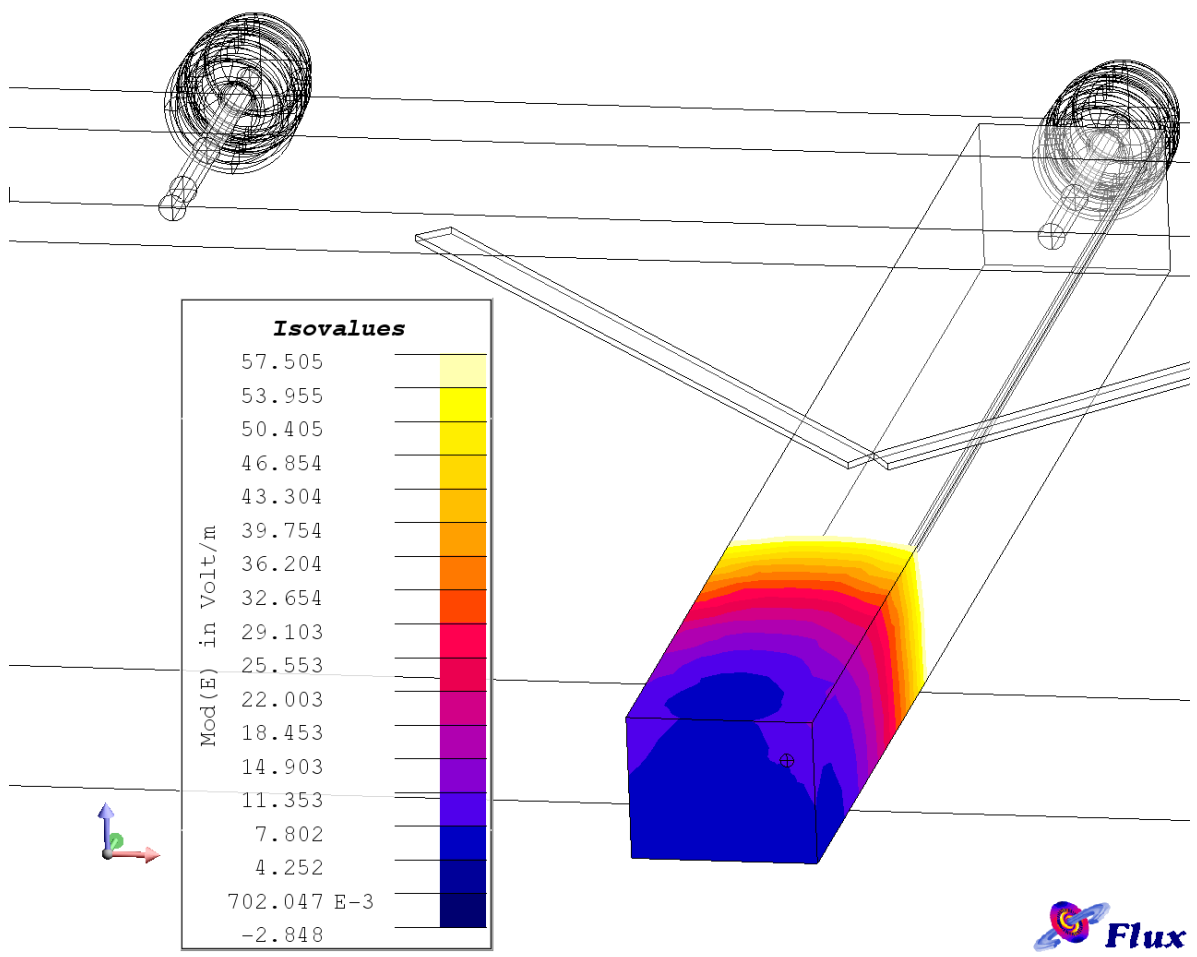

Figura 4.37: Campo elétrico na base do poste de concreto com um vergalhão.

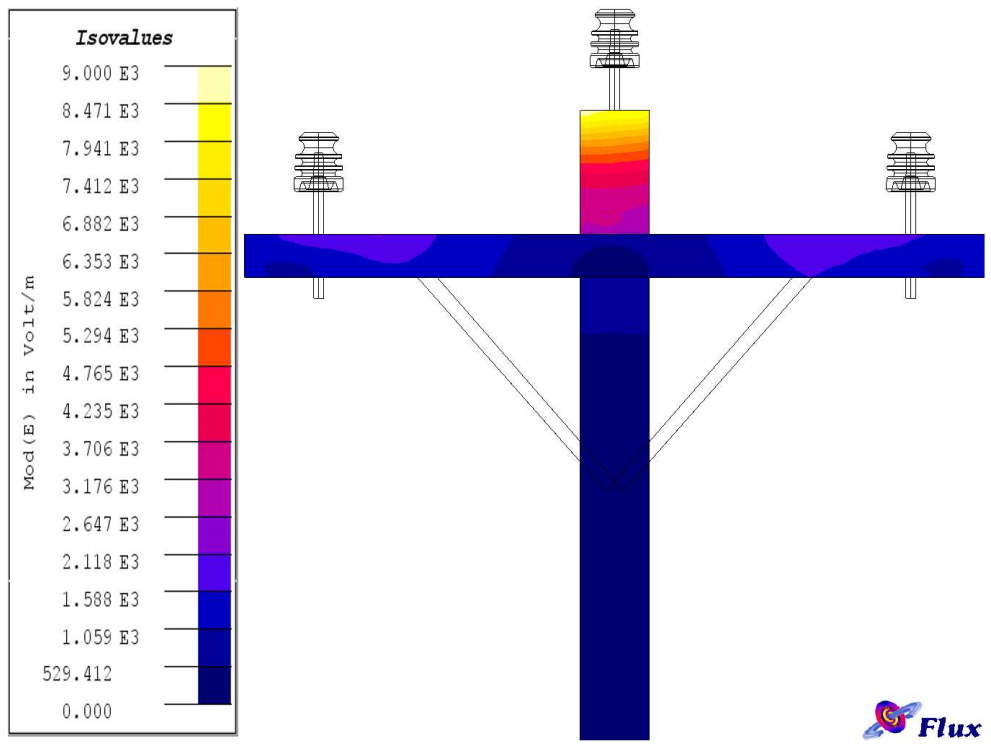

Figura 4.38: Campo elétrico na estrutura - poste de ferro.

\subsection{Análise Direta da Atual e da Nova Estrutura em Poste de Madeira}

Para facilitar a interpretação dos resultados demonstrados e analisados nesse capítulo, temse a tabela 4.5 resumindo os valores das diferenças entre as linhas equipotenciais nas regiões 
críticas das estruturas. Ressalta-se que ao mudar a geometria, essa análise deve ser feita em cada estrutura separadamente, pois os piores casos em uma determinada geometria podem estar localizados em pontos diferentes em outras, conforme exposto no início dessa seção (seção 4.2.3).

Tabela 4.5: Diferenças de potencial entre as linhas equipotenciais próximas ao isolador da fase C e o ponto de conexão da mão francesa com o poste.

\begin{tabular}{|c|c|c|}
\hline Tipo do distúrbio & Estrutura Atual & Nova Estrutura \\
\hline Máxima DDP entre as fases A e B & $481 \mathrm{~V}$ & $770 \mathrm{~V}$ \\
\hline Máxima DDP entre as fases A e C & $480 \mathrm{~V}$ & $805 \mathrm{~V}$ \\
\hline Máxima DDP entre as fases B e C & $900 \mathrm{~V}$ & $735 \mathrm{~V}$ \\
\hline
\end{tabular}

Apesar de as diferenças de potencial apresentadas na tabela 4.5 para a nova estrutura serem maiores do que as da estrutura atual, ressalta-se que o NBI da estrutura é dado pelo ponto mais crítico da estrutura e, no caso da estrutura atual, tem-se que o NBI é menor devido ao posicionamento do isolador central próximo ao ponto de conexão da mão francesa com o poste. Além disso, vale frisar que os valores foram inferiores aos limites apresentados em IEEE-Std1410 (2004), $250 \mathrm{kV} / \mathrm{m}$ como segundo componente de isolação, e em Darveniza et al. (1967), que podem variar de 32,81 até $426,51 \mathrm{kV} / \mathrm{m}$ para a madeira seca e de 0 até $196,85 \mathrm{kV} / \mathrm{m}$ em dias chuvosos. 


\section{Capítulo 5}

\section{Análise de Desempenho da Linha de Distribuição}

O desempenho elétrico de uma linha de distribuição depende de alguns fatores como a geometria dos condutores, a resistência elétrica do condutor, a altura do condutor com relação ao solo, a corrente que percorre o condutor, enfim, existem vários fatores que podem interferir no desempenho das linhas de distribuição.

Nesse capítulo, propõe-se a análise do desempenho da linha de distribuição considerando a geometria dos condutores de acordo com a estrutura atualmente utilizada comparada à linha com a geometria de acordo com a estrutura proposta nesse trabalho.

Coloca-se que somente a geometria das linhas foi alterada na simulação dos dois casos e as demais variáveis como a resistividade do solo, altura da cruzeta com relação ao solo, resistividade do condutor e demais váriaveis necessárias para as simulações foram inalteradas. Assim, através do programa DIgSILENT PowerFactory foram feitas as simulações de fluxo de carga e de máximo carregamento para os dois casos, que posteriormente são comparados.

\subsection{Modelagem da Linha de Distribuição no programa DIgSI- LENT PowerFactory}

O início do desenvolvimento do software DIgSILENT PowerFactory ocorreu no ano de 1976. Desde seu início o DIgSILENT PowerFactory tem crescido e conta, nos dias de hoje, com uma vasta gama de análises e recursos que são necessários para planejar, operar e manter qualquer as- 
pecto do sistema de energia. O nome DIgSILENT provém de DIgital SImuLation and Electrical $\boldsymbol{N} e \boldsymbol{T}$ work e algumas de suas principais possibilidades de utilização seguem abaixo (DigSILENT (2010)):

- Fluxo de carga e análise completa de curtos-circuitos;

- Análise e otimização de rede de baixa tensão;

- Dimensionamento de cabos (IEC Cable Sizing);

- Simulação dinâmica e transitória (ElectroMagnetic Transients (EMT));

- Análise da proteção, harmônica e de estabilidade de tensão, dentre outras.

Nesta pesquisa, o programa DIgSILENT PowerFactory foi utilizado com o intuito de realizar uma análise do desempenho da linha de distribuição utilizando a estrutura atual (Figura 3.2) do desempenho da linha que dispõe da nova estrutura (Figura 4.20), em regime permanente.

Para a modelagem da linha de distribuição no programa DIgSILENT PowerFactory foram utilizados equivalentes de rede representando a subestação, um trecho da linha de distribuição (14,6 km) e uma carga. A simplificação na modelagem é possível pois o interesse é restrito à análise do desempenho da linha de distribuição que interliga o barramento da subestação ao barramento da carga.

A Figura 5.1 apresenta o diagrama unifilar do sistema modelado no DIgSILENT PowerFactory.

Todos os componentes utilizados na modelagem do sistema no programa DIgSILENT PowerFactory foram configurados com os dados utilizados anteriormente no programa ATP (Cf. Capítulo 3). Porém, como são programas distintos, a formatação dos dados de entrada apresenta algumas diferenças.

Assim como o ATP possui uma rotina para o cálculo dos parâmetros elétricos das linhas (rotina LCC), o DIgSILENT PowerFactory também possibilita esse cálculo através da inserção das distâncias entre os condutores, da altura destes com relação ao solo, e os valores referentes aos dados do condutor utilizado. Assim, os parâmetros elétricos para a estrutura atual e para a nova estrutura foram calculados no próprio DIgSILENT PowerFactory.

A análise do desempenho da linha foi realizada e baseada em dois estudos: no de fluxo de potência (seção 5.2) e no estudo de máximo carregamento da linha de distribuição (seção 5.3). 


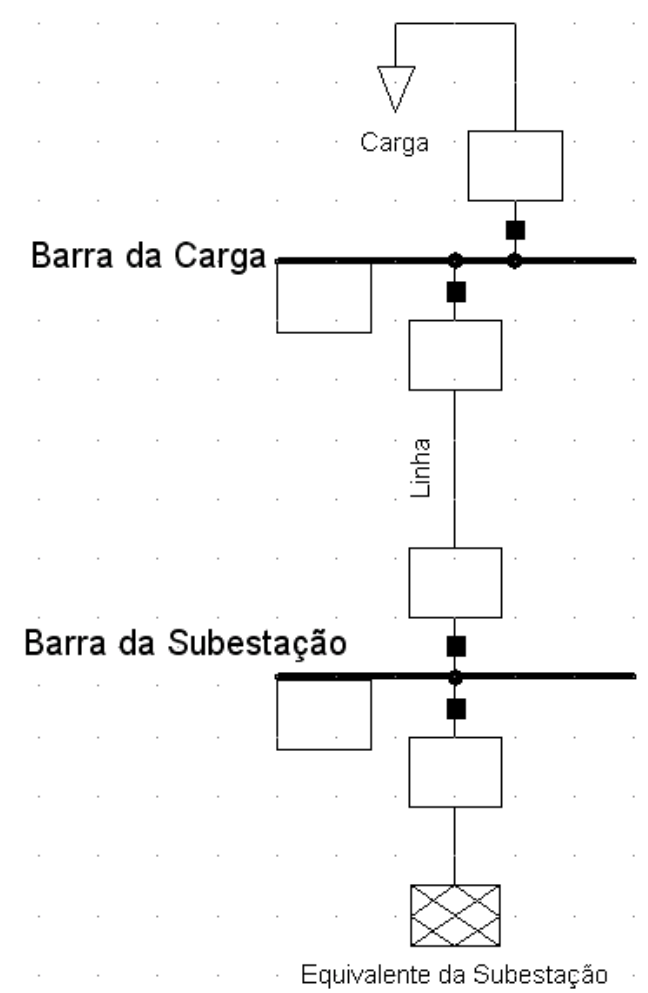

Figura 5.1: Sistema modelado no programa DIgSILENT PowerFactory.

\subsection{Estudo de Fluxo de Potência}

O estudo de fluxo de potência do sistema possibilitou a comparação entre a linha com a estrutura atualmente empregada (Figura 3.2) e a linha com a nova estrutura (Figura 4.20) focando as análises nas tensões nos terminais da linha (barramento da subestação e barramento da carga), no desequilíbrio de tensão e nas perdas da linha.

A Figura 5.2 apresenta o resultado da simulação do fluxo de potência para a linha atual operando com o máximo carregamento. Já a Figura 5.3 apresenta os resultados para a linha de distribuição utilizando a nova estrutura, também com o máximo carregamento.

Para facilitar a comparação das figuras apresentadas anteriormente é utilizada a Tabela 5.1 que apresenta os valores das tensões e seus ângulos expressos em p.u. (por unidade) e graus respectivamente. Nota-se uma pequena variação nos valores das tensões na barra da carga, apresentando uma leve melhora com a utilização da nova estrutura. Essa comparação é feita através da componente de sequência positiva da tensão, denotando uma melhora de $0,402 \%$.

Além da pequena redução na queda de tensão observada na barra da carga, outro ponto que se deve ressaltar é a redução do desequilíbrio de tensão, causado pela própria linha, também na 


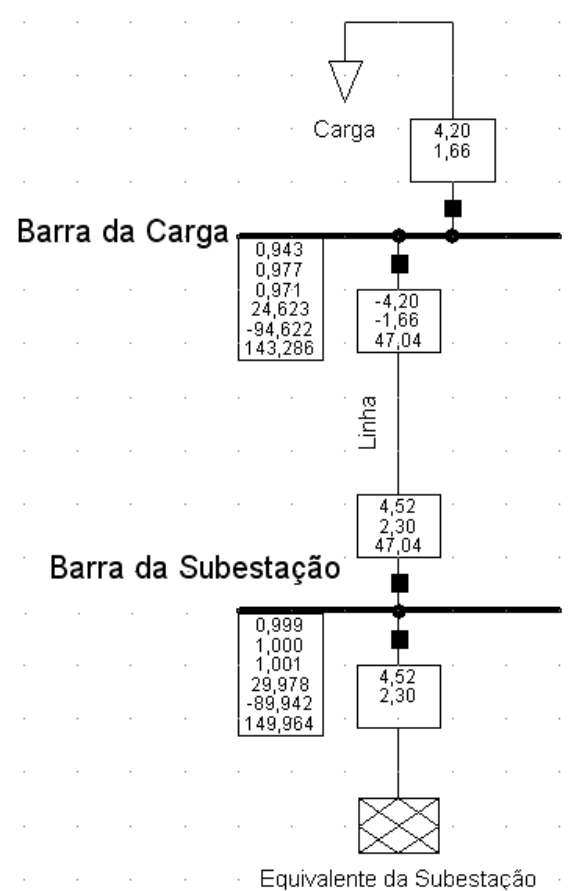

Figura 5.2: Resultado do fluxo de potência para o sistema com a estrutura atualmente utilizada.

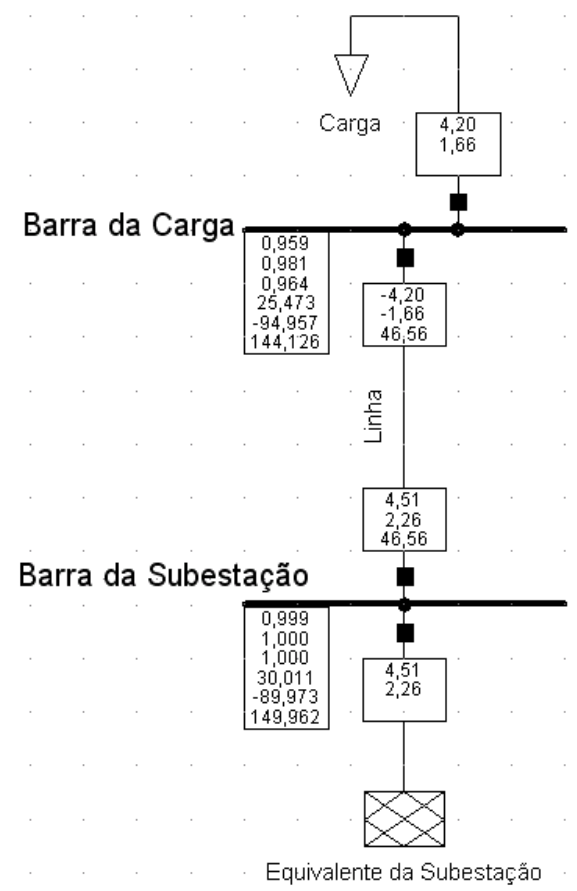

Figura 5.3: Resultado do fluxo de potência para o sistema com a estrutura proposta.

barra da carga. Para a realização do cálculo do desequilíbrio de tensão, foi utilizado o método das componentes simétricas (Fortescue, 1918; Stevenson, 1978; Biasotto et al., 2008) que considera a relação entre o módulo da componente de sequência negativa e o módulo da componente de sequência positiva, conforme a equação 5.1 (ANEEL, 2007). 
Tabela 5.1: Tensões nas três fases para a linha com a estrutura atual e a nova estrutura.

\begin{tabular}{|c|c|c|c|c|}
\hline \multirow{2}{*}{$\begin{array}{c}\text { Tensões de } \\
\text { Fase }\end{array}$} & \multicolumn{2}{|c|}{ Estrutura Atual } & \multicolumn{2}{c|}{ Estrutura Proposta } \\
\cline { 2 - 5 } & Barra da Subestação & Barra da Carga & Barra da Subestação & Barra da Carga \\
\hline Va (pu) & 0,999 & 0,943 & 0,999 & 0,959 \\
\hline Øa (graus) & 29,978 & 24,623 & 29,978 & 25,473 \\
\hline Vb (pu) & 1,000 & 0,977 & 1,000 & 0,981 \\
\hline$\varnothing b$ graus) & $-89,942$ & $-94,622$ & $-89,942$ & $-94,957$ \\
\hline Vc (pu) & 1,001 & 0,971 & 1,000 & 0,964 \\
\hline$\varnothing c$ (graus) & 149,964 & 143,286 & 149,964 & 144,126 \\
\hline
\end{tabular}

$$
F D \%=\frac{V_{-}}{V_{+}} * 100
$$

O Teorema de Fortescue (Fortescue, 1918) aplicado à análise de um sistema elétrico de potência qualquer proporciona facilidades em inúmeros cálculos. Este teorema decompõe um sistema trifásico desequilibrado em três sistemas trifásicos, de três fasores balanceados, denominados de componentes simétricas de sequência positiva, negativa, e zero.

O sistema trifásico de sequência positiva possui três fasores balanceados de mesmo módulo e com defasagem de $\mathbf{1 2 0}^{\circ}$. Esse sistema de fasores possui sequência de fase igual ao do sistema original, portanto, apresenta o mesmo sentido de rotação, sendo também chamado de sequência direta. O sistema de sequência negativa, assim como o de positiva, possui três fasores balanceados e de mesmo módulo com suas defasagens de $\mathbf{1 2 0}^{\circ}$. Porém, o sentido de rotação é inverso ao do sistema original. O sistema de sequência zero apresenta os três fasores com o mesmo módulo, porém em fase, possuindo a mesma sequência de fase que o sistema original. Por apresentarem sempre o mesmo módulo, divergindo apenas no ângulo de fase, todos os cálculos podem ser restritos a apenas uma das fases do sistema e, posteriormente, adicionando a defasagem angular, é possível saber os valores das demais fases.

Tais fasores podem ser representados na forma matricial, conforme equação 5.2. 


$$
\left(\begin{array}{c}
V_{a} \\
V_{b} \\
V_{c}
\end{array}\right)=\left(\begin{array}{ccc}
1 & 1 & 1 \\
1 & a^{2} & a \\
1 & a & a^{2}
\end{array}\right) *\left(\begin{array}{c}
V_{a 0} \\
V_{a+} \\
V_{a-}
\end{array}\right)
$$

Para encontrar as componentes $\boldsymbol{V}_{\boldsymbol{a} \mathbf{0}}, \boldsymbol{V}_{\boldsymbol{a}+}$ e $\boldsymbol{V}_{\boldsymbol{a}}$ basta aplicar a matriz inversa como mostrado pela equação 5.3 .

$$
\left(\begin{array}{c}
V_{a 0} \\
V_{a+} \\
V_{a-}
\end{array}\right)=\frac{1}{3}\left(\begin{array}{ccc}
1 & 1 & 1 \\
1 & a & a^{2} \\
1 & a^{2} & a
\end{array}\right) *\left(\begin{array}{c}
V_{a} \\
V_{b} \\
V_{c}
\end{array}\right)
$$

Onde $\boldsymbol{V}_{\boldsymbol{a}}, \boldsymbol{V}_{\boldsymbol{b}}$ e $\boldsymbol{V}_{\boldsymbol{c}}$ são as tensões eficazes nas fases A, B e C, respectivamente. $\boldsymbol{V}_{\boldsymbol{a} \mathbf{0}}, \boldsymbol{V}_{\boldsymbol{a}+}$ e $\boldsymbol{V}_{\boldsymbol{a}}$ - são as componentes de sequência zero, positiva e negativa da fase A, onde "a" é chamado "operador rotacional", recebendo o valor igual a $\mathbf{1} \angle \mathbf{1 2 0}^{\circ}$. Este possui a função de rotacionar de $\mathbf{1 2 0}^{\mathbf{o}}$ qualquer fasor considerado.

Com os valores de tensão obtidos na simulação feita através do programa DIgSILENT PowerFactory, e utilizando-se das fórmulas expostas acima, é possível obter os valores dos desequilíbrios de tensão para a linha que utiliza a estrutura atual e a nova proposta.

$$
\left(\begin{array}{c}
V_{a 0} \\
V_{a+} \\
V_{a-}
\end{array}\right)=\frac{1}{3}\left(\begin{array}{ccc}
1 & 1 & 1 \\
1 & a & a^{2} \\
1 & a^{2} & a
\end{array}\right) *\left(\begin{array}{c}
13013,4 \angle 24,623 \\
13482,3 \angle-94,622 \\
13399,8 \angle 143,286
\end{array}\right)=\left(\begin{array}{c}
2,1331 \angle-72,25 \\
13297,07 \angle 24,42 \\
287,23 \angle-164,82
\end{array}\right)
$$

Aplicando o resultado obtido na equação 5.4 na equação 5.1, tem-se que o desequilíbrio de tensão observado no barramento da carga com a linha de distribuição que utiliza a estrutura atual foi de $2,16 \%$ (equação 5.5 ).

$$
F D_{\text {Atual }} \%=\frac{287,23}{13297,07} * 100=2,16 \%
$$

Pelo mesmo processo de cálculo para a linha que utiliza a nova estrutura (equações 5.6 e 5.7), nota-se que o valor do desequilíbrio de tensão no barramento da carga, foi menor do que o apresentado anteriormente (equação 5.5). 


$$
\begin{gathered}
\left(\begin{array}{c}
V_{a 0} \\
V_{a+} \\
V_{a-}
\end{array}\right)=\frac{1}{3}\left(\begin{array}{ccc}
1 & 1 & 1 \\
1 & a & a^{2} \\
1 & a^{2} & a
\end{array}\right) *\left(\begin{array}{c}
13234,2 \angle 25,473 \\
13537,8 \angle-94,957 \\
13303,2 \angle 144,126
\end{array}\right)=\left(\begin{array}{c}
0,6098 \angle 166,985 \\
13357,762 \angle 24,881 \\
184,238 \angle 157,094
\end{array}\right) \\
F D_{\text {Proposta } \%=\frac{184,238}{13357,762} * 100=1,378 \%}
\end{gathered}
$$

A linha que utiliza a nova estrutura apresentou uma pequena redução nas perdas de potência ativa e uma redução um pouco maior nas perdas de potência reativa. A comparação entre a linha que utiliza as duas estruturas é feita pela Tabela 5.2.

Tabela 5.2: Comparação entre as perdas ativa e reativa para a linha de distribuição em análise.

\begin{tabular}{|c|c|c|}
\hline & Potência Ativa (MW) & Potência Reativa (MVAr) \\
\hline Estrutura Atual & 0,32 & 0,64 \\
\hline Estrutura Nova & 0,31 & 0,59 \\
\hline
\end{tabular}

A variação nas perdas apresentadas na Tabela 5.2 eram esperadas, visto que a impedância de uma linha trifásica de distribuição consiste na resistência dos condutores e nas reatâncias indutivas mútuas, que são resultantes do efeito dos campos magnéticos que circundam os condutores (Kersting (2012)). A parte da potência ativa é mais afetada pela mudança na parte resistiva da impedância, o que não foi alcançado neste trabalho, uma vez que se utiliza do mesmo condutor para as duas estruturas. Já a parte reativa apresenta uma maior variação, pois as distâncias e o posicionamento dos condutores mudam a forma como os campos magnéticos que circundam os condutores interagem, modificando as reatâncias indutivas mútuas do sistema para valores menores, como é o caso para a nova estrutura da cruzeta.

\subsection{Estudo de Máximo Carregamento}

Para a realização deste estudo, foi empregada uma técnica bastante difundida na análise da estabilidade de tensão em linhas de transmissão de energia elétrica, as curvas de Potência Ativa pela Tensão (Curva PV) (Kundur et al., 1994).

A Figura 5.4 apresenta as curvas PV de uma linha de transmissão apenas para ilustrar o 
seu comportamento quando se tem uma variação no fator de potência e, principalmente, para demonstrar o lugar geométrico dos pontos críticos. Ressalta-se que do ponto de vista da estabilidade de tensão, todos os pontos acima do lugar geométrico dos pontos críticos apresentarão condição de operação satisfatória. Qualquer outro ponto de operação fará com que a linha de transmissão entre em colapso.

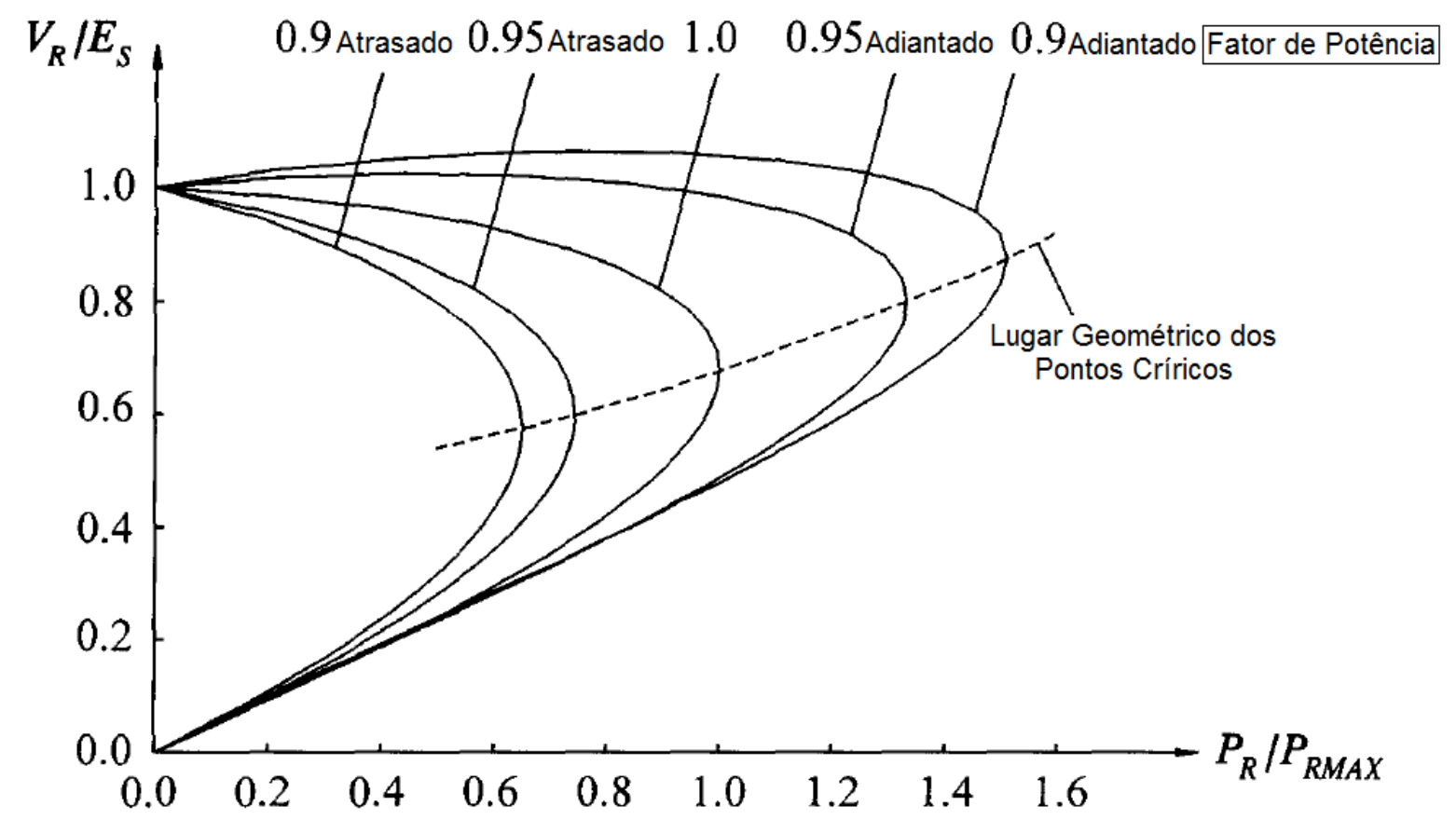

Figura 5.4: Curva PV para um sistema de transmissão genérico. (Fonte:Kundur et al. (1994))

Para realizar o estudo de máximo carregamento, foi considerada uma variação na potência da carga e, para cada nova situação, foi registrada a tensão no barramento da carga. Como o principal interesse nos sistemas de distribuição é manter a tensão entregue ao consumidor final dentro de limites pré-estabelecidos e adequados, foram considerados e aceitos os valores de tensão entre 0,93 p.u. e 1,05 p.u. ((ANEEL, 2007)). Dessa maneira, ao invés de analisar o "joelho" da curva, será analisado o instante em que as curvas PV ultrapassam o limite inferior estabelecido de 0,93 .

A simulação para a obtenção da curva PV foi feita com auxílio do DIgSILENT Programming Language (DPL), uma ferramenta de programação interna ao DIgSILENT PowerFactory que oferece automatização para algumas tarefas. Uma delas é o cálculo da curva PV, atividade que necessita da realização do estudo do fluxo de potência para cada alteração efetuada no valor da carga. A simulação foi realizada considerando o valor inicial da carga até valores próximos a 10 MW, dando um total de 66 amostras. 


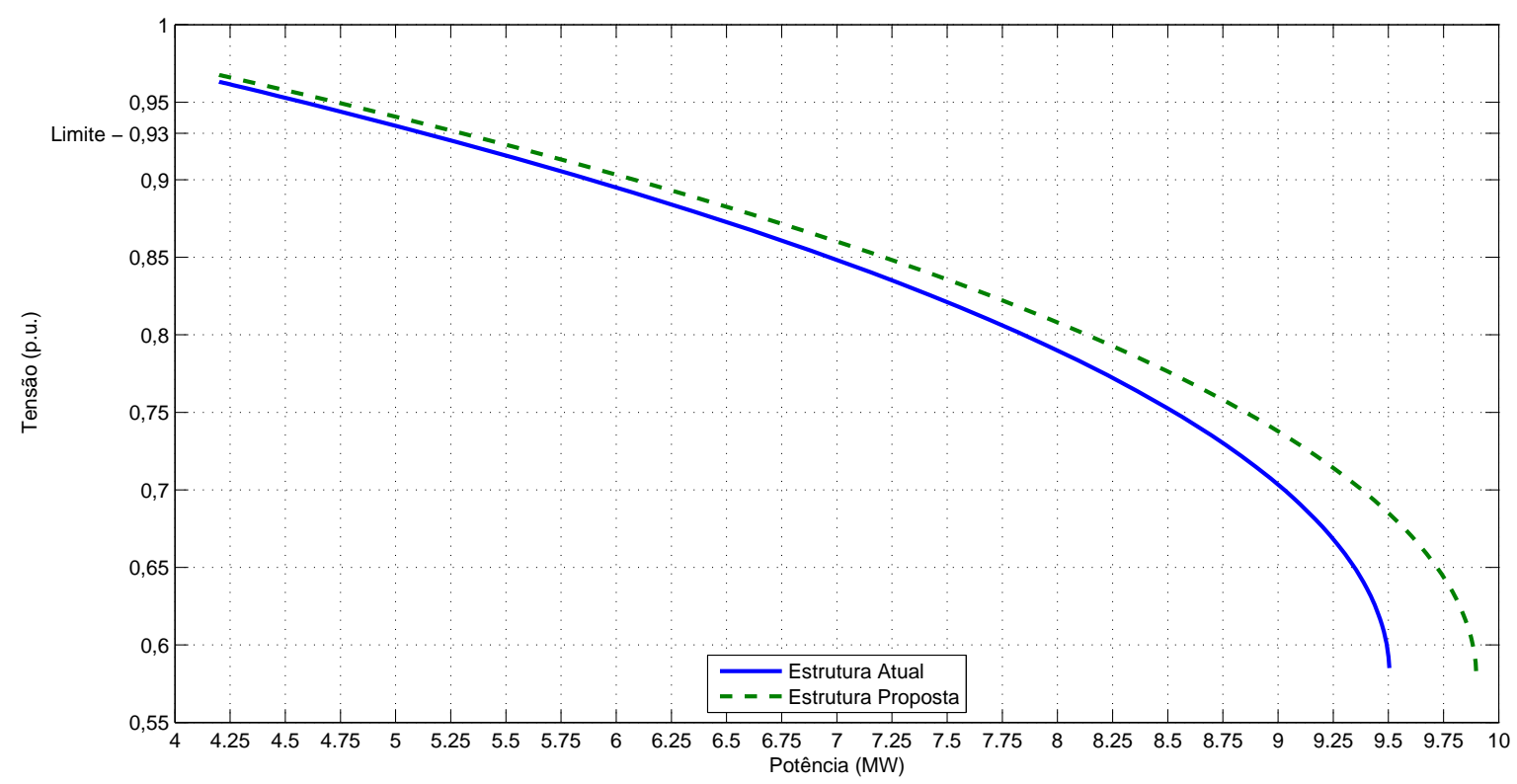

Figura 5.5: Curva PV para a linha que utiliza a estrutura atual e a nova cruzeta.

Na Figura 5.5 é possível notar que a linha tracejada na cor verde, que representa a curva PV referente à linha de distribuição utilizando a nova cruzeta, permaneceu acima da linha que representa o caso atual (linha sólida na cor azul). Isso traz a informação de que para alimentar a mesma potência, a queda de tensão ao final da linha que utiliza a nova estrutura será menor, e que essa linha poderá transmitir mais potência que a linha atual $(0,2688 \mathrm{MW})$, sem que haja violação do limite mínimo de tensão estabelecido. 


\section{Capítulo 6}

\section{Ensaios Elétricos e Mecânicos para a}

\section{Nova Estrutura}

Para dar fechamento a esta metodologia de análise, coloca-se a importância da realização dos ensaios elétricos e mecânicos da nova estrutura antes de colocá-la em operação. O objetivo principal desses ensaios é observar o desempenho da nova estrutura para os sistema de distribuição de energia elétrica, empregando-se a cruzeta de MLC com 1,5 metros de comprimento.

\subsection{Ensaios Elétricos da Nova Estrutura}

Para restringir os efeitos elétricos apenas na estrutura em questão, sugere-se que sejam feitos ensaios com postes de madeira e de concreto, com ponto de aterramento na conexão da mão francesa com o poste.

Todos os ensaios devem ser realizados em conformidade com a norma NBR 6936 (Técnicas de Ensaios Elétricos de Alta Tensão) (ABNT, 1992), em todos os isoladores, para a verificação do nível de isolamento entre as fases e entre a fase mais crítica (fase posicionada no meio da cruzeta) e o terra.

\subsubsection{Tensão de impulso atmosférico}

Um impulso é considerado como um transitório de tensão não periódico aplicado no sistema e geralmente atinge um valor de pico rapidamente, depois apresenta um decaimento lento até zero. Os impulsos a que as linhas estão sujeitas podem ser classificados como impulsos atmosféricos 
e impulsos de manobra. O que difere um impulso atmosférico de um impulso de manobra é o tempo de subida da onda, também chamado de frente de onda. Nos impulsos atmosféricos o tempo de subida da onda até seu valor de pico varia entre valores menores que um até algumas dezenas de microssegundos. Já os impulsos de manobra apresentam um tempo de subida da onda que varia entre algumas dezenas de microssegundos até milhares de microssegundos.

Para tensões acima de $230 \mathrm{kV}$ as sobretensões transitórias devidas aos impulsos de manobras podem ser consideradas mais importantes do que as provenientes de descargas atmosféricas, isso porque os impulsos de manobras estão diretamente relacionados ao nível de tensão do sistema (Gomez, 2007). Já para linhas menores de $230 \mathrm{kV}$, os estudos decorrentes das sobretensões transitórias geradas por impulsos atmosféricos são os mais importantes e devem ser considerados.

Para a realização de simulações e ensaios é considerado, normalmente, um formato para o impulso atmosférico, chamado de impulso atmosférico "pleno", que apesar de não ser exatamente como o real, o representa muito bem e torna possível os ensaios em laboratório. O impulso atmosférico pleno possui um tempo de subida de $1,2 \boldsymbol{\mu} \boldsymbol{s}$ e um tempo de descida de $50 \boldsymbol{\mu} \boldsymbol{s}$. O impulso de manobra possui alguns tempos de subida e descida padronizados para ensaios. Um exemplo é a onda que possui o tempo de $250 \mu s$ para a subida e $2500 \mu s$ para a descida (IEEEStd-4, 1995). A figura 6.1 representa um formato de impulso onde $\boldsymbol{T}_{\mathbf{1}}$ representa o tempo de subida e $\boldsymbol{T}_{\mathbf{2}}$ o tempo de descida.

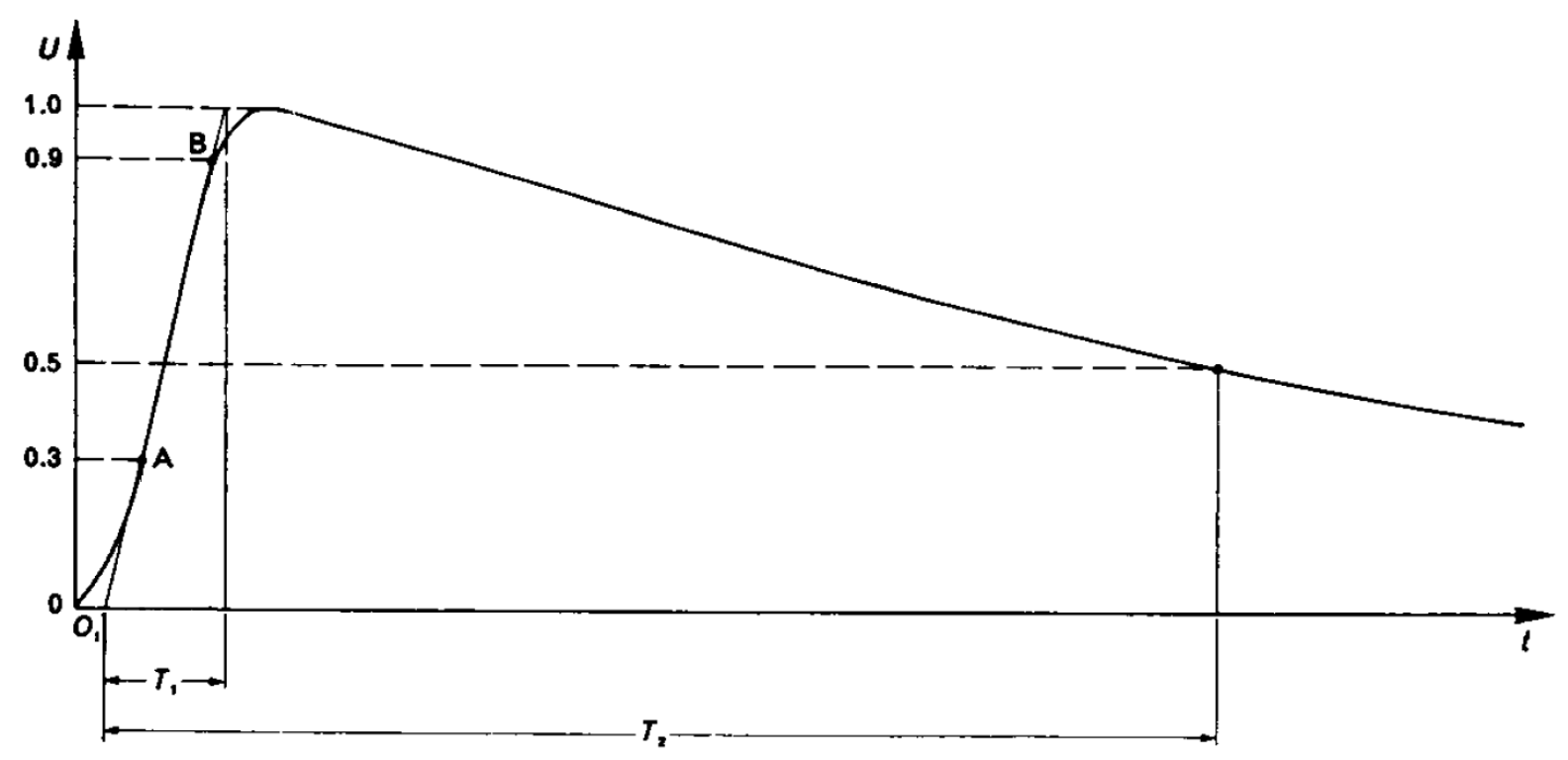

Figura 6.1: Impulso atmosférico pleno. Fonte: (IEEE-Std-4, 1995)

Para a realização dos ensaios podem ser considerados os ensaios de tensão disruptiva e os de tensão suportável. 
Os ensaios de tensão disruptiva de descarga fornecem os valores de tensão em que irão ocorrer a ruptura do dielétrico do objeto sob ensaio. Ressalta-se que a descarga disruptiva em dielétricos sólidos causam perdas permanentes no dielétrico.

Assim, coloca-se que também existem ensaios de tensão suportável, que são realizados, de acordo com IEEE-Std-4 (1995), aplicando alguns impulsos da tensão nominal suportável ao equipamento sob ensaio e verificando se houve ou não a falha (defeito) do equipamento. Não ocorrendo falha alguma, utilizando-se de métodos de detecção e de equipamentos padronizados, o objeto sob ensaio é aprovado ((IEEE-Std-4, 1995).

\subsubsection{Ensaios elétricos sob frequência industrial}

Os ensaios elétricos sob frequência industrial são realizados aplicando-se uma tensão senoidal com uma frequência entre 45 e $60 \mathrm{~Hz}$ e, assim como os impulsos atmosféricos, são classificados como ensaio de tensão disruptiva e de tensão suportável.

Como colocado anteriormente, os ensaios de tensão disruptiva causam danos irreparáveis aos dielétricos sólidos, assim, causam danos à estrutura sob ensaio. Para esses ensaios a tensão deve ser aplicada, ao objeto sob ensaio, de maneira crescente, a fim de evitar efeitos de sobretensão devido à transientes de comutação. A elevação da tensão deve ser feita lentamente para proporcionar uma leitura exata no instrumento de medição. Após atingir o valor nominal do ensaio e permanecer por um tempo especificado, o valor da tensão deve ser reduzido, porém não de maneira abrupta, pois também poderá gerar transientes de comutação que podem causar danos ou resultados errôneos.

Para os ensaios de tensão disruptiva, caso haja o rompimento do dielétrico, deve ser registrado o valor da tensão medida no instante imediatamente anterior a ocorrência do mesmo.

Para os ensaios de tensão suportável, o objeto sob ensaio é aprovado desde que não haja nenhuma falha (defeito) acusada pelos equipamentos de medição utilizados.

Todos os ensaios devem ser realizados para ambientes secos e úmidos.

Para o ensaio em ambiente seco, o objeto sob ensaio deve estar seco e limpo e a temperatura do local deve ser igual à temperatura ambiente.

Para os ensaios úmidos existem vários tipos de especificações a serem seguidos uma vez que imitar a chuva natural não é um procedimento simples. Um ensaio padrão é descrito na tabela 6.1 (IEEE-Std-4, 1995). 
Tabela 6.1: Condição de precipitação padrão. Fonte: (IEEE-Std-4 (1995))

\begin{tabular}{|c|c|c|c|c|}
\hline \multicolumn{3}{|c|}{ Taxa de precipitação $\mathrm{mm} / \mathrm{min}$} & \multicolumn{2}{c|}{ Parâmetros da água } \\
\hline $\begin{array}{c}\text { Componente } \\
\text { Horizontal }\end{array}$ & $\begin{array}{c}\text { Componente } \\
\text { Vertical }\end{array}$ & $\begin{array}{c}\text { Limite } \\
\text { Individual }\end{array}$ & $\begin{array}{c}\text { Temperatura } \\
\text { Ambiente }\left({ }^{\boldsymbol{o}} \boldsymbol{C}\right)\end{array}$ & $\begin{array}{c}\text { Resistividade } \\
(\boldsymbol{\Omega} \cdot \boldsymbol{m})\end{array}$ \\
\hline $1,0-2,0$ & $1,0-2,0$ & 0,5 (da média) & \pm 15 & $100 \pm 15$ \\
\hline
\end{tabular}

\subsection{Ensaio Mecânico da Nova Estrutura}

Para validar a estrutura e liberá-la para o uso em campo, é necessário que seja feito o ensaio de flexão da cruzeta. Esse ensaio é estipulado pela ABNT (1984).

O ensaio deverá ser realizado em todas as faces da cruzeta, conforme ilustra a figura 6.2.

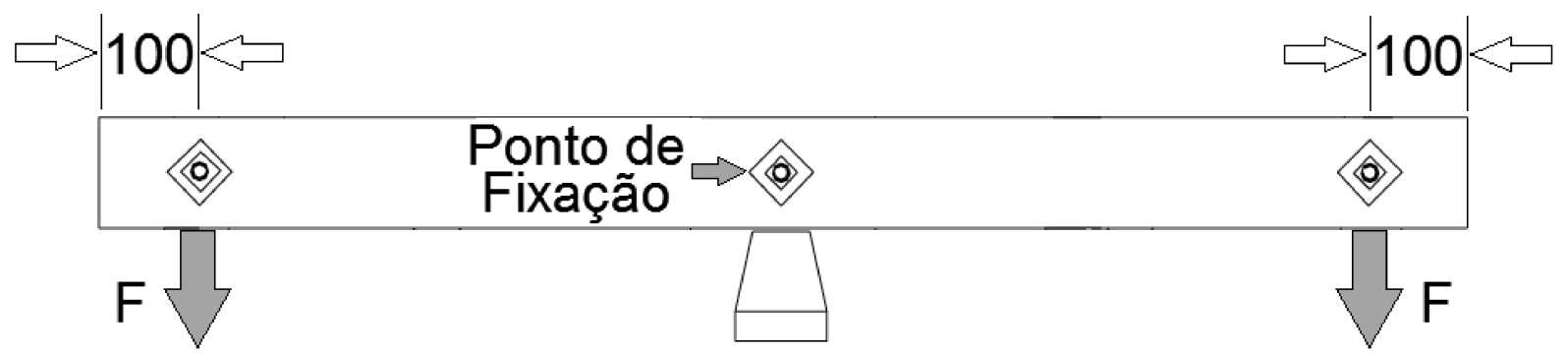

Figura 6.2: Ensaio de flexão.

A tabela 6.2 apresenta os valores limites de resistência nominal de flexão para as cruzetas de 2 e 2,4 metros de comprimento ABNT (1984).

Tabela 6.2: Resistência à flexão. (Fonte: ABNT (1984))

\begin{tabular}{|c|c|c|c|c|}
\hline Comprimento & Descrição do & Resistência & \multicolumn{2}{|c|}{ Flecha (mm) } \\
\cline { 4 - 5 } L $(\mathrm{mm})$ & carregamento & $\mathrm{F}(\mathrm{daN})$ & Máxima & Residual máximo \\
\hline \multirow{3}{*}{2000} & Nominal & 400 & 75 & 3 \\
\cline { 2 - 5 } & Máximo excepcional & 560 & 100 & 5 \\
\cline { 2 - 5 } & Mínimo de ruptura & 800 & - & - \\
\hline \multirow{3}{*}{2400} & Nominal & 400 & 115 & 5 \\
\cline { 2 - 5 } & Máximo excepcional & 560 & 163 & 8 \\
\cline { 2 - 5 } & Mínimo de ruptura & 800 & - & - \\
\hline
\end{tabular}

Ressalta-se que, apesar de não constar na tabela 6.2 os valores para cruzetas com o comprimento de 1,5 m, os valores dos ensaios realizados deverão apresentar resultados melhores do que os colocados para cruzetas maiores de 2,0 e 2,4 m. Ao diminuir o tamanho da cruzeta, mantendo o ponto de apoio centralizado, reduz-se o momento fletor gerado pelas forças aplicadas, o que refletirá em melhores resultados do que os apresentados. Tendo em vista os resultados apresentados, coloca-se a possibilidade de uma futura redução na espessura da cruzeta proposta. 


\section{Capítulo 7}

\section{Comentários Finais}

Como anteriormente apresentado, buscou-se, em parceria com o LaMEM, LSEE e CPFL, definir e apresentar uma metodologia para a obtenção de um novo padrão para as estruturas de redes de $15 \mathrm{kV}$, baseando-se nas atualmente empregadas. Foram avaliados vários tipos de padrões e suas variações. O principal intuito de se analisar padrões diferentes das estruturas utilizadas na distribuição foi o de proporcionar uma diminuição do tamanho das cruzetas hoje em dia utilizadas.

Sendo assim, o objetivo primordial desse trabalho foi a redução do tamanho da cruzeta de madeira e, atrelados a esse objetivo, buscou-se também o aumento do NBI da estrutura, a redução das perdas ativas e reativas da rede, diminuição da queda de tensão ao final da linha de distribuição e a redução do desequilíbrio da tensão fornecida.

Os resultados apresentados na seção 4.1 mostram que as distâncias utilizadas na estrutura do tipo "N1" (figura 3.2) apresentam uma grande margem de segurança, o que já era esperado quando do início da pesquisa. Para todos os casos analisados, não surgiram diferenças de potencial entre os pontos analisados que pudessem romper o dielétrico da cruzeta de madeira, e muito menos o dielétrico do ar, que são, de acordo com IEEE-Std-1410 (2004), 250 kV/m e 600 $\mathrm{kV} / \mathrm{m}$ respectivamente.

As análises realizadas mostraram a suportabilidade da estrutura em uso pela concessionária de energia com relação aos curtos-circuitos que a linha de distribuição pode vir a estar sujeita e com relação à operação normal do sistema. Tais resultados já eram esperados e, até certo ponto, foram e estão constantemente sendo validados em campo, uma vez que esta estrutura em específico é utilizada por várias concessionárias de distribuição de energia elétrica no Brasil. 
Com base nos resultados iniciais, a pesquisa foi direcionada à busca de um novo modelo de cruzeta. Buscou-se, através deste modelo, uma redução significativa da quantidade de madeira utilizada, aproveitando contudo, ao máximo, os componentes já existentes e utilizados pelas concessionárias. O modelo proposto apresenta uma redução de $0,5 \mathrm{~m}$ de cruzeta que, multiplicado pela quantidade de cruzetas utilizadas em uma linha de distribuição passa a ser um valor significativo com relação à economia e à redução da madeira utilizada.

É importante destacar que a redução de $0,5 \mathrm{~m}$ de cruzeta equivale a uma redução de $25 \%$ da madeira utilizada, o que transposto para a quantidade de 60.000 cruzetas utilizadas pela concessionária na manutenção e expansão das linhas de distribuição, significa uma redução de $243.000 \boldsymbol{m}^{\mathbf{3}}$ (duzentos e quarenta e três mil metros cúbicos) de madeira por ano. Assim, com a redução da quantidade de madeira e a construção de cruzetas utilizando-se da técnica de MLC, feita apenas com madeiras provenientes de reflorestamentos, têm-se uma cruzeta confeccionada levando-se em conta os aspectos contemporâneos de preservação ambiental.

Ressalta-se que apesar da redução do tamanho da cruzeta, as distâncias entre os condutores são maiores do que na atual estrutura utilizada (figura 3.2). No modelo empregado em campo, a distância entre as fases B e C é de 0,6 metros com relação ao eixo X. Agora, no novo modelo, a distância no eixo $\mathrm{X}$ foi mantida. Porém, devido à elevação do isolador central, a distância entre os condutores passa a ser de 0,65 m. Manter esta distância entre os condutores se torna importante principalmente pelo balanço dos cabos que podem se tocar ocasionando curtoscircuitos, assim como apresentado em Xu et al. (2009). Sendo assim, apesar da cruzeta de madeira ter demonstrado um bom desempenho nas simulações executadas, limitou-se em manter essa distância entre os condutores para evitar curtos-circuitos bifásicos devido ao balanço dos cabos.

Vale considerar a possibilidade de aumentar mais a distância entre os isoladores das fases A e C, mantendo o tamanho da cruzeta em 1,5 m. Assim, os isoladores ficariam distantes 1,3 m um do outro, e não mais 1,2 m. Isto é possível pois, na estrutura utilizada atualmente, a distância entre os isoladores das fases A e C e a extremidade da cruzeta é de 0,10 m. Já na nova estrutura esta distância é de 0,15 m. Outra alternativa é manter as distâncias como estão no novo modelo e reduzir 0,10 metros de cruzeta. Assim, o comprimento da cruzeta não mais seria de $1,5 \mathrm{~m}$, mas sim de $1,4 \mathrm{~m}$.

Outro aspecto significativo desta nova proposição é a distância entre o pino do isolador central e a mão francesa. Na estrutura atualmente empregada (tipo N1), tem-se que o pino do isolador 
central encontra-se praticamente sobre a conexão da mão francesa com a cruzeta. Isso faz com que o NBI da estrutura seja reduzido, pois ele é dado pelo ponto mais vulnerável da estrutura (IEEE-Std-1410, 2004). Na estrutura proposta neste trabalho (figura 4.20), a distância entre o pino dos isoladores das fases A e C (localizados nas extremidades da cruzeta), e os pontos de conexão da mão francesa com a cruzeta, é de 0,2 m. Isso traz um aumento no CFO da estrutura de $50 \mathrm{kV}$.

Conforme apresentado e discutido anteriormente, o curto-circuito ilustrado pela seção 3.2.3, quando analisado sobre a estrutura atualmente utilizada pela concessionária, foi classificado como sendo o mais crítico, pois as distâncias entre os isoladores das fases B e C eram menores do que os isoladores das fases A e B. Contudo, para a nova estrutura, todos os casos analisados (seções 3.2.1, 3.2.2 e 3.2.3) apresentaram a mesma importância, uma vez que a estrutura proposta é simétrica, em função da nova geometria da cruzeta indicada.

Através das análises realizadas no Capítulo 5 foi possível perceber um melhor desempenho na operação da linha de distribuição utilizando a nova estrutura. Analisando o fornecimento da tensão pelo sistema, observa-se uma redução de $0,402 \%$ na queda de tensão ao final do alimentador, bem como uma redução no desequilíbrio da tensão, que passou de $2,16 \%$ (estrutura atual) para 1,378\% (nova estrutura). Na análise das perdas ativas, percebeu-se uma pequena melhora, 0,01 MW. Porém, na análise das perdas reativas do sistema, a melhora foi mais significativa, reduzindo as perdas em 0,05 MVAr. Quanto às análises de máximo carregamento do sistema, coloca-se que a linha que utiliza a nova estrutura poderá transmitir 0,2688 MW a mais de potência do que a linha atual, sem que haja violação do limite mínimo de tensão estabelecido (ANEEL, 2007).

Vale enfatizar a necessidade dos ensaios laboratoriais (elétricos e mecânicos) apontados no Capítulo 6 para validar e dar um encaminhamento final à metodologia apresentada.

Finalizando, pelos resultados compilados até o momento, frente às análises computacionais realizadas (dispondo dos softwares ATP, FLUX 3D e DigSILENT Power Factory), pode-se apontar um satisfatório desempenho da nova geometria de cruzeta apresentada para a classe de $15 \mathrm{kV}$. 


\section{Referências Bibliográficas}

ABNT (1984). NBR 8458 - Cruzetas de madeira para redes de distribuição de energia elétrica. Rio de Janeiro, Brasil.

ABNT (1992). NBR 6936 - Técnicas de Ensaios Elétricos de Alta Tensão. Rio de Janeiro, Brasil.

AIEE, C. R. (1956). Impulse flaskovers of combinations of line insulators, air gaps, and wood structural members. Power Apparatus and Systems, Part III. Transactions of the American Institute of Electrical Engineers 75(3), 16 -21.

Altafim, R., J. Silva, H. Basso, C. Junior, J. Sartori, R. Altafim, G. Chierice, e A. Silveira (2004). Study of timber crossarms coated with castor oil-based polyurethane resins: electrical and mechanical tests. In Electrical Insulation, 2004. Conference Record of the 2004 IEEE International Symposium on, pp. 556 - 559.

Ametani, A. (2007). The history of transient analysis and the recent trend. IEEJ Transactions on Electrical and Electronic Engineering 2(5), 497-503.

ANEEL, P. (2007). Procedimentos de distribuição de energia elétrica no sistema elétrico nacional - prodist: Módulo 8 - qualidade da energia elétrica.

Armstrong, H., H. Stoelting, e E. Veverka (1967). Impulse studies on distribution line construction. Power Apparatus and Systems, IEEE Transactions on PAS-86(2), 206 -214.

Asboll, E. (1988). Laminated wood structures in norwegian transmission lines. In Overhead Line Design and Construction: Theory and Practice, 1989., International Conference on, pp. $36-39$.

Assan, A. (2003). Método dos Elementos Finitos: Primeiros Passos. Ed. da UNICAMP.

ATP (1987). Alternative Transients Program - Rule Book. 
Biasotto, E., P. de Oliveira, M. Oleskovicz, e D. Coury (2008). Uma análise dos desequilíbrios de tensão e corrente trifásicos baseada em compontentes simétricas e sistemas fuzzy. In VIII Conferência Internacional de Aplicações Industriais - Induscon.

Biasotto, E., P. S. Oliveira, M. Lima, M. Oleskovicz, J. C. M. Vieira, D. V. Coury, M. Suzuki, e S. A. N. Miranda (2010). Análise da elevação da tensão operativa de linhas de distribuição baseada na simulação computacional de campos elétricos e de linhas equipotenciais utilizando o método dos elementos finitos. In XVIII Congresso Brasileiro de Automática, Bonito-Ms, Brasil.

COMSOL, A. (2001). FEMLAB: Reference Manual. COMSOL.

Coulomb, J., Y. Du Terrail, e G. Meunier (1985). Flux3d, a finite element package for magnetic computation. Magnetics, IEEE Transactions on 21(6), $2499-2502$.

CPFL (2009). Rede Primária Condutores Nus 15kV e 25kV - Estruturas Básicas - Montagem. Disponível em "http://www.cpfl.com.br/LinkClick.aspx?fileticket=2Jd YewyCZsY\%3D\&tabid=1418\&mid=2065".

Darveniza, M., G. Limbourn, e S. Prentice (1967). Line design and electrical properties of wood. Power Apparatus and Systems, IEEE Transactions on (11), 1344-1356.

de Oliveira, P., E. Biasotto, M. Lima, J. Vieira, M. Oleskovicz, D. Coury, M. Suzuki, S. Miranda, e H. Querne (2011). Voltage elevation analysis of overhead distribution lines using the finite element method. In Power and Energy Society General Meeting, 2011 IEEE, pp. 1 -8.

DigSILENT (2010). DigSILENT PowerFactory - Power System Analysis Software. Disponível em "http://www.digsilent.de".

Dommel, H. (1969). Digital computer solution of electromagnetic transients in single-and multiphase networks. Power Apparatus and Systems, IEEE Transactions on PAS-88(4), 388 -399 .

Fields, V. (1999). Opera-2d user guide. Vector Fields Limited, England.

Fields, V. (2004). Opera-3d reference manual. Vector Fields Limited, England.

Fortescue, C. L. (1918). Method of symmetrical co-ordinates applied to the solution of polyphase networks. American Institute of Electrical Engineers, Transactions of the XXXVII(2), 1027 $-1140$. 
Frey, W. e P. Althammer (1961). The calculation of electromagnetic transients on lines by means of a digital computer. Brown Boveri Rev 48(5/6), 344-355.

Fuchs, R. (1977). Transmissão de energia elétrica: linhas aéreas: teoria das linhas em regime permanente. Livros Técnicos e Cienfíficos.

Gomez, P. (2007). Validation of atp transmission line models for a monte carlo study of switching transients. In Power Symposium, 200\%. NAPS '07. 39th North American, pp. $124-129$.

Grzybowski, S., J. Kappenman, e W. Radasky (2006). Electrical strength of distribution insulators under steep front, short duration pulse. In Electromagnetic Compatibility, 2006. EMC-Zurich 2006. 17th International Zurich Symposium on, pp. 610-613. IEEE.

Gustavsen, B., L. Rolfseng, O. Andresen, H. Christensen, B. Falch, K. Jankila, T. Myhr, H. Sandvik, e H. Thomassen (2002). Simulation of wood-pole replacement rate: application to distribution overhead lines. Power Delivery, IEEE Transactions on 17(4), 1050 - 1056.

IEEE-Std-1410 (2004). Ieee guide for improving the lightning performance of electric power overhead distribution lines. IEEE Std 1410-2004 (Revision of IEEE Std 1410-1997).

IEEE-Std-4 (1995). Ieee standard techniques for high-voltage testing (revision of ieee std 4-1 978). IEEE Std 4-1995, i-129.

Kersting, W. (2012). Distribution system modeling and analysis. CRC press.

Kontargyri, V., I. Gonos, I. Stathopoulos, e A. Michealides (2006). Simulation of the electric field on high voltage insulators using the finite element method. In Electromagnetic Field Computation, 2006 12th Biennial IEEE Conference on, pp. 373-373. IEEE.

Kundur, P., N. Balu, e M. Lauby (1994). Power system stability and control, Volume 4. McGrawhill New York.

Liebel, S. e R. Mueller (1994). Douglas fir crossarms: solid sawn vs. laminated comparison. In Transmission and Distribution Conference, 1994., Proceedings of the 1994 IEEE Power Engineering Society, pp. 581-586. IEEE.

Lusignan, J. T. e C. J. Miller (1940). What wood may add to primary insulation for withstanding lightning. American Institute of Electrical Engineers, Transactions of the 59(9), $534-540$.

Maxwell, J. (1865). A dynamical theory of the electromagnetic field. Philosophical Transactions of the Royal Society of London 155, 459-512. 
Maxwell, J. (1873). A treatise on electricity and magnetism, Volume 1. Clarendon Press.

Meunier, G., J. Sabonnadiere, e J. Coulomb (1991). The finite element post-processor of flux3d (field computation package). Magnetics, IEEE Transactions on 27(5), 3786 - 3791.

Monticelli, A. (1983). Fluxo de carga em redes de energia elétrica. Editora Edgard Blucher Ltda.

Nestler, F. (1974). The characterization of wood-preserving creosote by physical and chemical methods of analysis. Technical report, DTIC Document.

Pihler, J. e I. Ticar (2005). Design of systems of covered overhead conductors by means of electric field calculation. Power Delivery, IEEE Transactions on 20(2), 807 - 814.

Queiroz, I. B., M. G. G. Neri, e E. G. Costa (2006). Mapeamento do campo elétrico em isoladores poliméricos com defeitos. Simpósio Brasileiro de Sistemas Elétricos.

Rasolonjanahary, J., L. Krahenbuhl, e A. Nicolas (1992). Computation of electric fields and potential on polluted insulators using a boundary element method. Magnetics, IEEE Transactions on 28(2), $1473-1476$.

Ross, P. (1947). Burning of wood structures by leakage currents. American Institute of Electrical Engineers, Transactions of the 66(1), 279-287.

Salari, J., A. Mpalantinos, e J. Silva (2009). Comparative analysis of 2-and 3-d methods for computing electric and magnetic fields generated by overhead transmission lines. Power Delivery, IEEE Transactions on 24(1), 338-344.

Santos, C. J., C. Escobar, e D. S. Souza (2008). Aplicação eficiente de reguladores de tensão ajustados com o dispositivo compensador de queda de tensão na linha (ldc). In Congreso Latinoamericano de Distribución Eléctrica.

Schimidt, W. (1979). Materiais Elétricos Isolantes e Magnéticos (Segunda ed.). São Paulo, SP: Ed. Edgard Blucher Ltda.

Sebestyn, I. (2002). Electric-field calculation for hv insulators using domain-decomposition method. Magnetics, IEEE Transactions on 38(2), $1213-1216$.

Simpson, T. (1997). Maxwell on the electromagnetic field: a guided study. Masterworks of discovery. Rutgers University Press.

Stevenson, W. (1978). Elementos de análise de sistemas de potência. McGraw Hill. 
Tzinevrakis, A., D. Tsanakas, e E. Mimos (2008). Analytical calculation of the electric field produced by single-circuit power lines. Power Delivery, IEEE Transactions on 23(3), 14951505.

Vlastos, A. e S. Gubanski (1991). Surface structural changes of naturally aged silicone and epdm composite insulators. Power Delivery, IEEE Transactions on 6(2), 888 -900.

Wedepohl, L. (1963). Application of matrix methods to the solution of travelling-wave phenomena in polyphase systems. Electrical Engineers, Proceedings of the Institution of 110(12), $2200-2212$.

Weida, D., T. Steinmetz, M. Clemens, D. Stefanini, e J. Seifert (2009). Benefits of higher order elements for electrostatic simulations of large-scale 3d insulator structures. In Electrical Insulation Conference, 2009. EIC 2009. IEEE, pp. 558-561. IEEE.

Wintle, H. (1998). Maxwell and the boundary element method: a historical puzzle. Electrical Insulation Magazine, IEEE 14(6), 23 -25.

Wong, K. e M. Rahmat (2010). Study of leakage current distribution in wooden pole using ladder network model. Power Delivery, IEEE Transactions on 25(2), 995 -1000.

Xu, X., H. Yang, e K. Craven (2009). Magnetically induced swing movement of overhead power line conductors in a transition span subsequent to an initial fault. Electric Power Systems Research 79(5), 809-817.

Yamashita, H., T. Nakamae, T. Okano, M. Hammam, C. Burns, e G. Adams (1993). A color graphics display of the field intensity around the insulator on $13.2 \mathrm{kv}$ distribution lines. Power Delivery, IEEE Transactions on 8(4), $1696-1702$.

Youngquist, J., F. Brey, e J. Jung (1977). Structural feasibility of parallel-laminated veneer crossarms. forest service research paper. Technical report, Forest Products Lab., Madison, Wis.(USA).

Zangiácomo, A. (2003). Emprego de espécies tropicais alternativas na produção de elementos estruturais de madeira laminada colada. Dissertação de Mestrado, Universidade de São Paulo.

Zemljaric, B. (2011). Calculation of the connected magnetic and electric fields around an overhead-line tower for an estimation of their influence on maintenance personnel. Power Delivery, IEEE Transactions on 26(1), $467-474$. 
Zienkiewicz, O. e R. Taylor (2000). The finite element method: The basis. Butterworthछ̈Heinemann, London 1.

Zimmerman, W. (2004). Process modelling and simulation with finite element methods. Series on stability, vibration, and control of systems. World Scientific. 